\title{
INVESTIGATION OF AMMONIA ADSORPTION \\ ON FLY ASH DUE TO INSTALLATION OF SELECTIVE CATALYTIC REDUCTION SYSTEMS
}

FINAL TECHNICAL REPORT

Principal Authors:

G. F. Brendel and J. E. Bonetti, Ph.D. GAI Consultants, Inc.

R. F. Rathbone

Center for Applied Energy Research

R. N. Frey, Jr.

Air/Compliance Consultants, Inc.

November 2000

DOE Award No. DE-FC26-98FT40028

Subcontract No. 98-166-GAl

GAI Consultants, Inc.

570 Beatty Road

Monroeville, PA 15146

Center for Applied Energy Research

University of Kentucky

3572 Iron Works Pike

Lexington, KY 40511

Air/Compliance Consultants, Inc.

1050 William Pitt Way 
Pittsburgh, PA 15238 


\section{PUBLICATION ACKNOWLEDGMENT}

This report was prepared with the support of the U.S. Department of Energy, National Energy Technology Laboratory, through its Cooperative Agreement No. DE-FC26-98FT40028 with West Virginia University Research Corporation, and with the support of Dominion Generation. However, any opinions, findings, conclusions, or recommendations expressed herein are those of the author(s) and do not necessarily reflect the views of West Virginia University, the U.S. Department of Energy, or Dominion Generation. 


\section{ABSTRACT}

This report summarizes an investigation of the potential impacts associated with the utilization of selective catalytic reduction (SCR) systems at coal-fired power plants. The study was sponsored by the U.S. Department of Energy Emission Control By-Products Consortium, Dominion Generation, the University of Kentucky Center for Applied Energy Research and GAI Consultants, Inc. SCR systems are effective in reducing nitrogen oxides (NOx) emissions as required by the Clean Air Act (CAA) Amendments. However, there may be potential consequences associated with ammonia contamination of stack emissions and combustion by-products from these systems. Costs for air quality, landfill and pond environmental compliance may increase significantly and the marketability of ash may be seriously reduced, which, in turn, may also lead to increased disposal costs. The potential impacts to air, surface water, groundwater, ash disposal, ash utilization, health and safety, and environmental compliance can not be easily quantified based on the information presently available.

The investigation included:

- a review of information and data available from published and unpublished sources;

- baseline ash characterization testing of ash samples produced from several central Appalachian high-volatile bituminous coals from plants that do not currently employ SCR systems in order to characterize the ash prior to ammonia exposure;

- an investigation of ammonia release from fly ash, including leaching and thermal studies; and

- $\quad$ an evaluation of the potential impacts on plant equipment, air quality, water quality, ash disposal operations, and ash marketing. 


\section{TABLE OF CONTENTS}

Section

Page

PUBLICATION ACKNOWLEDGMENT

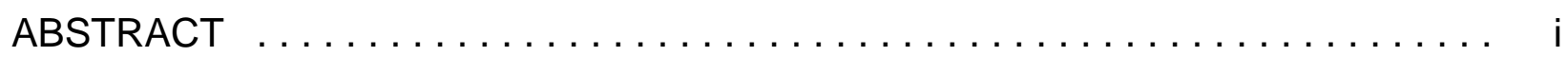

TABLE OF CONTENTS $\ldots \ldots \ldots \ldots \ldots \ldots \ldots \ldots \ldots \ldots \ldots \ldots \ldots \ldots \ldots \ldots \ldots \ldots$

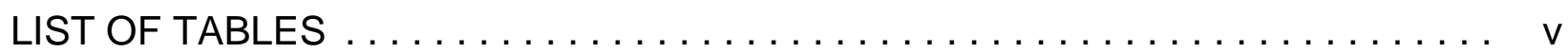

LIST OF FIGURES $\ldots \ldots \ldots \ldots \ldots \ldots \ldots \ldots \ldots \ldots \ldots \ldots \ldots \ldots \ldots \ldots \ldots$

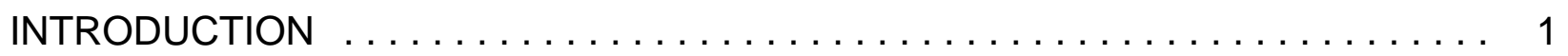

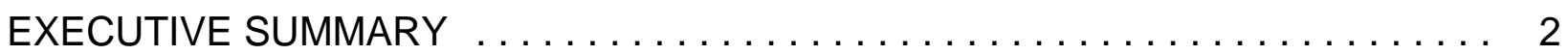

Ammonia Adsorption and Release $\ldots \ldots \ldots \ldots \ldots \ldots \ldots \ldots \ldots \ldots 2$

Thermal Analysis . . . . . . . . . . . . . . . . . . . . . 2

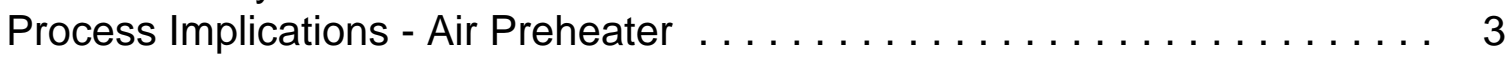

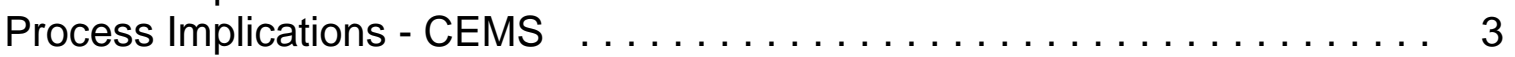

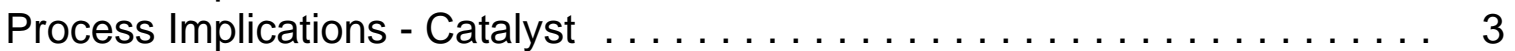

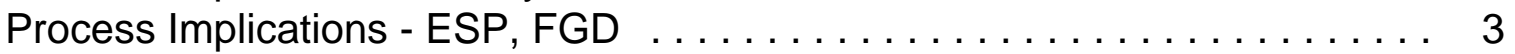

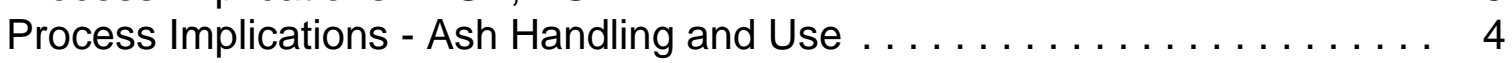

Air Quality Impacts ......................... 4

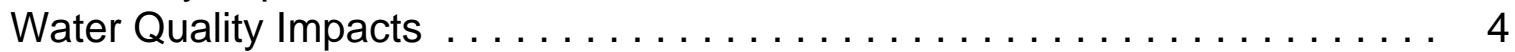

LABORATORY INVESTIGATION OF AMMONIA RELEASE $\ldots \ldots \ldots \ldots \ldots \ldots .6$

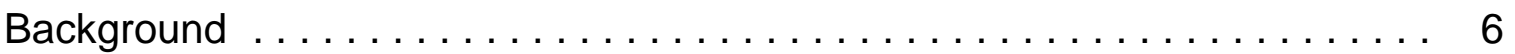

Ammonia Slip and Adsorption of Ammonia on Fly Ash . . . . . . . 6

Ammonia Chemistry ...................... 7

Ammonia in Aqueous Solution $\ldots \ldots \ldots \ldots \ldots \ldots \ldots \ldots$

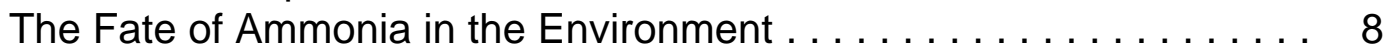

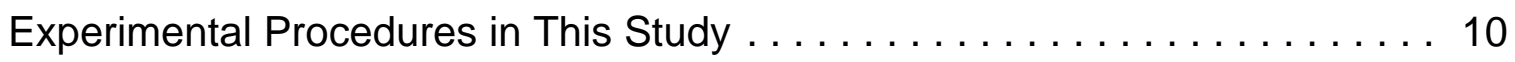

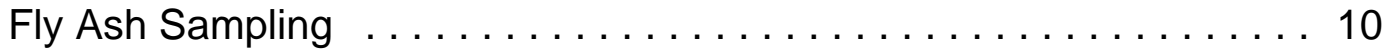




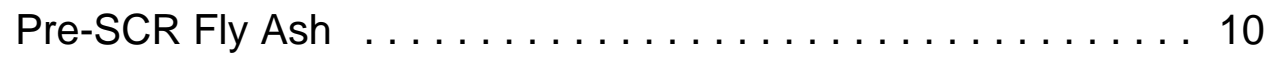

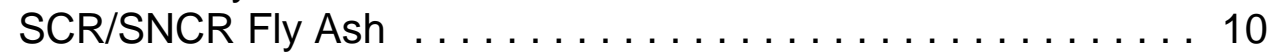

\section{TABLE OF CONTENTS (Continued)}

Section

Page

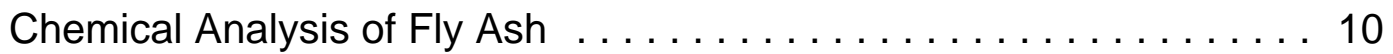

Ammonia Measurement . . . . . . . . . . . . . . . . . . 10

Ammonia Gas ........................... 10

Ammonia Content of Fly Ash . . . . . . . . . . . . . 11

Ammonia Content of Fly Ash Leachate/Supernatant . . . . . . . 11

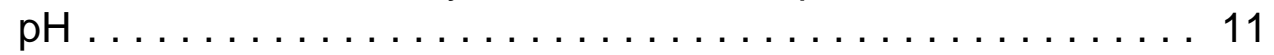

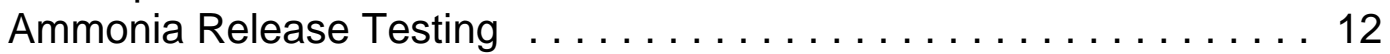

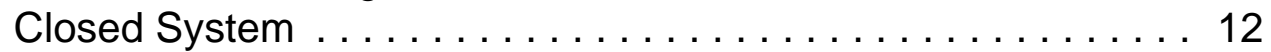

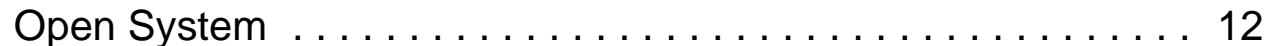

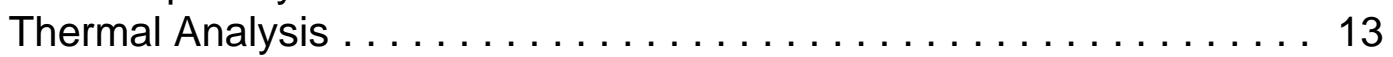

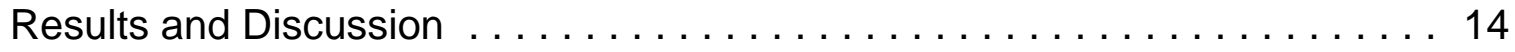

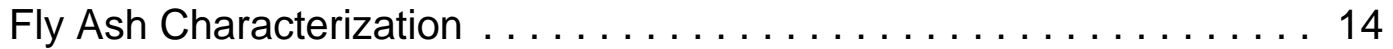

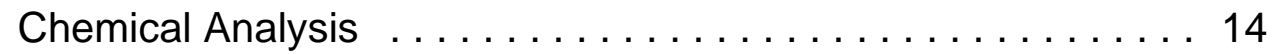

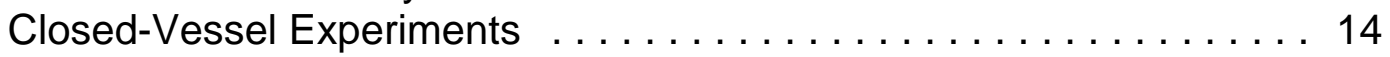

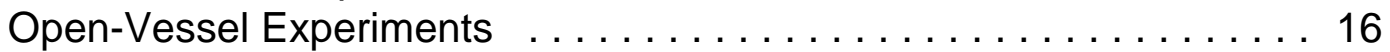

Thermal Analysis . . . . . . . . . . . . . . . . . . 18

Mass Spectra of Ammonia Salts .............. 18

TG-MS Analysis of Ammoniated Ash . . . . . . . . . . 20

HEALTH AND ENVIRONMENTAL IMPACTS OF AMMONIA $\ldots \ldots \ldots \ldots \ldots 22$

Environmental Protection Agency $\ldots \ldots \ldots \ldots \ldots \ldots \ldots \ldots \ldots \ldots$

Clean Air Act (CAA) $\ldots \ldots \ldots \ldots \ldots \ldots \ldots \ldots \ldots \ldots \ldots \ldots \ldots \ldots \ldots \ldots$

Emergency Planning and Community Right-to-Know (EPCRA) . . . . 24

Comprehensive Environmental Response, Compensation and

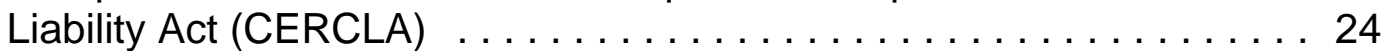

Occupational Safety and Health Administration . . . . . . . . . . . 24

PROCESS IMPLICATIONS, EQUIPMENT EFFECTS, AMBIENT AIR IMPACTS . . 25

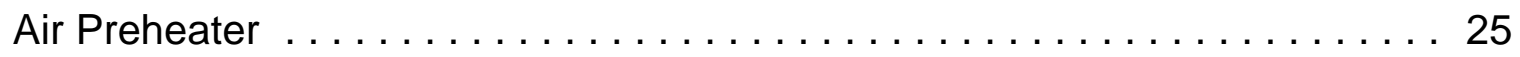

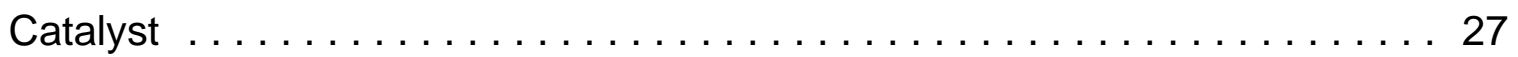

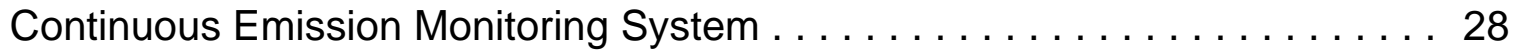

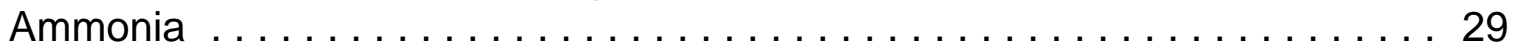

Particulate and Acid Gas Control Systems $\ldots \ldots \ldots \ldots \ldots \ldots \ldots \ldots$

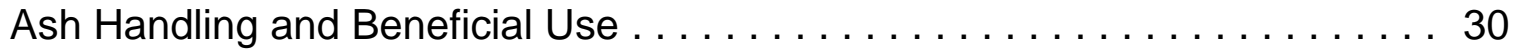

Ambient Air Impacts . . . . . . . . . . . . . . . . . . . 31

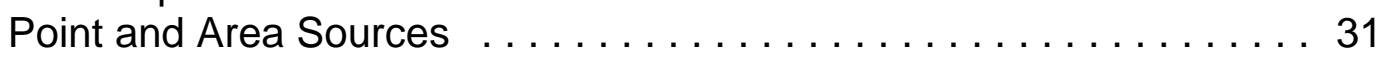

Accidental Release ...................... 32 


\section{TABLE OF CONTENTS (Continued)}

Section

Page

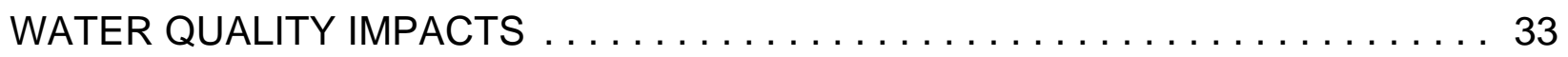

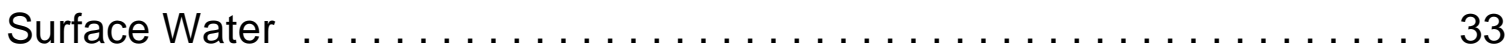

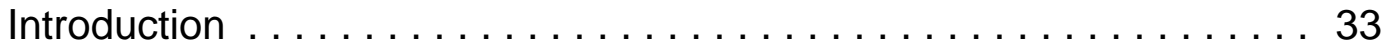

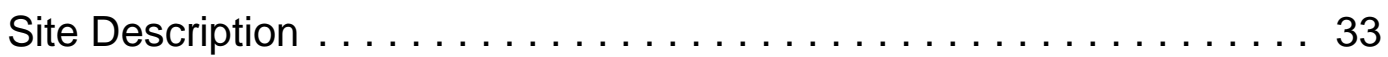

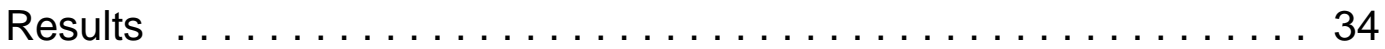

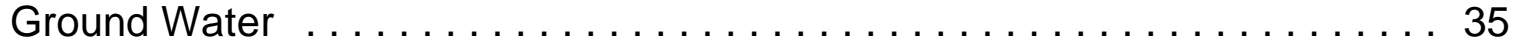

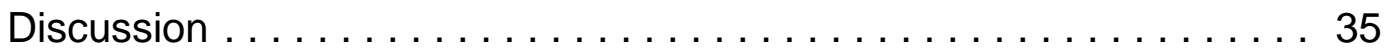

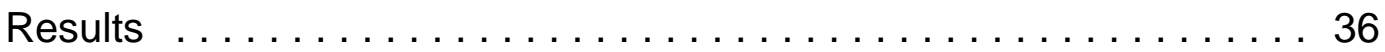

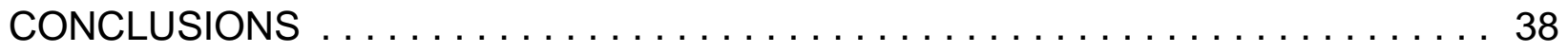

Ammonia Adsorption and Release $\ldots \ldots \ldots \ldots \ldots \ldots \ldots \ldots \ldots \ldots$

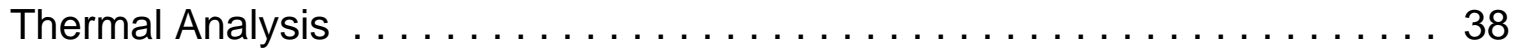

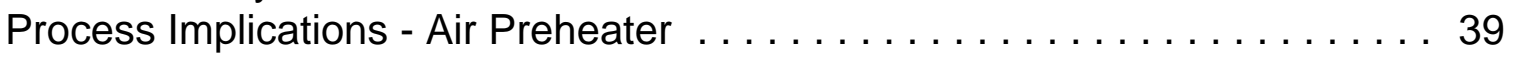

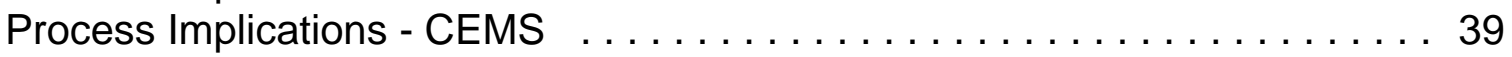

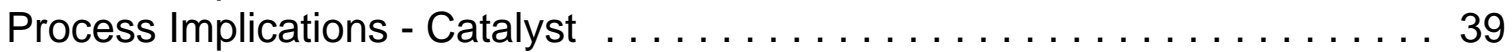

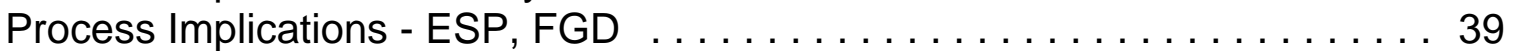

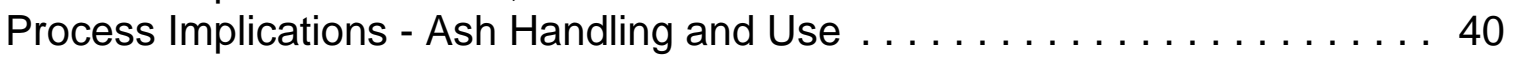

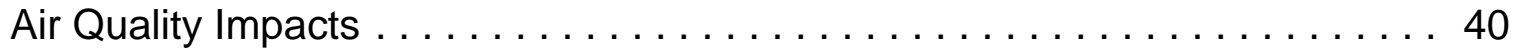

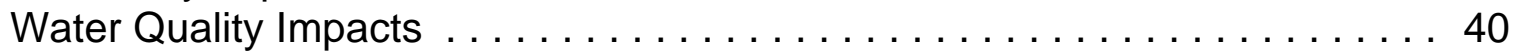

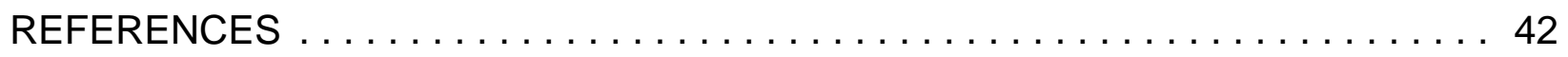

TABLES

FIGURES 


\section{LIST OF TABLES}

\section{Table Title}

$1 \quad$ Ammonia Solubility

2 Properties of "Pre-SCR" Fly Ash Samples

3 Ash Properties for Selected Plants with SCR/SNCR Systems

$4 \quad$ Onset Temperature for Ammonia Evolution from Ammonia Salts

5 Onset Temperature for Low- and High-Temperature Ammonia Evolution from SCR/SNCR Fly Ash Samples

6 Summary of Surface Water Quality Predictions for Site A

7 Summary of Predicted Leachate Concentrations for Landfill Site B

8 Summary of Surface Water Quality Predictions for Site B

9 Summary of Surface Water Quality Predictions for Site C 


\section{LIST OF FIGURES}

\section{Figure Title}

1 Nitrogen functional groups on a hypothetical carbon surface, introduced from treatment of the carbon with ammonia

2 Ammonia species in aqueous solution as a function of $\mathrm{pH}$ at $25 \mathrm{EC}$

3 The effects of temperature on ammonia species distribution in aqueous solution at various $\mathrm{pH}$ levels

4 Effect of salinity (ionic strength) on the percent of un-ionized $\mathrm{NH}_{3}$ in aqueous solution at $25 \mathrm{EC}$

5 The effect of $\mathrm{pH}$ on the rate of ammonia loss from water at 20EC

6 The effect of temperature on the rate of ammonia loss from water at different $\mathrm{pH}$ levels

$7 \quad$ Calibration curve for Gas Tec 3La ammonia detection tube

8 Ammonia release from fly ash "W" in distilled water under closed conditions

9 Ammonia release from fly ash "P1" in distilled water under closed conditions

10 Ammonia release from fly ash " $\mathrm{S}$ " in distilled water under closed conditions

11 Ammonia release from fly ash " $\mathrm{L}$ " in distilled water under closed conditions

12 Ammonia release from fly ash "H" in distilled water under closed conditions

13 Ammonia release from fly ash " $\mathrm{H}$ " under open conditions at room temperature

14 Ammonia release from fly ash "H" under open conditions at low temperature 


\section{LIST OF FIGURES (Continued)}

\section{Figure Title}

15 Ammonia release from fly ash "S" under open conditions at room temperature

16 Ammonia release from fly ash "S" under open conditions at low temperature

17 Ammonia release from fly ash "B" under open conditions at room temperature

18 Ammonia release from fly ash "B" under open conditions at low temperature

19 Ammonia release from fly ash " $\mathrm{L}$ " under open conditions at room temperature

20 Ammonia release from fly ash "O" under open conditions at room temperature

21 Ammonia release from mixture of pre-SCR fly ash "C2" and water, to which approximately $67 \mathrm{mg} / \mathrm{L}$ (ppm) $\mathrm{NH}_{3}$ as $\left(\mathrm{NH}_{4}\right)_{2} \mathrm{SO}_{4}$ has been added, under open conditions at room temperature

22 TG-MS results for ammonium sulfite in helium

23 TG-MS results for ammonium sulfate in helium

24 TG-MS results for ammonium sulfate and fly ash "MT" in helium

25 Theoretical weight loss vs. experimental weight loss for ammonium bicarbonate upon heating

26 TG-MS spectra for fly ash "MT" heated in He atmosphere

27 TG-MS spectra for fly ash "MT" heated in $\mathrm{He}-\mathrm{O}_{2}$ atmosphere

28 TG-MS spectra for fly ash " $\mathrm{H}$ " heated in He atmosphere

29 TG-MS spectra for fly ash "O" heated in He atmosphere

$30 \quad$ TG-MS spectra for fly ash "W" heated in He atmosphere

31 TG-MS spectra for fly ash " $\mathrm{H}$ " heated in $\mathrm{He}-\mathrm{O}_{2}$ atmosphere

32 TG-MS spectra for fly ash "O" heated in $\mathrm{He}-\mathrm{O}_{2}$ atmosphere 


\section{LIST OF FIGURES (Continued)}

\section{Figure Title}

33 TG-MS spectra for fly ash "W" heated in $\mathrm{He}-\mathrm{O}_{2}$ atmosphere

$34 \quad$ TG-MS spectra for fly ash "L" heated in He atmosphere

35 TG-MS spectra for fly ash "P1" heated in He atmosphere

36 TG-MS spectra for fly ash "L" heated in $\mathrm{He}-\mathrm{O}_{2}$ atmosphere

37 TG-MS spectra for fly ash "P1" heated in $\mathrm{He}-\mathrm{O}_{2}$ atmosphere

38 TG-MS spectra for fly ash "S" heated in He atmosphere

39 TG-MS-spectra for fly ash "B" heated in He atmosphere

40 TG-MS spectra for fly ash "S" heated in $\mathrm{He}-\mathrm{O}_{2}$ atmosphere

41 TG-MS spectra for fly ash "B" heated in $\mathrm{He}-\mathrm{O}_{2}$ atmosphere 


\section{INTRODUCTION}

The CAA Amendments of 1990 mandate reductions in emissions of NOx from coal-fired electric utility boilers. Currently, the technology most widely used in utility boilers for NOx reduction is combustion modification using low NOx burners, frequently combined with overfire air. Although this technology has proven to be the most cost-effective way to achieve NOx reductions of up to 50 percent, many electric utilities must attain higher levels of NOx reduction at their plants.

The only commercially available technologies capable of achieving high levels of NOx removal (more than 50 percent) are two post-combustion processes: SCR and selective non-catalytic reduction (SNCR), or a hybrid SCR/SNCR process. Each of these technologies uses a reagent (usually ammonia) to react with NOx and to reform as molecular nitrogen and water. Unreacted ammonia is carried with the flue gases through the duct system, with a large part deposited as ammonium bisulfate in the fly ash collected by the electrostatic precipitator (ESP), and a smaller amount exiting the stack. As much as 70 to 80 percent of the unreacted ammonia is retained on the fly ash.

This study investigated the processes of ammonia adsorption and release, and addresses some of the possible effects of ammoniated ash including:

- effects on surface and ground water quality, at ash ponds, ash site detention ponds and ash landfills, and compliance with water quality standards;

- impacts on air quality stack limits for ammonia and/or particulates;

- compliance with OSHA airborne exposure limits at ash facilities and/or at the property line;

- effects on ESP performance, Continuous Emissions Monitoring Systems (CEMS), and on the efficiency of flue gas desulfurization (FGD) equipment;

- effects of the ability to utilize or sell ash.

This report presents the findings of an investigation of these potential effects for SCR systems installed at power plants burning central Appalachian high-volatile bituminous coal. 


\section{EXECUTIVE SUMMARY}

This report presents the findings of an investigation of the potential impacts associated with the utilization of selective catalytic reduction (SCR) systems at coal-fired power plants. The investigation included: an extensive review of information and data from published and unpublished sources; discussions with vendors and operators of SCR/SNCR systems; a laboratory investigation of ammonia release using ash samples from power plants burning central Appalachian high-volatile bituminous coals; and an evaluation of potential air and water quality impacts based on computer modeling of several hypothetical scenarios. The major findings of the investigation are summarized below.

\section{Ammonia Adsorption and Release}

- Most of the ammonia present on fly ash is highly water soluble, and is completely dissolved into solution within several hours.

- $\mathrm{pH}$ exerts the dominant influence on ammonia speciation in solutions of fly ash and water.

- The effect of temperature on ammonia species in solution was much less pronounced than $\mathrm{pH}$, although it did exert a strong influence on the rate of ammonia loss from solution.

- SCR/SNCR fly ash that produces a high $\mathrm{pH}$ in aqueous solution can potentially produce ammonia odors when wetted. Ammonia odors from fly ashes that produce a low $\mathrm{pH}$ solution will be negligible.

- $\mathrm{NH}_{4}{ }^{+}$ion is stable in fly ash/water mixtures at low $\mathrm{pH}$ and is not out-gassed. However, conversion of at least a portion of it to $\mathrm{NO}_{3}{ }^{2-}$ and $\mathrm{NO}_{2}{ }_{2}^{2-}$ is likely in the natural environment because of the presence of nitrifying bacteria.

\section{Thermal Analysis}

- TG-MS can be used to detect ammonia release from fly ash upon heating by monitoring the ratio of amu $17 / 18$.

- Evolution of high temperature ammonia is typically associated with amu 44 release, which probably represents $\mathrm{CO}_{2}$ evolution, suggesting that the ammonia may be bound by unburned carbon in the ash. 
- When heated in an oxidizing atmosphere, "high temperature ammonia" appeared to be susceptible to $\mathrm{NO}_{x}$ conversion, usually in association with amu 44 release, suggesting a possible catalytic role of the carbon in the ammonia-to- $\mathrm{NO}_{\mathrm{x}}$ conversion

\section{Process Implications - Air Preheater}

- Early SCR installations experienced significant air preheater plugging and corrosion resulting from formation and deposition of ammonium bisulfate.

- These problems can be resolved by proper system configuration and by limiting ammonia slip to less than 2 parts per million (ppm), although some industry experts advocate even lower levels.

\section{Process Implications - CEMS}

- Operators at several U.S. installations have had difficulty in maintaining CEMS at the operating conditions before the SCR (hot, dirty, etc.).

- Stack NOx measurements used to determine ammonia injection levels are not an effective means to optimize performance.

\section{Process Implications - Catalyst}

- Catalyst deactivation can result from arsenic poisoning, ammonia salt deposition, alkaline metal poisoning, calcium sulfate masking, and fly ash plugging.

- Catalyst masking by calcium sulfate has become a major issue with Powder River Basin coal due to the concentration and form of calcium it contains.

- Limestone addition has been used to limit arsenic poisoning for coal burning facilities with low available calcium.

- Units with high carbon fly ash may have a potential for fire as the unit is brought down from normal operation.

\section{Process Implications - ESP, FGD}

- Addition of SCR has had minimal impact on ESP performance at operating systems.

- Operators of FGD systems do not currently experience odor problems, although this can become a concern if the $\mathrm{pH}$ rises above approximately 9 and ammonia slip levels are elevated. 


\section{Process Implications - Ash Handling and Use}

- Well-designed SCR installations have efficient ammonia distribution and NOx removal systems. This results in low ammonia slip $(0-2$ ppmv) and yields a corresponding ammonia on ash concentration at the lower range of those studied (- $50-100 \mathrm{ppm})$.

- Operators of new SCR systems have not had to change ash handling systems.

- Odor has not become a problem at landfills or impoundments.

- Fly ash uses involving the addition of alkaline material, such as concrete, have been impacted by ammonia odors. Although ammonia does not affect the performance of concrete, the aversion to ammonia odor can limit ash sales.

\section{Air Quality Impacts}

- Stack releases of ammonia are expected to have minimal impact.

- Ammonia release to the air from ash ponds, landfills and storage piles appears to be driven almost solely by the $\mathrm{pH}$ of the aqueous solution. In general, no odors or significant releases occur at $\mathrm{pH} 7$ - 8 or lower.

\section{Water Quality Impacts}

- Moisture is the controlling factor in the rate and amount of ammonia that will desorb from fly ash. In cases where the ash is placed in ponds most or all of the ammonia will desorb into the pond water.

- Leachate and/or runoff at ash landfills will contain increased concentrations of ammonia. If and when these salts are contacted with water, they will most likely be dissolved and the resulting aqueous concentration of nitrogen-containing compounds will increase in the waters associated with the ash.

A mass balance model applied to three eastern power plants burning central Appalachian high-volatile coal and producing a relatively low-pH ash determined the following:

- The predicted increase in ammonia as $\mathrm{N}$ concentrations in surface water due to installation of SCR systems may be of concern depending on site specific factors such as the assimilative capacity of receiving surface waters and regulatory permitting procedures.

- The predicted increase in ammonia as $\mathrm{N}$ and nitrate as $\mathrm{N}$ concentrations in landfill leachate and surface water runoff will translate to increased concentrations and increased loading of nitrogen-containing compounds at treatment ponds. 
- Predicted concentrations of nitrate as $\mathrm{N}$ in ground water, which is hydraulically connected with disposal sites that will receive ash from SCR units, may exceed the current U.S. Environmental Protection Agency (USEPA) drinking water standard of $10 \mathrm{mg} / \mathrm{L}$ whenever the ammonia concentration on the ash approaches $200 \mathrm{mg} / \mathrm{kg}$. 


\section{LABORATORY INVESTIGATION OF AMMONIA RELEASE}

\section{Background}

\section{Ammonia Slip and Adsorption of Ammonia on Fly Ash}

It is generally believed that up to 80 percent of the ammonia slip from SCR is adsorbed on the fly ash. The majority of ammonia on fly ash is believed to exist as ammonium salts, mainly ammonium sulfate and bisulfate (referred to as ammonium sulfates). Lesser amounts of other salts such as ammonium chloride are also possible. In addition to physically-adsorbed ammonium salts, ammonia could potentially be chemically sorbed to carbon surfaces. Reaction of activated carbons with ammonia, at temperatures of 200-400 degrees Celsius (EC), produces nitrogen-containing surface species such as those depicted in Figure 1 (Jansen and van Bekkum, 1994). The occurrence and fate of chemically-sorbed ammonia nitrogen in fly ash carbon, has not yet been studied. Although it is more tightly bound than physisorbed ammonia, and thus may not be released in an ash pond or landfill, it could be hydrolyzed in the high $\mathrm{pH}$ environment of concrete.

Most of the conclusions regarding ammonia in fly ash are inferred from plant component fouling deposits (e.g. Jordan and Casper, 1995), with a paucity of data obtained on the fly ash itself. An in-depth study of ammonia adsorption on fly ash was completed by Turner et al. (1994) in which ammonia/fly ash interactions were examined theoretically and experimentally. In this technical study, the authors calculated the upper-bound of ammonia adsorption by fly ash, in the absence of $\mathrm{SO}_{3}$, and found that the adsorption capacity was "significant". However, the NOx reduction observed commercially is close to stoichiometric, suggesting that only a small fraction of the ammonia ends up on the ash. Testing of fly ash contacted with different concentrations of ammonia in a gas stream indicated a monolayer adsorption capacity of 350 milligrams $(\mathrm{mg}) \mathrm{NH}_{3} / \mathrm{kg}$ ash. Turner and co-workers also found that the equilibrium adsorption capacity of $\mathrm{NH}_{3}$ (at 500 ppm gas concentration) on fly ash reached a minimum at about 350EC, which is within the operating range for a high-dust SCR unit. Furthermore, low temperature ammonia adsorption (i.e., <- 120EC) is increased by moisture in the fly ash.

The work of Turner et al. provided insight into the adsorption of ammonia on fly ash in the absence of gaseous $\mathrm{SO}_{2}$, the presence of which could cause precipitation of ammonium sulfates. More recent work by Electric Power Research Institute (EPRI) (O'Connor et al., 1999; Golden, 2000) has continued the study by conducting laboratory experiments on the adsorption of ammonia from a synthetic flue gas containing $\mathrm{SO}_{2}$. The goal of the EPRI studies 
has been to determine the relative propensity of different fly ashes for ammonia adsorption and to correlate fly ash physicochemical properties with adsorption properties. Adsorption isotherms indicated that fly ashes produced from different coals and firing conditions do indeed exhibit a wide range of adsorption capacity. Although several correlations with chemical composition have been proposed, the fly ash properties responsible for the differences are not clearly understood. EPRI also concluded that, regarding the environmental implications of ammonia-laden ash, further studies were warranted.

\section{Ammonia Chemistry}

Ammonia is a colorless, polar, toxic gas that is highly soluble in water:

$$
\mathrm{NH}_{3(\mathrm{~g})}+\mathrm{nH}_{2} \mathrm{O}_{(\text {()) }} \int \mathrm{NH}_{3} \cdot \mathrm{nH}_{2} \mathrm{O}_{(\mathrm{aq})}
$$

Aqueous ammonia is a weak base, releasing hydroxide and ammonium ions into solution upon dissociation. Although ammonium hydroxide is conveniently expressed as $\mathrm{NH}_{4} \mathrm{OH}$, dissolved ammonia is actually present in a hydrated form that is hydrogen bonded to at least three water molecules (Thurston et al., 1974). Increasing the partial pressure of ammonia gas results in an increase in ammonia solubility, as described by Henry's Law:

$$
\mathrm{k}_{\mathrm{H}}=\left(\mathrm{NH}_{3(\mathrm{aq})}\right) / \mathrm{P}_{\mathrm{NH} 3(\mathrm{~g})}
$$

where $\mathrm{k}_{\mathrm{H}}$ is Henry's Law constant, $\left(\mathrm{NH}_{3(\mathrm{aq})}\right)$ is the concentration of ammonia in aqueous solution, and $\mathrm{P}_{\mathrm{NH} 3(\mathrm{~g})}$ is the partial pressure of ammonia gas (from Sander, 1999).

Ammonia solubility is affected by temperature, with an increase in temperature causing a decrease in the Henry's Law constant (Table 1):

$$
\operatorname{lnk}_{H}=4092 / T-9.70
$$

where $\mathrm{T}=$ temperature in Kelvin (from Dasgupta and Dong, 1986).

Increasing the salinity of water can cause a "salting-out" effect, thus lowering ammonia solubility at a single temperature (Dasgupta and Dong, 1986; Lang et al., 1998). This effect is small in most natural fresh waters but can become significant in solutions of higher salinity such as seawater and brines (Bower and Bidwell, 1978). Similar to ammonia gas, the ammonium salts are also highly soluble in water (Table 1 ).

\section{Ammonia in Aqueous Solution}

Aqueous ammonia nitrogen is present in two forms: un-ionized $\mathrm{NH}_{3}$ and ionized $\mathrm{NH}_{4}{ }^{+}$. Un-ionized $\mathrm{NH}_{3}$ is highly toxic to aquatic organisms whereas $\mathrm{NH}_{4}^{+}$is much less so (Thurston et al., 1974). The relationship between the two species can be expressed as the equilibrium reaction:

$$
\mathrm{NH}_{3} \cdot \mathrm{nH}_{2} \mathrm{O}_{(\mathrm{aq})} \int \mathrm{NH}_{4}^{+}+\mathrm{OH}^{-}+(\mathrm{n}-1) \mathrm{H}_{2} \mathrm{O}_{(1)}
$$


The relative abundance of these two forms is primarily a function of $\mathrm{pH}$ and, to a lesser extent, temperature. Increasing the $\mathrm{pH}$ and the temperature causes an increase in the fraction of unionized $\mathrm{NH}_{3}$. Figure 2 shows the effects of $\mathrm{pH}$ on the equilibrium ammonia species distribution in water at 25EC. At a pH of approximately 9.2 un-ionized $\mathrm{NH}_{3}$ and $\mathrm{NH}_{4}^{+}$ion are present in equal amounts. Raising the temperature shifts the curves to the left (lower $\mathrm{pH}$ ), whereas lowering the temperature causes a shift to the right (higher $\mathrm{pH}$ ).

Figure 3 shows in greater detail the effects of temperature at different $\mathrm{pH}$. Note that, although the proportion of the two species is affected by temperature at all $\mathrm{pH}$ levels, the most pronounced influence (from a practical standpoint) is at intermediate $\mathrm{pH}$.

As mentioned above, salinity can exert an influence on ammonia solubility as well as on the species distribution. Figure 4 presents graphically the effects of salinity on the percent unionized ammonia in seawater, calculated by Bower and Bidwell (1978). With respect to potential odor problems occurring during the handling and storage of ammoniated fly ash, the effects of salinity are of minor significance but could be important for toxicity since criteria for aquatic life can be very low (e.g. $<1 \mathrm{mg} / \mathrm{L}$, dependent on organisms being considered, $\mathrm{pH}$, temperature, salinity, and whether the criterion is acute or chronic; EPA, 1999).

Although ammonia can be complexed by metal ions such as $\mathrm{Cu}^{2+}$ in solution, this effect is not significant except at metal concentrations that would be toxic to aquatic life (API, 1981).

\section{The Fate of Ammonia in the Environment}

Ammonia in aqueous solution can be transformed/removed via a number of pathways. At elevated $\mathrm{pH}$ (i.e., > 9), $\mathrm{NH}_{3}$ gas will readily be lost from solution, thus removing a significant amount of ammonia nitrogen. The rate of ammonia loss from water to the atmosphere is primarily controlled by $\mathrm{pH}$, temperature, and wind speed: an increase in any of these variables causes an increase in the rate of ammonia loss (Weiler, 1979). Suspended particles can also increase the loss rate. The effect of $\mathrm{pH}$ on ammonia loss rate, from a solution containing 100 $\mathrm{mg} / \mathrm{L}$ ammonia $\mathrm{N}$ at $20 \mathrm{EC}$, is shown in Figure 5. These data were calculated using data of Emerson et al. (1975) and the rate loss equation from Weiler (1979):

$$
[N]=\left[N_{0}\right] \exp -\left\{\frac{\mathrm{KeAt}_{\mathrm{e}}}{\mathrm{V}\left(1+[\mathrm{H}] / \mathrm{Ka}_{\mathrm{a}}\right)}\right\}
$$

where $[\mathrm{N}]$ is the nitrogen concentration after time $(\mathrm{t}),\left[\mathrm{N}_{\mathrm{o}}\right]$ is the initial concentration, $\mathrm{K}_{\mathrm{e}}$ is the exchange coefficient, $\mathrm{K}_{\mathrm{a}}$ is the ammonium dissociation constant, $[\mathrm{H}]$ is the hydrogen ion concentration, and $\mathrm{A} / \mathrm{V}$ is the area to volume ratio of the water body.

The data in Figure 5 were calculated using exchange coefficients estimated from Weiler's data for a well-stirred water body with an $\mathrm{A} / \mathrm{V}=0.1$ and negligible wind speed. These data indicate that $\mathrm{pH}$ has a dramatic effect on ammonia loss from solution, due to its effect on the proportion of un-ionized $\mathrm{NH}_{3}$ in solution. At a pH of 9.5 , slightly more than half of the ammonia $\mathrm{N}$ is present as un-ionized $\mathrm{NH}_{3}$ (at equilibrium). As the $\mathrm{NH}_{3}$ gas leaves the water, re- 
establishment of equilibrium causes more $\mathrm{NH}_{4}{ }^{+}$to dissociate to $\mathrm{NH}_{3}$ thus eventually depleting the total ammonia $\mathrm{N}$. At high $\mathrm{pH}$, most of the ammonia is present as un-ionized $\mathrm{NH}_{3}$, causing the total ammonia $\mathrm{N}$ concentration to decrease more rapidly. Conversely, at low pH (e.g. 4.5) the proportion of $\mathrm{NH}_{3}$ is very small which causes the total ammonia $\mathrm{N}$ to persist for a much longer time.

The effects of temperature, at different levels of $\mathrm{pH}$, were also calculated from Weiler (1979), and are depicted in Figure 6 . The calculated data predict that at a low $\mathrm{pH}$ increasing the temperature has practically no effect on the ammonia loss rate from water (after 100 hours). However, at higher $\mathrm{pH}$ the effect of temperature can be significant, with an increase in temperature causing an increase in the rate of ammonia evolution (Figure 6). For a utility ash pond environment, seasonal variations in water temperature could cause noticeable changes in ammonia odors emanating from the pond, as well as the concentration of ammonia in the pond discharge, provided that the $\mathrm{pH}$ is sufficiently high. At low $\mathrm{pH}$, the seasonal variations would have essentially no effect on odors or ammonia discharge, at least in the context of ammonia loss by out-gassing.

Ammonia $\mathrm{N}$ can also be removed from water by adsorption onto soil particles. This adsorption can be in the form of $\mathrm{NH}_{3}$ weakly adsorbed on the surfaces, and as $\mathrm{NH}_{4}^{+}$that is more strongly bound as an exchanged ion. Although physically adsorbed $\mathrm{NH}_{3}$ would be subject to movement within groundwater, exchanged $\mathrm{NH}_{4}^{+}$is much more stable and thus is not subject to appreciable migration (Delwiche, 1970; Coffee and Bartholomew, 1964). The exchange surfaces in soils are primarily clay minerals and, to a lesser extent, organic particles. Certain clay minerals have a net negative charge due to the substitution of aluminum for silicon in the mineral structure. To offset the charge imbalance, positively charged ions such as $\mathrm{K}^{+}$and $\mathrm{Na}^{+}$adsorb onto the clays. The positive charge of the $\mathrm{NH}_{4}$ ion thus causes it to be exchanged onto some clays. Although the exchanged $\mathrm{NH}_{4}{ }^{+}$ion is chemically adsorbed on the clays, it is affected by other ions in solution and, therefore, can be released at a later time if the water chemistry changes significantly (e.g. increased concentration of other cations).

The conversion of ammonia nitrogen to nitrate and nitrite ("nitrification") is largely a bacterial process, carried out in the presence of oxygen by Nitrobacter and Nitrosomonas, respectively. The nitrification rate is mainly limited by oxygen diffusion and thus is increased in shallow, well-mixed, particle-laden water columns and within sediments near the sedimentwater interface (Keeney, 1972; Chen et al., 1972; Kholdebarin and Oertli, 1977a). The optimum $\mathrm{pH}$ for nitrifying bacteria has been determined to be approximately 8-9 (Kholdebarin and Oertli, 1977b). Unlike $\mathrm{NH}_{4}{ }^{+}$, nitrate $\left(\mathrm{NO}_{3}{ }^{2-}\right)$ and nitrite $\left(\mathrm{NO}_{2}{ }^{2-}\right)$ are anions in aqueous solution and are highly mobile within soil water (Delwiche, 1970). At this time, it is not known whether nitrification would occur to a significant extent within a utility ash pond, although conversion to nitrate and/or nitrite would likely occur in the natural water bodies downstream of a pond or landfill discharge. Moreover, there are many nitrate and nitrite transformations that can occur in surface and ground water, the majority of which would probably not directly influence utilities producing, handling, and disposing of ammoniated fly ash. Consequently, these reactions are not discussed in detail in this report. More thorough descriptions of the 
fates of nitrogen in the natural environment can be found in Keeney (1972) and Delwiche (1970).

Finally, most algae can utilize ammonia and nitrate as a source of nitrogen and can therefore deplete the amount of ammonia nitrogen present in surface waters. In fact, some species prefer ammonia over nitrate (API, 1981).

\section{Experimental Procedures in This Study}

\section{Fly Ash Sampling}

Pre-SCR Fly Ash. Fly ash was sampled from electrostatic precipitator hoppers from three power plants that do not currently inject ammonia for $\mathrm{NO}_{x}$ reduction, but will be installing SCR in the near future. All of the plants currently burn pulverized low-sulfur central Appalachian coal. Ash produced at one of these plants is currently disposed in ponds, whereas the other two employ landfilling.

SCR/SNCR Fly Ash. Samples of fly ash produced at power plants that currently operate SCR or SNCR systems for $\mathrm{NO}_{x}$ reduction were obtained in order to study the release of ammonia from the fly ash. Another sample was acquired from a plant that has injected ammonia for opacity control. The fly ash produced at plants that are injecting ammonia is herein referred to as "ammoniated fly ash". At the request of the participating power plants, detailed information regarding the plant configuration cannot be provided.

\section{Chemical Analysis of Fly Ash}

Elemental analysis was conducted on pulverized sub-samples which were ignited at 500EC in an oxidizing furnace. The major element oxides were determined using a Phillips PW2404 $x$-ray spectrometer in accordance with ASTM D 4326. Carbon, hydrogen, and nitrogen content was determined using a LECO CHN 2000 as per ASTM D 5373. The LOI was determined by heating the samples in air at $900 \mathrm{EC}$ for one (1) hour, and the free lime content was obtained using the ASTM C 25 procedure.

\section{Ammonia Measurement}

Ammonia Gas. Ammonia gas can be measured using several established techniques, which were evaluated for this project. An ammonia gas detector was seriously considered initially, but was prohibitively expensive. Gas detection tubes, containing various types of reagent, were concluded to be more suitable. Sensidyne/GasTec ammonia detection tube $3 \mathrm{La}$ was tested early in the project. This was accomplished by preparing a stock solution of $1000 \mathrm{mg} / \mathrm{L}$ $\mathrm{NH}_{3}$ (as $\mathrm{NH}_{4} \mathrm{Cl}$ ) and diluting it to different concentrations. The solutions (100 ml each) were placed into $500 \mathrm{ml}$ Erlenmeyer flasks, the $\mathrm{pH}$ adjusted to $>12$, and sealed using a two hole rubber stopper (with the holes plugged with smaller stoppers). After 24 hours, a GasTec tube was inserted into the two-hole stopper and the other hole partially uncovered. One-hundred $\mathrm{cm}^{3}$ of the solution head-space was then drawn through the detector tube using a GasTec Model 800 pump, and the ammonia concentration (in ppm) read directly from the tube. Figure 
7 shows the results of this testing and, when compared with $\mathrm{NH}_{3}$ gas values calculated from Henry's Law, indicated that the GasTec tubes would provide a satisfactory measurement of ammonia evolved from a fly ash/water solution.

Another type of detector tube was considered, which contains carbon or silica impregnated with sulfuric acid (CISA or SISA). As with the GasTec tubes, a known volume of ammonialaden air is pulled through the tube, the trapped ammonia is desorbed in distilled/de-ionized water and analyzed using ion chromatography (OSHA, 1991; NIOSH, 1996) or absorption spectrophotometry with an indicator added to the solution (NIOSH, 1994). These techniques would likely provide more accurate ammonia determinations for large volumes of air. However, for this study the small quantities of air sampled $(0.1 \mathrm{~L})$, combined with the considerable amount of labor involved for each of the OSHA and NIOSH procedures, favored the GasTec tube over the CISA/SISA methodologies.

Ammonia Content of Fly Ash. Determination of the amount of water soluble ammonia on the ammoniated fly ash samples was conducted using an Orion 95-12 ammonia-specific electrode. Mixtures of 25 percent fly ash and 75 percent distilled/deionized water were prepared and agitated thoroughly in $250 \mathrm{ml}$ polyethylene bottles. After setting for 24 hours, the mixture was filtered through a Whatman 3 cellulose filter, and the filtrate $\mathrm{pH}$ adjusted to $>12$ using $10 \mathrm{M}$ aqueous $\mathrm{NaOH}$. The $\mathrm{NaOH}$ also served as a background electrolyte to adjust the ionic strength of the sample solutions to approach that of the standard solutions. Ammonia in solution was determined using the calibrated ammonia electrode, and the ammonia content on the solid fly ash calculated (assuming all aqueous ammonia originated from the ash).

Ammonia Content of Fly Ash Leachate/Supernatant. For the ammonia release experiments, un-ionized ammonia in aqueous solution was measured using the ammoniaspecific electrode described above, without adjustment of the solution $\mathrm{pH}$ or ionic strength. Although this introduced a slight error in the measurements, $\mathrm{NaOH}$ was not added because one of the goals of the experiments was to determine the amounts of un-ionized $\mathrm{NH}_{3}$ and $\mathrm{NH}_{4}{ }^{+}$ ion in the fly ash leachate and supernatant (described below) at the "natural" pH of the fly ash.

Ammonium ion concentration in solution was measured using a calibrated Orion 93-18 ammonium ion-specific electrode. Due to interferences with other monovalent cations in solution the $\mathrm{NH}_{4}{ }^{+}$concentrations reported herein are higher than the actual concentrations. This was particularly noticeable at lower $\mathrm{NH}_{4}{ }^{+}$concentrations (i.e., $<20-25 \mathrm{ppm}$ ): at high ammonia contents, the ammonia $\mathrm{N}$ concentration determined using the ammonium-specific electrode was similar to that obtained using the ammonia gas-sensing electrode. The ammonium ion electrode was selected for use in this study, despite the interferences, because it can provide fairly rapid, inexpensive, repeatable approximations of the ammonium content in fly ash leachate. When combined with data obtained using the ammonia gassensing electrode, the ammonium-specific electrode can provide insight into the relative proportions of $\mathrm{NH}_{3}$ and $\mathrm{NH}_{4}{ }^{+}$in the leachate, and changes in their concentration with time.

$\boldsymbol{p H}$. The $\mathrm{pH}$ produced by the fly ash samples in aqueous solution was determined following the same procedures used for ammonia determination. A calibrated Orion Triode $\mathrm{pH}$ 
electrode with temperature compensation was employed in these tests. This electrode was used for all $\mathrm{pH}$ measurements in the study.

\section{Ammonia Release Testing}

Closed System. Ammonia release from fly ash in a closed system was studied using Pyrex columns that were 60 centimeters $(\mathrm{cm})$ long and $4.25 \mathrm{~cm}$ in diameter. The fly ash and water mixture was supported within the column by a porous glass frit overlain by 50 grams $(\mathrm{g})$ of washed, graded sand. Fly ash $(135 \mathrm{~g})$ was slurried with 300 milliiters $(\mathrm{ml})$ of distilled water in a polyethylene bottle and the mixture poured into the Pyrex column, followed by washing the remaining fly ash from the bottle and column sides with $100 \mathrm{ml}$ of distilled water. This procedure yielded a total ash content of 25 percent by weight. A two-hole rubber stopper was fitted tightly over the opening at the top of the column, and the holes sealed using smaller stoppers. Eight to ten columns were prepared for each ash such that periodic measurements could be made over the course of two (2) months. At each specified interval, ammonia in the sealed head-space was measured using the GasTec ammonia-sensing tubes, followed by draining the water through the fly ash bed and out the bottom of the column into an Erlenmeyer flask. The volume of leachate recovered was measured and recorded. Un-ionized $\mathrm{NH}_{3}, \mathrm{NH}_{4}{ }^{+}$ ion, and $\mathrm{pH}$ were measured in the leachate. After draining the leachate from each column, the column of wet fly ash was removed and a sample analyzed for moisture content. This was accomplished in order to calculate a mass balance for the water added versus that removed. The data confirmed that a negligible loss of water by evaporation occurred during the experiments.

Because of the fineness and/or cementitious nature of several of the ash samples (which prevents water percolation through the ash column), ammonia release experiments for these samples ("P1" and "W") were conducted in stoppered $500 \mathrm{ml}$ polyethylene bottles, using $50 \mathrm{~g}$ of fly ash with $150 \mathrm{ml}$ distilled water (25 percent fly ash). In these experiments the head-space ammonia gas was measured, followed by filtering the solution through a Whatman 3 paper filter. $\mathrm{NH}_{3}$ and $\mathrm{NH}_{4}{ }^{+}$concentration, $\mathrm{pH}$, and temperature were then determined.

Open System. Ammonia release from fly ash/water mixtures open to the atmosphere was studied using $1 \mathrm{~L}$ "square ratio" polyethylene beakers. The mixtures comprised 25 percent by weight fly ash and 75 percent distilled/de-ionized water. Prior to preparing the ash/water mixtures, the density of each fly ash was estimated in order that the quantity of fly ash and water could be adjusted to a total volume of $1 \mathrm{~L}$. The density was estimated by placing a specified mass of fly ash into a graduated cylinder and tapping the cylinder sides to settle the ash column. Water was slowly added to the ash in the cylinder, and given sufficient time to completely permeate the ash, until it reached the top of the ash column. The amount of water added, the volume of the water + ash, and the fly ash dry mass were used to calculate the density.

The samples were prepared by mixing a specified amount of fly ash with distilled water in 1 $L$ polyethylene bottles, shaking the mixtures thoroughly in the sealed bottles, followed by pouring the fly ash/water slurries into the $1 \mathrm{~L}$ beakers. 
After a brief period whereupon the fly ash was allowed to settle, the fly ash supernatant (i.e., the solution overlying the fly ash) was analyzed periodically for un-ionized $\mathrm{NH}_{3}, \mathrm{NH}_{4}{ }^{+}$ion, $\mathrm{pH}$, and temperature using the procedures and equipment described above. Prior to each measurement, the supernatant was gently stirred to mix the solution. At the conclusion of each experiment (e.g. 14 days), the fly ash was mixed thoroughly with the water, poured through a Whatman 3 filter in a Büchner funnel, and the filtered leachate analyzed. This provided an indication of the amount of ammonia remaining within the fly ash bed.

Ammonia release from the fly ash supernatant in the open vessels was studied at two temperatures: 24EC and 2-3EC. The temperature was controlled by placing the beakers into a water bath that was controlled with a heating element or with crushed ice for the room temperature and low temperature experiments, respectively. In order to compensate for evaporation at room temperature, the total mass of the beaker with fly ash and water was determined, compared with the starting mass, and the required amount of distilled water added. In contrast, during the low temperature experiments water actually condensed into the beakers from the humidity in the air. Although ice was continuously added over the course of the low-temperature experiments, temperature excursions up to as high as $10 \mathrm{EC}$ occasionally occurred overnight.

\section{Thermal Analysis}

Samples of fly ash and reagent-grade salts, $\left(\mathrm{NH}_{4}\right)_{2} \mathrm{SO}_{4}, \mathrm{NH}_{4} \mathrm{HSO}_{4},\left(\mathrm{NH}_{4}\right)_{2} \mathrm{SO}_{3} \cdot \mathrm{H}, \mathrm{O}, \mathrm{NH} \mathrm{HCO}_{3}$ $\left(\mathrm{NH}_{4}\right)_{2} \mathrm{CO}_{3} \cdot \mathrm{H}_{2} \mathrm{O}$ and $\mathrm{NH} \mathrm{Cl}_{4}$ were analyzed by thermogravimetric analysis - mass spectrometry (TG-MS). Pure ammonium salts and mixtures of ammonium salts and "pre-SCR" fly ash were analyzed to establish decomposition temperatures and the effects of ash on decomposition. These data were then compared with the results obtained from the ammoniated ash samples. The concentrations of salts added to the pre-SCR ash were: $0.5,1.0$, and 2.0 percent $\left(\mathrm{NH}_{4}\right)_{2} \mathrm{SO}_{4} ; 1.0$ percent $\mathrm{NH}_{4} \mathrm{Cl}$, and $0.125,0.25,0.5,1,2$, and 4 percent $\mathrm{NH}_{4} \mathrm{HCO}_{3}$.

The instruments used were a Netzsch Jupiter STA 449C thermogravimetric analyzer (TG) coupled to a Balzer Thermostar quadrapole mass spectrometer (MS). The two instruments are coupled via a heated fused silica capillary transfer line from the exit tube of the TG furnace to the MS detector. The MS was equipped with two detectors, a faraday cup and a secondary emissions multiplier. The dry ash sample size was between 100-200 mg. All samples tested were analyzed under two atmospheres, inert ( $\mathrm{He}$ only) and oxidizing (10 percent $\mathrm{O}_{2}$ in $\mathrm{He}$ ) with total gas purge flow over the samples of $200 \mathrm{ml} / \mathrm{min}$ metered at room temperature and pressure. The TG heating regime was $20 \mathrm{EC} / \mathrm{min}$ to $900 \mathrm{EC}$. Mass spectra were acquired either in histogram mode where each scan acquired the spectra for the range 1-100 atomic mass unit (amu) or in multiple ion detection (MID) mode with the specific detection of masses $17,18,28,30,35,44,48$, and 64 . Spectra were acquired every 10 and 5 seconds in histogram and MID modes, respectively. Identification of ammonia versus water evolution was determined by the calculation of the ratio of the MS signal for amu 17 to amu 18 . Higher signal ratios were determined to be ammonia by comparison with signal ratios of the pure ammonia salts. 


\section{Results and Discussion}

\section{Fly Ash Characterization}

Chemical Analysis. Selected properties of the "pre-SCR" fly ashes are provided in Table 2. The data indicate that the three power plants have produced fairly similar ash that would be classified as low-calcium oxide "Class F" fly ash. The chemical properties of the ammoniated fly ash samples are provided in Table 3. It is evident from this table that the samples encompass a wide range of $\mathrm{LOI}$, chemical composition, soluble ammonia content, and $\mathrm{pH}$ (in aqueous solution). Comparison of the ammonia concentrations determined in this study with those provided by several of the power plants (typically using the Kjedahl technique) indicates that most of the ammonia present on fly ash is readily water soluble, probably as ammonium salts. This result is not unexpected, as the presence of ammonium sulfate and bisulfate on SCR/SNCR fly ash has been inferred for a number of years (e.g., Cichanowicz, 1999). In addition, the effect of $\mathrm{pH}$ on ammonia species became evident early in the study: samples "B", "S", "H", "W", and "L" produced noticeable ammonia odors in water, whereas ashes "P1" and "O" did not.

\section{Closed-Vessel Experiments}

At the onset of the project, testing was completed on fly ash "W" because it contained a significant amount of ammonia, produced a high pH in solution, and thus should produce a measurable amount of ammonia gas. It was therefore deemed to be a good sample for initial testing. The sample is a Class $\mathrm{C}$, high-calcium fly ash that possesses cementitious properties and was, therefore, tested using the polyethylene bottle procedure. In order to prevent the material from hardening in the bottle, the ash/water mixture was periodically agitated throughout the experiment, although some setting still occurred. Figure 8 shows the results obtained for short-term testing of ash "W". Although there was a large degree of scatter in the data, it is evident that this fly ash released a significant quantity of ammonia into solution, and that the high pH (12.25; Table 3) caused a large amount of $\mathrm{NH}_{3}$ gas to form that resulted in a strong ammonia emission from the solution.

In contrast, fly ash "P1" produced a much lower $\mathrm{pH}$ in solution (3.6-3.7), and thus the ammonia was present almost entirely as $\mathrm{NH}_{4}{ }^{+}$ion, resulting in a negligible release of $\mathrm{NH}_{3}$ gas from the solution. Because of the fineness of this ash (i.e., low permeability), the ammonia release experiments were conducted in the stoppered $500 \mathrm{ml}$ polyethylene bottles. Figure 9 presents the $\mathrm{NH}_{4}{ }^{+}$concentration data acquired for this sample over the course of several months. After an initial increase, the $\mathrm{NH}_{4}{ }^{+}$concentration remained constant after approximately 1 hour and during the remainder of the experiment. These data suggest that the $\mathrm{NH}_{4}{ }^{+}$ion remained essentially stable in solution under these conditions.

Figures 10 through 12 provide a graphical summary of experimental results obtained at room temperature (approximately 23EC) for fly ash "S", "L", and "H" within the pyrex columns. For each of these fly ash samples, the $\mathrm{pH}$ decreased over the course of the measurements, suggesting that atmospheric $\mathrm{CO}_{2}$ infiltrated the columns. At these elevated $\mathrm{pH}$ values, note that the proportion of un-ionized $\mathrm{NH}_{3}$ is much higher than $\mathrm{NH}_{4}^{+}$ion. The relative abundance 
of un-ionized $\mathrm{NH}_{3}$ in solution was also manifested as a measurable quantity of $\mathrm{NH}_{3}$ gas in the head-space, which took several weeks to reach a stable maximum value.

The concentration of $\mathrm{NH}_{3}$ gas released from fly ash "S" increased from 5-6 ppm to approximately $10 \mathrm{ppm}$ during the experiment, although the concentration of aqueous $\mathrm{NH}_{3}$ was initially $24 \mathrm{mg} / \mathrm{L}$ (ppm) and decreased to approximately $20 \mathrm{mg} / \mathrm{L}$ (Figure 10). Although it is possible that the slight decrease in aqueous $\mathrm{NH}_{3}$ was caused by the out-gassing of $\mathrm{NH}_{3}$ from solution into the head-space, there is still a significant discrepancy between the expected and the measured $\mathrm{NH}_{3}$ gas concentrations. Using Henry's Law and the GasTec tube calibration graph (Figure 7), the expected gas concentration is $21 \mathrm{ppm}$. In order to investigate this discrepancy, the water from one of the Pyrex columns was drained through the fly ash bed until the water level coincided with the top of the ash bed. The collected leachate was then poured back into the column (which was then re-sealed at the top) and allowed to sit for 24 hours. Measurement of the head-space gas after 24 hours revealed a gas concentration of $23 \mathrm{ppm}$ (Figure 10, "recycled"), much closer to the calculated value. Furthermore, ash/water mixtures prepared and sealed in polyethylene bottles ( 25 percent ash/75 percent water) released 20 $\mathrm{ppm} \mathrm{NH}_{3}$ gas into the bottle head-space. This suggested that the water used to wash down the sides of the Pyrex columns, during the ash preparation step, remained relatively dilute and was not in equilibrium with the ammonia concentration within the underlying ash bed. Apparently, under these closed conditions, the $\mathrm{NH}_{3}$ gas did not freely migrate from the " $\mathrm{S}$ " ash into the overlying solution, despite the high $\mathrm{pH}(12.1$, decreased to 11.0) of the solution.

Sample "L" was unlike the other samples in that it was obtained from an air heater collector and thus comprised a considerably coarser particle size. Figure 11 provides the ammoniarelease data for this ash. The aqueous $\mathrm{NH}_{3}$ and $\mathrm{NH}_{4}{ }^{+}$concentrations remained more-or-less constant at 33-35 mg/L and 7-10 mg/L, respectively, whilst the $\mathrm{NH}_{3}$ gas concentration in the head-space progressively increased over the course of the testing. In fact, after nearly 2 months the gas continued to evolve into the head-space, although the last measured concentration (28 ppm) was probably very close to the equilibrium concentration. The $\mathrm{pH}$ decreased from 11.7 to 10.1 during the experiment. In contrast to fly ash "S", the ammonia gas migrated more freely from the coarser and lower carbon ash " $\mathrm{L}$ " into the overlying solution, although the out-gassing rate was very slow. It is also apparent that either the proportion of $\mathrm{NH}_{4}{ }^{+}$ion did not increase as the $\mathrm{pH}$ decreased or, more likely, that the ion-specific electrode lacked the sensitivity to detect the changes.

Some of the conclusions derived from samples "W", "P1", "S", and "L" can also be applied to the data obtained on fly ash "H" (Figure 12): the elevated $\mathrm{pH}$ resulted in aqueous $\mathrm{NH}_{3}$ being the dominant species, a significant quantity of $\mathrm{NH}_{3}$ gas was released from the ash, and the gas required a long period of time to reach an equilibrium concentration in the head-space. However, the high concentration of ammonia in this ash was associated with dramatic fluctuations in the aqueous $\mathrm{NH}_{3}$ readings. The $\mathrm{NH}_{3(\mathrm{aq})}$ concentration decreased during the experiment until the final measurement (Day 59) which increased substantially from the previous ones (Figure 12). The $\mathrm{NH}_{3}$ gas measurement would have provided information as to whether the high $\mathrm{NH}_{3(\mathrm{aq})}$ value was simply an artefact of the electrode technique or represented the actual concentration. However, the gas concentration was sufficiently high to exceed the maximum that is measurable using the detector tube. It is possible that the ash 
loaded into the final column actually contained a very high concentration of ammonia and that the ammonia content of the ash was not homogeneously distributed within the bulk sample.

\section{Open-Vessel Experiments}

Figures 13 through 21 show the results of the open-vessel ammonia release experiments conducted on fly ash samples that exhibit a range of $\mathrm{pH}$ values in aqueous solution. Fly ash "H" initially produced a pH of 10.6-10.7 at room temperature, which progressively decreased to 8.8 after 13 days (Figure 13). Un-ionized $\mathrm{NH}_{3}$ is the dominant species in solution initially, although the fraction of $\mathrm{NH}_{3}$ and $\mathrm{NH}_{4}^{+}$became equal when the $\mathrm{pH}$ decreased to 9.6-9.7. After this, $\mathrm{NH}_{4}{ }^{+}$became the dominant species, whilst the total ammonia concentration continued to decrease as the $\mathrm{NH}_{3}$ out-gassed from the solution. At the conclusion of the ammonia release experiment, the ash and supernatant were thoroughly mixed, filtered through a Whatman 3 cellulose filter, and the $\mathrm{NH}_{3}$ and $\mathrm{NH}_{4}{ }^{+}$concentration, $\mathrm{pH}$, and temperature measured. The ammonia (represented here as ammonia $\mathrm{N}$ ) remaining in the ash bed was calculated using an equation that describes the mixing of two components:

$$
N_{A}=\frac{N_{T}-\left(N_{S} * f S\right)}{1-f S}
$$

where $\mathrm{N}_{\mathrm{A}}=$ ammonia $\mathrm{N}$ concentration in the ash interstitial water, $\mathrm{N}=$ ammonia $\mathrm{N}$ concentration in the total solution, $\mathrm{N}_{\mathrm{S}}=$ ammonia $\mathrm{N}$ concentration in the supernatant, and $f_{S}=$ fraction of supernatant in the total solution (equation modified from Faure, 1991)

The fractions of supernatant and ash interstitial water were experimentally determined for each sample, and the ammonia $\mathrm{N}$ was calculated using the un-ionized $\mathrm{NH}_{3}$ concentration (determined with the gas-sensing electrode) and the fraction of un-ionized $\mathrm{NH}_{3}$ in the solutions (from Emerson et al., 1975).

The final ammonia N concentration in the supernatant of fly ash "H" after 59 days was $12 \mathrm{mg} / \mathrm{L}$, whereas that in the entire mixture was $39 \mathrm{mg} / \mathrm{L}$. Using equation (6), the concentration of ammonia $\mathrm{N}$ in the fly ash interstitial water was $70 \mathrm{mg} / \mathrm{L}$. These data suggest that the rate at which ammonia was expelled from the fly ash was lower than the rate of out-gassing from the solution, although most of the ammonia was released from the ash.

Temperature had a significant, and expected, effect on ammonia release from fly ash " $\mathrm{H}$ " (Figure 14): lowering the temperature to 2-3EC resulted in a marked reduction in the rate of ammonia out-gassing from solution. At the conclusion of the 11 day experiment, the amount of ammonia $\mathrm{N}$ in the supernatant was $113 \mathrm{mg} / \mathrm{L}$ whereas within the fly ash the calculated concentration was $96 \mathrm{mg} / \mathrm{L}$. This indicates that, at this low temperature, the ammonia diffusion through the fly ash kept pace with out-gassing from the supernatant. The $\mathrm{pH}$ at 2-3EC was about 1 unit higher than at 23-24EC but decreased at a similar rate in both experiments. The higher $\mathrm{pH}$ at low temperature is possibly a consequence of the higher solubility of $\mathrm{Ca}(\mathrm{OH})_{2}$. The reason(s) for the ash containing more ammonia than the supernatant is not known at this time. It is possible that the difference is simply an experimental artefact, 
possibly caused by temperature variations between the calibration standards and the sample. Although during the experiment the ammonia calibration was conducted at 2-3EC, the temperature of the total (filtered) solution (ash interstitial water + supernatant) was 17EC. The calibration for this final measurement was conducted at room temperature (19EC), and the 2Etemperature difference could have induced significant error. It is also possible that the ash interstitial water actually contained slightly higher ammonia (total) than the supernatant. The $\mathrm{pH}$ of this water was slightly higher than that of the supernatant at the end of the 11 day experiment, as evidenced by the higher pH of the total water volume (10.2@ 17EC) compared with the supernatant alone (10.0 @ 2EC). The ash interstitial water would contain a higher percentage of un-ionized $\mathrm{NH}_{3}$ (60 percent) than the supernatant (50 percent), which would increase the rate of ammonia evolution from the ash bed into the supernatant, thus depleting the ammonia content of the former compared with the latter. However, this is merely a hypothesis and would require additional testing to confirm or refute.

The release of ammonia from fly ash "S" at 23-24EC was very similar to that from "H". This ash initially produced a pH of about 11.5 , which decreased to 8.9 after nearly 3 weeks (Figure 15). The un-ionized $\mathrm{NH}_{3}$ concentration in solution rapidly decreased to $<1 \mathrm{mg} / \mathrm{L}$ within several days, whilst the $\mathrm{NH}_{4}{ }^{+}$remained at a low, more-or-less constant concentration throughout the experiment. It is worth noting that the fraction of $\mathrm{NH}_{4}{ }^{+}$became greater than the un-ionized $\mathrm{NH}_{3}$ after approximately 5 days, when the $\mathrm{pH}$ decreased below 10 (bearing in mind, however, that the measured $\mathrm{NH}_{4}{ }^{+}$concentrations are higher than the true concentrations because of interferences with other ions). The final ammonia $\mathrm{N}$ concentrations were $0.5 \mathrm{mg} / \mathrm{L}$ and 1.5 $\mathrm{mg} / \mathrm{L}$ in the supernatant and within the ash, respectively. This indicates that after 20 days, the ammonia $\mathrm{N}$ concentrations in the ash bed and in the overlying solution were similar.

Figure 16 provides graphically the data obtained for fly ash "S" at low temperature, and again illustrates the effect of temperature on ammonia release from ash. Due to time constraints, this experiment was conducted for a shorter duration than the room temperature experiment. The time axis in Figure 16 is scaled the same as in Figure 15 to allow a direct comparison of the data. At 2-3EC, the rate of un-ionized $\mathrm{NH}_{3}$ decrease was substantially lower than that at 23-24EC. Similar to fly ash "H", the pH at low temperature was about 1 unit greater than at the higher temperature. After 11 days the total ammonia $\mathrm{N}$ in the supernatant was $6 \mathrm{mg} / \mathrm{L}$, whilst the ash interstitial solution contained $7 \mathrm{mg} / \mathrm{L}$ ammonia $\mathrm{N}$. This result is similar to that found for ash "H", and indicates that the rate of ammonia loss from the ash bed was similar to that from the overlying solution at the lower temperature.

The ammonia release from fly ash "B" at 23-24EC was similar to that observed for samples "H" and "S", although "B" exhibited an initially lower pH of 9.9 (Figure 17). Correspondingly, the fraction of $\mathrm{NH}_{4}^{+}$ion was higher for this fly ash. Early in the experiment the $\mathrm{N}_{4}^{\mathrm{H} H}$ measurements fluctuated, which was probably caused by ions being expelled into the supernatant from the fly ash, as well as suspended solids that eventually settled. The $\mathrm{NH}_{3}$ electrode is much less sensitive to these effects, thus the $\mathrm{NH}_{3}$ concentration decreased in a more continuous manner (Figure 17). The relatively low $\mathrm{pH}$, compared with "H" and "S", resulted in a slower rate of un-ionized $\mathrm{NH}_{3}$ decrease in solution with time. $\mathrm{NH}_{4}^{+}$ion became the dominant species within 10 hours of the start of the experiment and then decreased in concentration at a similar rate as un-ionized $\mathrm{NH}_{3}$ as the total ammonia $\mathrm{N}$ was depleted by $\mathrm{NH}_{3}$ 
out-gassing. After 13 days, the total ammonia $\mathrm{N}$ concentration was $2 \mathrm{mg} / \mathrm{L}$ in the supernatant and $3 \mathrm{mg} / \mathrm{L}$ within the ash pore water, which indicates that the majority of ammonia had migrated from the ash bed into the overlying solution. Depletion of the remaining ammonia after 13 days would occur at a slow rate due to the comparatively low solution $\mathrm{pH}$ that decreased asymptotically to approximately 8.4 , which is near the $\mathrm{pH}$ of calcium carbonate in equilibrium with atmospheric $\mathrm{CO}_{2}$.

As was observed with the previous samples ("H" and "S") lowering the temperature to 2-3EC substantially lowered the rate of ammonia loss from the fly ash "B"/water mixture (Figure 18). Although the concentration of un-ionized $\mathrm{NH}_{3}$ in solution steadily decreased over the course of the 11 day, $\mathrm{NH}_{4}{ }^{+}$concentration increased during the first 3-4 days whereupon it remained ostensibly constant (although there were substantial fluctuations; Figure 18). The fractions of $\mathrm{NH}_{3}$ and $\mathrm{NH}_{4}{ }^{+}$became equal at a $\mathrm{pH}$ of -10.5 , which is about $0.5 \mathrm{pH}$ units higher than predicted at this temperature. Again, this is probably caused by $\mathrm{Na}^{+}$and $\mathrm{K}^{+}$interfering with the accuracy of the ammonium-specific electrode. Similar to fly ash "H", the final concentration of ammonia $\mathrm{N}$ in the supernatant was higher $(25 \mathrm{mg} / \mathrm{L})$ than that within the ash $(16 \mathrm{mg} / \mathrm{L})$.

The ammonia release profiles at 23-24EC for ash "L", an air heater sample, are provided in Figure 19. This ash produced an initial $\mathrm{pH}$ of 12.0 that decreased asymptotically to 8.4 after 13 days. The concentration of un-ionized $\mathrm{NH}_{3}$ decreased exponentially from $23 \mathrm{mg} / \mathrm{L}$ to $<0.5$ $\mathrm{mg} / \mathrm{L}$ over the course of the experiment, whilst the $\mathrm{NH}_{4}{ }^{+}$ion progressively increased to an (apparently) constant concentration of $8-9 \mathrm{mg} / \mathrm{L}$ (Figure 19) which is, as predicted, much higher than the final un-ionized $\mathrm{NH}_{3}$ concentration. At the conclusion of the experiment, the ammonia $\mathrm{N}$ concentration of the supernatant was $3 \mathrm{mg} / \mathrm{L}$, whereas within the ash interstitial solution there remained a concentration of $12 \mathrm{mg} / \mathrm{L}$.

In contrast to ash "H", "B", "S", and "L", fly ash "O" produced an initially very low solution $\mathrm{pH}$ of 3.8 that increased to a maximum of approximately 4.2 over the course of the experiment (Figure 20). Unlike the previous two samples, the $\mathrm{NH}_{4}{ }^{+}$ion was clearly more abundant than the $\mathrm{NH}_{3}$ species, and exhibited a constant concentration during the 20 day experiment. This indicated that, even under open conditions, most if not all of the $\mathrm{NH}_{4}{ }^{+}$ion remained in solution and is not transformed (i.e., to nitrate/nitrite) or out-gassed. Nearly identical results were obtained with the non-ammoniated fly ash "C2", described above, that was slurried with distilled water containing - 70 ppm NH $\mathrm{N}_{3}\left(\right.$ as $\left(\mathrm{NH}_{4}\right)_{2} \mathrm{SO}_{4}$; Figure 21).

\section{Thermal Analysis}

Mass Spectra of Ammonia Salts. In order to acquire a small database on the decomposition temperatures of pure ammonia salts, several salts were tested by TG-MS. In all cases ammonia evolution was detected and identified by the ratio of the intensity of amu 17 to 18 , the major mass ions for ammonia and water respectively. Since amu 17 is a minor mass ion detected in the spectra of water, it was necessary to use the ratio of amu 17/18 to identify ammonia in the spectra. An example of the mass spectra acquired during decomposition of the ammonia salts is shown in Figure 22 which gives the TG-MS results for $\left(\mathrm{NH}_{4}\right)_{2} \mathrm{SO}_{3}{ }^{*} \mathrm{H}_{2} \mathrm{O}$ decomposition in $\mathrm{He}$. The onset temperature for ammonia evolution was $120 \mathrm{EC}$ which was preceded by the evolution of water which was clearly indicated by the sharp 
increase in amu 17/18 ratio. Amu 64 which is the major mass ion for $\mathrm{SO}_{2}$, a likely decomposition product of $\mathrm{SO}_{3}$ was detected associated with the ammonia evolution.

Table 4 provides the decomposition onset temperature for ammonia release from all salts studied in both inert and oxidizing atmospheres. Several salts were run in triplicate with the agreement in the onset temperatures within $\pm 5 \mathrm{EC}$. Ammonia evolution from the carbonates and sulfite began at low temperatures, only very slightly above $100 \mathrm{EC}$; whereas ammonia release from chloride and the sulfates was detected at much higher temperatures above $214 \mathrm{EC}$ for ammonium bisulfate and as high as $356 \mathrm{EC}$ for ammonium sulfate. There was an increase in the decomposition onset temperature of 6 to 57EC between inert and oxidizing gas flow conditions; otherwise, the mass loss and mass spectra were similar. In all cases, ammonia release was associated with the detection by MS of the corresponding anions. However, the spectra for ammonium chloride and the sulfates showed a post-weight loss release of mass ions associated with the salt. Figure 23 shows this post-weight loss mass ion detection for the decomposition of ammonium sulfate in He. These trailing mass ions were most likely associated with the re-condensation of the salts in the capillary transfer line from the thermal analyzer to the mass spectrometer since the maximum temperature at which the transfer line is capable of running is $200 \mathrm{EC}$ and these salts decompose above that temperature.

Mixtures of three of the salts with fly ash "MT" were studied in order to determine the influence of ash on decomposition of the salt and also to explore the possibility of using the mixtures to calibrate the mass spectra to quantify the amount of ammonia released. The three salts used in these mixtures were $\left(\mathrm{NH}_{4}\right)_{2} \mathrm{SO}_{4}, \mathrm{NH}_{4} \mathrm{Cl}$, and $\mathrm{NH}_{4} \mathrm{HCO}_{3}$ As previously mentioned during the decomposition of the pure ammonium sulfate and chloride, post weight loss mass ions were evident in their spectra. In the presence of ash, this was not as apparent possibly due to weight loss associated with other components of the ash. However, in all cases in the presence of ash high temperature ammonia was detected. Figure 24 shows the TG-MS results for 1 percent ammonium sulfate heated in He. These results, compared with the results for the decomposition of the pure salt (Figure 23), show an ammonia release corresponding to the ammonia released by the pure salt and an additional elevation of the amu 17/18 ratio which increased from $400 \mathrm{EC}$ to the end of the analysis. Similar results were observed for the 1 percent ammonium chloride - ash mixture. More work is needed to determine if this high temperature ammonia is the result of interactions with the ash or refluxing in the capillary transfer line. However, as will be shown later not all ashes exhibited high temperature ammonia release which tends to support the existence of ammonia salt - ash interactions and not refluxing which would be independent of the ash analyzed.

Due to the complication with post weight loss mass ion detection with ammonium sulfates and chloride, the carbonates or sulfite appeared to be better candidates for making calibration standards for quantifying the ammonia spectra. Six concentrations of ammonium bicarbonate from 0.125 to 4 percent were tested and yielded good mass spectra indicating ammonia and carbon dioxide as the major mass ions released corresponding to the weight loss associated with the decomposition of the ammonium bicarbonate. However, weight loss by the mixtures were consistently less than the theoretical weight loss consistent with the concentration of the salt in the ash (Figure 25). Since the weight loss for the sulfates and the chlorides were 
always in very good agreement with the theoretical weight losses expected, it is believed that the lower than theoretical weight losses are a function of the low temperature of decomposition of the carbonates and the loss of ammonia from the mixtures during blending and storage. This would make the low temperature salt unsuitable for use to calibrate $\mathrm{ms}$ spectra.

TG-MS Analysis of Ammoniated Ash. For the eight ash samples analyzed by TG-MS, mass ions which were found to be release with ammonia or in proximity to ammonia release were those associated with sulfates or sulfites and carbon. Mass 48 and 64, the major masses ions for $\mathrm{SO}_{2}$, always responded in an identical manner and were the major ions associated with ammonium sulfate and sulfite decomposition. Identically, 28 and 44, the major masses for $\mathrm{CO} / \mathrm{CO}_{2}$ always produced the same spectral profile. Therefore, only amu 44 and 64 were plotted on the graphs of the data. Amu 30 was used to represent $\mathrm{NO}_{\mathrm{x}}$ since it is the major mass ion in the spectra for both $\mathrm{NO}$ and $\mathrm{NO}_{2}$. An increase above baseline in the intensity ratio of amu 17/18 was considered ammonia release. Amu 64 release concurrent with ammonia release was also usually accompanied by post ammonia release amu 64 detection by the MS. The ammonia evolution onset temperatures are summarized in Table 5.

Ammonia release was detected in seven of the eight study ash samples. "MT" had no detectable ammonia evolution and a constant amu 17/18 ratio (Figure 26 and 27). The other seven samples could be divided into three groups based on their ammonia evolution temperatures and the profiles of their TG-MS analyses in He. Three ashes, "H", "O", and "W" released both low (below 400EC) temperature and high (above 500EC) temperature ammonia (Figures 28, 29, and 30). The onset temperatures for release of the low temperature ammonia from the three ashes were 187, 268, and 242EC while evolution of the high temperature ammonia began at 706, 628, and 518EC for the " $\mathrm{H}$ ", "O", and "W" ashes respectively. All three samples had high temperature amu $44\left(\mathrm{CO}_{2}\right)$ release simultaneous with ammonia release. " $\mathrm{H}$ " and "O" had both amu 44 and 64 released during the low temperature ammonia evolution but no anion associated mass ions were found for fly ash "W". These three ashes behaved quite differently when heated in an oxidizing atmosphere (Figures 31, 32, and 33). For two ashes, "O" and "W", $\mathrm{NO}_{x}$ evolution replaced some of the ammonia evolution. All of the ammonia released for the "O" ash appeared to be converted to $\mathrm{NO}_{x}(\mathrm{amu} 30$ ) since no ammonia was detected and $\mathrm{NO}_{x}$ was released over the same temperature range (Figure 32). There was release of amu $44\left(\mathrm{CO}_{2}\right)$ simultaneous with amu $30\left(\mathrm{NO}_{\mathrm{x}}\right)$ evolution. The low temperature ammonia released from the "W" ash appeared to be converted to $\mathrm{NO}_{\mathrm{x}}$ and there also appeared to be conversion of some of the high temperature ammonia to $\mathrm{NO}_{x}$ since there was a terminal amu 30 release detected slightly after the evolution of most of the high temperature ammonia (Figure 33). However, the high temperature ammonia evolution associated with $\mathrm{CO}_{2}$ release was still detected. The "H" ash continued to have a low temperature ammonia release associated with amu 64 detection similar to the TG-MS analysis in $\mathrm{He}$. There was a large terminal release of amu 44 but no high temperature ammonia evolution and no apparent conversion of ammonia to $\mathrm{NO}_{\mathrm{x}}$ (Figure 31 ).

Two ashes, "L" and "P1", had only low temperature ammonia releases when subjected to TGMS in a He atmosphere (Figures 34 and 35). The onset of these releases were 387 and 
347EC, respectively. Both had amu $64\left(\mathrm{SO}_{2}\right)$ evolution during and after the ammonia release and both had $\mathrm{CO}_{2}$ (amu 44) released with maximum evolution shortly after the maximum ammonia release. When analyzed in helium, "L" showed two $\mathrm{NO}_{x}$ releases with onsets at 447 and $746 \mathrm{EC}$ which occurred simultaneous with $\mathrm{SO}_{2}$ release. These two ashes as with the previously discussed ash samples behaved differently when analyzed in an oxidizing atmosphere (Figure 36 and 37). No ammonia appeared to be released from the "L" sample (Figure 36) and the two amu $30\left(\mathrm{NO}_{\mathrm{x}}\right)$ peaks observed in Figure 34 for the He atmosphere analysis were enhanced and merged into one larger peak suggesting some conversion of ammonia to $\mathrm{NO}_{x}$. The onset temperature for this broad peak was the same as the onset temperature of the first $\mathrm{NO}_{x}$ peak for the analysis in He. The TG-MS of the "P1" ash in 10 percent $\mathrm{O}_{2}$ in He showed two amu 30 ( $\mathrm{NO}$ \& peaks with no ammonia release at $347 \mathrm{EC}$ and the appearance of a corresponding amu 30 peak at the same temperature (Figure 37). There was an ammonia release with onset at 566EC which had concurrent $\mathrm{MS}$ detection of $\mathrm{CO}_{2}, \mathrm{SO}_{2}$ and $\mathrm{NO}_{\mathrm{x}}$ evolution.

The remaining two ashes, "S" and "B", released ammonia only at high temperatures when heated in He (Figures 38 and 39). Onset temperatures were 626 and 578EC, respectively. In both cases, ammonia evolution appeared to be associated with both amu 44 and 64 . However, in both cases ammonia evolution was preceded by amu 64 release and both had terminal amu 44 detection. Both of these ashes appeared to have conversion of all or some of the ammonia to $\mathrm{NO}_{x}$, amu 30, when analyzed in an oxidizing atmosphere (Figures 40 and 41). Onset of the amu 30 evolution coincided with the onset of ammonia release in the $\mathrm{He}$ analyses. In both cases, amu 30 release occurred during amu 44 releases and slightly after amu 64 evolution. 


\section{HEALTH AND ENVIRONMENTAL IMPACTS OF AMMONIA}

A review the potential health and environmental impacts of ammonia is an important consideration of the impacts of the SCR process. There are several major potential impacts from ammonia to be considered. These include:

- Airborne (inhalation) exposure to workers from ammonia off-gassing from ammoniated ash during ash handling operations.

- Direct skin contact from handling ammoniated ash.

- Airborne (inhalation) exposure to workers from liquified anhydrous ammonia used in the SCR process equipment during loading/unloading of ammonia in storage containers, leakage from valves and process piping.

- Public and worker airborne (inhalation) exposure and direct contact from liquified anhydrous ammonia resulting from an accidental release of large quantities from storage or processing operations.

Ammonia is widely used in industrial processes in large quantities. The specific hazard of exposure to ammonia is dependant on the form of ammonia being used and its state. Ammonia may be handled and used as a compressed or liquified gas as anhydrous ammonia, aqueous solutions of 28 percent ammonia, commonly called aqua-ammonia or ammonium hydroxide, or as a 10 percent solution, commonly known as household or cleaning ammonia.

Because it is a readily available form of reduced nitrogen it is widely used as a fertilizer in the form of anhydrous ammonia or ammonium hydroxide or as a source of nitrogen in dry fertilizers. It has a boiling point of -33EC (-27EF) and is easily liquified, which makes it useful in large industrial refrigeration systems, and is a volatile alkali, making it useful for cleaning.

Ammonia presents a potential hazard to humans from exposure through inhalation, direct contact to skin and mucous membranes and through ingestion. It is a severe irritant of the eyes, respiratory tract and skin. It may cause burning and tearing of eyes, runny nose, coughing, chest pains, and in cases of significant overexposure, may result in death. Inhalation of ammonia may cause severe breathing difficulties which may be delayed in onset. Ammonia is a corrosive chemical and can cause irritation and severe burns to the skin and 
eyes, and may cause permanent damage (NIOSH 1974). Exposure to concentrations of 2,500 to $6,500 \mathrm{ppm}$, as might be expected from accidents involving liquid anhydrous ammonia, causes corneal irritation, shortness of breath, bronchial spasm, chest pain and pulmonary edema, which may be fatal. Case studies have reported chronic airways hyperactivity and asthma, with associated obstructive pulmonary function changes following massive ammonia exposure. (Hathaway, et al.). Direct contact with liquid anhydrous ammonia on skin may cause severe first and second degree burns that may be fatal if extensive. Contact with the eyes may cause serious corneal injury and blindness.

OSHA has established a Permissible Exposure Limit (PEL) for worker exposure for ammonia of $50 \mathrm{ppm}$ as an eight-hour time-weighted average (TWA) to prevent eye, nose and throat irritation. NIOSH has established a Recommended Exposure Limit (REL) of 25 ppm as a TWA and 35 ppm as a Short-Term Exposure Limit (STEL) not to be exceeded during any 15 minute work period. The American Conference of Governmental Industrial Hygienists (ACGIH) has developed an occupational exposure standard for ammonia, known as a Threshold Limit Value (TLV) of 25 ppm as a TWA and 35 ppm as an STEL.

An important property of ammonia is its pungent and distinctive odor. Odor threshold varies with each individual and has been reported to range between 1 and $50 \mathrm{ppm}$ (NIOSH 1975). Concentrations of about $100 \mathrm{ppm}$ are reported to be uncomfortable to most individuals; concentrations in the range of 300 to $500 \mathrm{ppm}$ will cause people to voluntarily evacuate the area immediately (OSHA), with a concentration of $300 \mathrm{ppm}$ considered by NIOSH to be Immediately Dangerous to Life and Health (IDLH).

Although ammonia is lighter than air, when liquified ammonia is accidentally released in a catastrophic type accident, it may aerosolize and behave as a dense gas. In this situation it may travel along the ground and into basements and depressions in the terrain. This condition presents a very serious hazards to workers and the surrounding public.

The lower limit of flammability of ammonia is 16 percent, with the upper limit being 25 percent. This means that ammonia vapors in air at concentrations between 16 and 25 percent are considered to be a fire and explosion hazard.

Because ammonia is widely used in large quantities and presents a significant potential acute health hazard, it is classified as an Extremely Hazardous Substance (EHS) by the USEPA and OSHA and is subject to federal statutes and regulations regarding process safety, accident prevention, emergency planning and release reporting. A summary of these requirements follows (EPA 1998):

\section{Environmental Protection Agency}

\section{Clean Air Act (CAA)}

- Risk Management Program (RMP) Rule (40 CFR Part 68) - Facilities that have anhydrous ammonia in quantities greater than 10,000 pounds are required to develop a hazard assessment, a prevention program, and an emergency response program. 


\section{Emergency Planning and Community Right-to-Know (EPCRA)}

- Emergency Planning (40 CFR Part 355) - Facilities that have ammonia at or above 500 pounds must report to their Local Emergency Planning Committee (LEPC) and State Emergency Response Committee (SERC) and comply with requirements for emergency planning.

- Emergency Release Notification (40 CFR Part 355) - Facilities that release 100 pounds or more of ammonia must immediately report the release to the LEPC and SERC.

- Hazardous Chemical Reporting (40 CFR Part 370) - Facilities that have ammonia at or above 500 pounds must submit an Material Safety Data Sheet (MSDS) to their LEPC, SERC, and local fire department and comply with the Tier I/Tier II inventory reporting requirements.

- Toxic Chemical Release Inventory (TRI) (40 CFR Part 372) - Facilities that manufacture, process or otherwise use ammonia above the applicable threshold (25,000 or 10,000 pounds) must file annually a TRI form with the USEPA and state.

Comprehensive Environmental Response, Compensation and Liability Act (CERCLA)

- Hazardous Substance Release Reporting (40 CFR Part 302) - Facilities must report any environmental release of ammonia in excess of 100 pounds to the National Response Center (NRC). A release report may result in a response by the USEPA or another agency with emergency response authority.

\section{Occupational Safety and Health Administration}

- Process Safety Management (PSM) Standard (29 CFR 1010) - Anhydrous ammonia is listed as a highly hazardous substance. Facilities having ammonia in quantities at or above the threshold quantity of 10,000 pounds are subject to the requirements of this standard, which includes performing a process hazard analysis and maintaining the mechanical integrity of equipment. 


\section{PROCESS IMPLICATIONS, EQUIPMENT EFFECTS, AMBIENT AIR IMPACTS}

The process implications of retrofitting SCR technology to existing coal-fired power plants were investigated through a comprehensive search of current literature and internet sites, and through extensive interviews with SCR vendors, catalyst vendors, and plant operators. In general, the consensus is that the Japanese and German operating experiences are transferable to U.S. operations, with the limitation that the characteristics of coals burned at U.S. power plants can differ from the characteristics of coals burned in Japan and Europe in ways that can have significant impacts. Specific differences include arsenic content, calcium content (both high and low) and sulfur content. These differences exist not only between U.S. and international coals but also between U.S. coals (e.g. eastern vs. western). Another variable that can be significant when comparing U.S. and international operation is the level of $\mathrm{NO}_{x}$ reduction required.

The investigation focused on air preheaters, SCR catalysts, CEMS, ammonia storage systems, particulate and acid gas control systems, ash handling systems and the beneficial use of ash. The potential impact of SCR on ambient air quality and the potential for odors from ammonia and ammonia compounds were also evaluated.

It has been reported that retrofit cost, modifications and degree of difficulty can be very site specific. A general concern voiced by suppliers and operators is that resources will be very strained to meet current deadlines.

\section{Air Preheater}

Some of the early SCR installations experienced significant air preheater plugging and corrosion resulting from the formation and deposition of ammonium bisulfate. The plugging and corrosion caused reduced boiler efficiency, higher flue gas pressure drop, more frequent air preheater cleaning and washing, increased boiler downtime, and increased maintenance cost. Ammonium bisulfate is formed from ammonia, $\mathrm{SO}_{3}$ and water vapor. The primary factors controlling the formation and deposition of ammonium bisulfate are the level of ammonia, the level of $\mathrm{SO}_{3}$, the air preheater surface temperature profile, the air preheater surface material, and the air preheater physical configuration.

Higher levels of ammonia and $\mathrm{SO}_{3}$ result in higher levels of ammonium bisulfate deposition. Unreacted ammonia in the flue gas after the SCR system is referred to as the "ammonia slip." The $\mathrm{SO}_{3}$ level is a function of fuel sulfur content but is increased by oxidation of $\mathrm{SO}_{2}$ in the 
catalyst bed. The temperature window for ammonium bisulfate deposition is as wide as $300 \mathrm{EF}$ to $425 \mathrm{EF}$. The temperature window for sulfuric acid formation; which is primarily a function of $\mathrm{SO}_{3}$ level, is lower but must also be evaluated. Bare metal air preheater surfaces are subject to oxidation and corrosion that further increase deposition. Air preheater physical configuration is also an important factor and is addressed in several recent papers (Bondurant, 2000; Cooper, et al., 1999; and Becker, et al., 2000).

Minimizing ammonia slip controls the ammonia level in the SCR discharge. The oxidation of $\mathrm{SO}_{2}$ to $\mathrm{SO}_{3}$ in the catalyst bed is primarily controlled by catalyst design. The temperature window favorable for ammonium bisulfate deposition will occur at some point in the air preheater and the areas of the air preheater subject to this temperature window must be identified. Enamel surfaces have been found to resist deposition and corrosion. Based on an evaluation of the ammonium bisulfate and sulfuric acid potential condensation areas, the air preheater may require physical reconfiguration. This physical reconfiguration should be integrated with an evaluation of the sootblowing and water washing systems. Some facilities have increased steam preheating prior to the air preheater to raise the inlet air temperature and control the temperature profiles. Note that any boiler flue gas exit temperature change resulting from design or operational modifications will impact boiler efficiency and plant heat rate.

Another potential air preheater problem resulting from the addition of SCR is an increase in the air to gas pressure differential and resulting air to flue gas leakage. This problem is caused by a decrease in gas pressure due to the additional gas pressure drop across the SCR system. This issue is addressed in Bondurant, 2000. Fan capability must also be evaluated in the design phase because of the additional pressure drop caused by the reactor and because of the increased fouling potential in the air preheater. In the past, the increased air heater pressure drop resulting from deposition has been used as an indicator of increased ammonia slip.

Industry experience indicates that the most severe air preheater problems have resulted from elevated ammonia slip caused by factors such as catalyst deactivation (e.g. from arsenic poisoning) and design flaws (e.g. from leaking bypass dampers). Ammonia overfeed is also a potential concern. As discussed in the Continuous Emission Monitoring System section, ammonia feed control is complicated by the lack of reliable real time ammonia analyzers and by the difficulty in measuring SCR inlet NOx concentration in a "dirty" gas environment.

The general consensus among suppliers is that air preheater issues are now well understood and can be effectively dealt with to mitigate or eliminate operational impacts. Air preheater modification is evaluated in the SCR design phase and limitation of ammonia slip is required in the operational phase. The general recommendation is that ammonia slip be limited to not more than $2 \mathrm{ppm}$ at end of catalyst cycle. However, some industry experts advocate even lower values (Becker, et al. 2000). 


\section{Catalyst}

Catalyst deactivation has been an area of extensive research and operational (Gutberlet, et al., 2000; Gutberlet, et al., 1999; Elliot, et al.; and Sanyal, 2000). Catalyst deactivation results primarily from catalyst poisoning and the physical blockage of catalyst pores and surface. Deactivation can result from arsenic poisoning, ammonia salt deposition, alkaline metal poisoning, calcium sulfate masking, and fly ash plugging. Catalyst is supplied in both plate and honeycomb configuration.

Arsenic in the fuel results in the formation of gaseous $\mathrm{As}_{2} \mathrm{O}_{3}$, which can diffuse into the catalyst and act as a poison. The potential for arsenic poisoning is a function of several variables including arsenic in the fuel, furnace type and fly ash recirculation rate, and fly ash $\mathrm{CaO}$ content. The presence of $\mathrm{CaO}$ can mitigate the potential for arsenic poisoning through reaction with $\mathrm{As}_{2} \mathrm{O}_{3}$. Several facilities have evaluated the addition of limestone to minimize the gaseous arsenic compounds available to cause catalyst deactivation. Greater than 10 ppm arsenic has been reported as a trigger point for evaluation. It has been reported that the Seward, Pennsylvania facility is adding limestone, the Stanton, Florida facility is considering limestone addition and the recently constructed Montour, Pennsylvania facility has the capability for limestone addition. These examples highlight the potential impacts of coal variation between the U.S. and Europe. European coal generally has higher calcium content than eastern U.S. coal providing some inherent capability to mitigate arsenic impacts. It has been reported that increased fouling potential can result from limestone addition. The issue of the accuracy of arsenic measurements has been raised in the context of differences between U.S. and German measurement procedures.

As with the air preheater, deposition and plugging can result from the formation of ammonium bisulfate. The primary mechanism to avoid this problem in the catalyst bed is to maintain temperatures above the window for ammonium bisulfate formation. This is normally an issue only at part load operation, and an economizer bypass is the typical approach used to maintain adequate part load catalyst bed temperatures. Ammonia injection can be halted if necessary. A reactor bypass may also be installed (as reported for Birchwood) to completely protect the catalyst from adverse flue gas conditions. Note that any boiler flue gas exit temperature change resulting from design or operational modifications will impact boiler efficiency and plant heat rate.

Sodium and potassium can directly react with active catalyst material. Calcium can react with $\mathrm{SO}_{3}$ to form calcium sulfate that can mask the catalyst. Calcium sulfate masking potential has become a major issue with Powder River Basin (PRB) coal due to the concentration and form of calcium that it contains for certain manufacturers. It has been reported that some catalyst suppliers have become very cautious about making performance guarantees with PRB coal. Others actually prefer the PRB coal due to its more constant composition. Experience with PRB coal is being gained at the New Madrid facility.

Fly ash plugging generally results from excessive fly ash carryover to the catalyst or poor catalyst gas flow design. Gas, ash, and ammonia flow distribution modeling is critical in the 
design phase. Lessons learned have been incorporated into this process resulting in improved ammonia injection system and catalyst design and performance.

It has been reported that some European plants operating with high LOI materials have shown a potential for fire as the unit is brought down from normal operation. This potential arises from the presence of smoldering carbon coupled with increasing oxygen level. Vacuuming ash from the catalyst bed has been reported as an operating procedure used to mitigate this hazard.

One general solution to catalyst concerns is to add more catalyst in the initial design. In addition, all coal fired SCR reactors have spare catalyst volume with the capability to add 1 or 2 catalyst layers. The optimal design is determined through an evaluation of projected catalyst performance and projected capital and operating costs. Typical performance guarantees include ammonia slip less than $2 \mathrm{ppm}$ at end of catalyst cycle, minimum catalyst life in hours (some facilities use seasonal rather than year round operation) and a limit on $\mathrm{SO}_{2}$ to $\mathrm{SO}_{3}$ conversion percentage. Ammonia slip should initially be very low and will approach the $2 \mathrm{ppm}$ value over time. When catalyst is added or replaced the ammonia slip should show a step change reduction. Spare catalyst is typically added before catalyst is replaced. The catalyst management plan is significant because of the cost of catalyst. Interest is growing in the potential for in place, on site and off site catalyst reactivation techniques. Suppliers will typically design in the capability to remove catalyst test sections over time to develop the catalyst deactivation curve.

It appears that different catalysts have different capabilities with different coal specifications or that catalyst vendors are willing to take different levels of risk when making performance guarantees. It is reported that the bids from leading catalyst suppliers are normally very competitive. Catalyst suppliers have entered into various contractual arrangements; sometimes with the SCR supplier and sometimes directly with the end user. Comprehensive fuel specifications are important and the potential for future fuel switching should be considered. It appears that there are still lessons to be learned with regard to catalyst performance and deactivation as functions of coal feedstock and boiler design, with optimized up front catalyst design and subsequent catalyst management and with catalyst reactivation.

\section{Continuous Emission Monitoring System}

It is reported that operators of European SCR installations monitor oxides of nitrogen $\left(\mathrm{NO}_{x}\right)$ in and out of the SCR systems and use a control scheme based upon real time monitoring of SCR NO removal performance. However, the operators at several U.S. installations have had significant difficulty in maintaining CEMS at the operating conditions before the SCR (hot, dirty, etc). These installations generally maintain their ammonia injection levels based upon stack $\mathrm{NO}_{x}$ measurements with a site specific time delay factor incorporated into the process

control. Some difficulties have been reported with stack measurements including accounting for oxygen infiltration and the need to change metallurgy to molybdenum. The need for frequent calibration of the stack $\mathrm{NO}_{x}$ measurement has also been reported. 
There appears to be a growing consensus that reliable inlet $\mathrm{NO}_{x}$ measurement must be implemented to optimize control. The reasons cited for failure to achieve this include emphasis on low cost and lack of emphasis on proven technical capability. One facility reported some success with a dual monitor arrangement with monitors alternating operation and cleaning. The determination of the appropriate monitoring point(s) is not a trivial task because of flow and concentration gradients. One approach is to provide multiple ports to gather test data and to select the port(s) for permanent measurement based on the evaluation of the test data.

Continuous real time measurement of ammonia slip is desirable because of the importance of knowing and minimizing ammonia slip but is very difficult because of the dirty gas environment, the low concentration of ammonia, the potential for ammonia reaction with other compounds, and the potential for measurement interference. Realtime measurement of ammonia slip has been attempted at several facilities and a comprehensive test program of available ammonia analyzers has been conducted at the Stanton, Florida facility with EPRI involvement. The results have generally been disappointing with the exception of one or two analyzers tested at Stanton. It is reported that Stanton has developed confidence in at least one analyzer and intends to permanently install a continuous ammonia analyzer in 2000.

Grab samples can be taken periodically and analyzed for ammonia by wet chemistry methods. These measurements can be taken coincident with ammonia on ash measurements and an empirical relationship can be established between ammonia slip and ammonia on ash. This approach has been used in European and U.S. plants to estimate ammonia slip based on ammonia on ash. The exact numerical correlation is treated as site specific and is a function of temperature, contact time and various ash characteristics (e.g. higher carbon content generally results in greater ammonia adsorption). Regular ammonia on ash measurements can at a minimum provide valuable trend information. An order of magnitude estimate is that $2 \mathrm{ppm}$ ammonia slip will result in $100 \mathrm{ppm}$ ammonia on ash.

\section{Ammonia}

One of the most significant impacts on the facility is the addition of anhydrous or aqueous ammonia storage and handling systems. Anhydrous ammonia and aqueous ammonia above 20 percent are considered dangerous to human health. Given the size of some U.S. operations, over 250,000 pounds of ammonia may be stored in a single vessel. Accidental release of anhydrous ammonia is reportable to local, state and federal agencies. The site must develop, implement and maintain a RMP and PSM program. New operation and maintenance procedures must be developed. The facility employees must be properly trained and must become comfortable with the system. Employee concerns have been reported (at least initially). Risk communication to the general public typically includes a worst case analysis with potential impacts possible at up to a mile from the facility. The timing of these activities must support the overall project schedule and completion deadline. The selection of anhydrous or aqueous ammonia is based upon site-specific conditions, including; cost, system design and material handling issues. Because of the issues discussed above, the potential for urea to ammonia on-site generation is under significant evaluation with several pilot test and full-scale installations underway including Canal Station in Massachusetts. 
The anhydrous system is typically the lowest cost approach but may be precluded because of the issues discussed above. Generally the further the facility is located from populated or sensitive areas (e.g. schools) the greater the possibility that anhydrous will be acceptable. Aqueous systems are more often being contemplated at 19 percent ammonia rather than 29 percent ammonia because of reduced danger. The potential suppliers of on site ammonia generation systems claim to be economically competitive with aqueous systems. One SCR supplier expressed concern regarding the feasibility of on site generation for large plants.

Some suppliers and operators have reported problems with ammonia systems that appear to be the result of isolated poor equipment specification, selection or application rather than generic in nature. Malfunctions have been reported with pumps, seals, valves and level control instrumentation. Some malfunctions appear to be related to fluid phase. The consensus appears to be that the deficiencies are not in available technology but are in specific selections.

\section{Particulate and Acid Gas Control Systems}

With the exception of the Merrimack facility, the impact of SCR on ESP performance has generally been characterized as minimal and not an issue. Merrimack has added precipitators, but this is believed to be the result of undersized original precipitators. ESP resistivity has improved for several sites, with additional ash conditioning being unnecessary. Baghouse operation has also been minimally impacted, with the exception of facilities with the operating conditions to form ammonium bisulfate salt $\left(\mathrm{SO}_{3}\right.$, ammonia slip and temperature) resulting in the potential for significant bag plugging problems. Most facilities do not currently indicate odor issues associated with the FGD operations, although this may be a concern if the $\mathrm{pH}$ of the solution rises above approximately 9 and the ammonia slip levels are elevated. It was reported that a facility that used sodium bicarbonate for $\mathrm{SO}_{2}$ control experienced major ammonia odor problems when $\mathrm{pH}$ became elevated.

\section{Ash Handling and Beneficial Use}

No operating facility or vendor contacted identified any reported changes to the existing ash handling system after the addition of SCR. Several facilities evaluated the potential for dissolved ammonia to impact surface and ground water and possibly switching from a wet based ash-handling system to a dry one. Sites have generally opted to maintain unit operations in their current configuration.

Sites currently selling ash appear to have not experienced a significant impact on ash quality or beneficial use potential. However, ash buyers have expressed at least generic concerns about the presence of ammonia on ash. The issues appear to be perception and odor rather than actual quality impacts (e.g. when used for concrete). The level of concern may be regional in nature (e.g. less concern in a non-freezing climate) and may vary between commercial/industrial and residential use. Again, the key is to minimize ammonia slip. Elevated $\mathrm{pH}$ will definitely cause ammonia release to the air and resulting odor. One facility reported mixing ash with water and checking for ammonia release with a hand held monitor 
prior to sale. As discussed above, European operating experience has correlated ammonia on ash to slip levels after the SCR. These data are now being generated for U.S. locations and appear to be highly site specific and variable between sites. It is usually important for European facilities to maintain the salability of ash because of the high cost of landfilling and it appears that they have been able to do so.

\section{Ambient Air Impacts}

Air quality dispersion modeling of ammonia release from point (stack) and area (ponds, piles, impoundments, or landfills) sources was performed to evaluate the potential for SCR installations to have an adverse impact on ambient air quality. In addition, the potential ambient air impacts from the accidental release of ammonia from the storage and handling system were evaluated.

\section{Point and Area Sources}

To develop a more generalized evaluation of the point and area potential sources, the ISCST3 model was run using some generalized parameters. The generalized parameters include:

\section{Point Source}

$\begin{array}{lr}\text { Ambient Temperature }(\mathrm{K}) & 293 \\ \text { Stack Height }(\mathrm{m}) & 60 \\ \text { Stack Diameter }(\mathrm{m}) & 4 \\ \text { Exit Velocity }(\mathrm{m} / \mathrm{s}) & 10 \\ \text { Exit Temperature }(\mathrm{K}) & 400\end{array}$

\section{Area Source \\ Easterly Length $(m)$ Northerly Length $(m)$ \\ Release Height (m) \\ 50 \\ 3}

293

60

10

400

A non-site-specific screening meteorological database was prepared using the metisc.exe program developed by the Oregon Department of Environmental Quality, Air Quality program. This software develops worst case meteorology for use by ISCST3. A one-degree separation was assumed to develop a database of meteorological data. This database ensures the receptors modeled are directly downwind from the source and yields the highest potential impact. A fine and course receptor grid were specified to evaluate receptors at a 50-meter (m) spacing up to 5 kilometers $(\mathrm{km})$ and a $500-\mathrm{m}$ spacing up to $20 \mathrm{~km}$.

The review focused on the maximum predicted ground level ammonia concentration using flat rural terrain features. A ratio was developed to determine what source strength would be 
required to yield a $1 \mathrm{ppm}$ impact in the ambient air. The $1 \mathrm{ppm}$ value was specified to correspond to the concentration of ammonia in ambient air that would generally be perceived as an odor.

For the point source model (stack), the ammonia emission rate would need to exceed 2,700 pounds per hour (lb/hr) to yield a maximum ground level impact of $1 \mathrm{ppm}$. This mass emission rate corresponds to an ammonia slip of over $3,800 \mathrm{ppm}$ for the input stack parameters. Based upon projected design ammonia slip levels of 0-4 ppm, the maximum ground level impact from several site specific point sources modeled was predicted to be $0-4$ parts per billion (ppb).

Additional point source modeling runs were completed to evaluate the potential impact of nearby buildings on plume downwash and terrain features. These runs yielded similar results indicating minimal potential impacts for moderately downwashed plumes. Site specific modeling may be warranted if local conditions would result in a severely downwashed plume.

For the area source model (pond or landfill), the ammonia emission rate would need to be 1.5 $\mathrm{lb} / \mathrm{hr}$ to yield a maximum impact of $1 \mathrm{ppm}$. This roughly correlates to $10,000 \mathrm{lb} / \mathrm{hr}$ of ash with an ammonia concentration of $150 \mathrm{ppm}$ evolving all available ammonia to the air pathway. As used with the point source model, a fine and course receptor grid were specified to evaluate receptors at a $50-\mathrm{m}$ spacing up to $5 \mathrm{~km}$ and a $500-\mathrm{m}$ spacing up to $20 \mathrm{~km}$.

The potential for ammonia release to the air pathway from ponds, landfills, piles and impoundments appears to be driven almost solely by the $\mathrm{pH}$ of the aqueous solution. In general, if the $\mathrm{pH}$ is below 7-8, no odors or significant releases are observed. If the $\mathrm{pH}$ increases above $9-10$, all of the ammonia present in solution is released with the potential for significant near-field odors. Most facilities contacted operate with low $\mathrm{pH}$ ash management systems resulting in low odor emissions potential, where the primary impact to the environment is through water, not air pathways.

\section{Accidental Release}

Based upon accidental release modeling, the most significant potential for odor or public health impact is from the accidental worst case release of ammonia from a storage vessel or the rupture of the associated piping. Using the USEPA's RMPCOMP model, a downwind distance of 2.6 miles was predicted to reach the RMP regulatory toxic endpoint for ammonia $(0.14 \mathrm{mg} / \mathrm{L})$ for a worst case release of 20,000 pounds of liquefied anhydrous ammonia. The model assumed the entire vessel releases it's contents during a 10-minute event. Worst case meteorology of $1.5 \mathrm{~m} / \mathrm{s}$ windspeed and $\mathrm{F}$ stability class was estimated. 


\section{WATER QUALITY IMPACTS}

Ammonia associated with fly ash has the potential to present several problems with the disposal and/or the use of the fly ash. Once the fly ash is exposed to the SCR process there will be a significant quantity of soluble salts associated with the fly ash. These salts are expected to be ammonium bisulfate $\left(\mathrm{NH}_{4} \mathrm{HSO}_{4}\right)$ and ammonium sulfate $\left[\left(\mathrm{NH}_{4}\right)_{2} \mathrm{SO}_{4}\right]$. Moisture is the controlling factor in the rate and amount of ammonia that will desorb from fly ash. In cases where the ash is placed in ponds most or all of the ammonia will desorb into the pond water. Dry disposal will cause the leachate and/or runoff water to contain increased concentrations of ammonia. If and when these salts are contacted with water, they will most likely be dissolved and the resulting aqueous concentration of nitrogen-containing compounds will increase in the waters associated with the ash. This anticipated increase in the aqueous concentration of nitrogen-containing compounds may cause environmental concerns at power stations that store, dispose of, or use large quantities of fly ash on an annual basis. To evaluate the potential effects on surface water quality a steady state mass balance model was applied to three sites. One site has a wet ash disposal system and two sites have dry ash disposal systems.

\section{Surface Water}

\section{Introduction}

A mass balance model was used to predict the concentrations of nitrate containing compounds in the surface water at three sites. The mass-balance model assumed that the entire mass of nitrogen received at a specific surface water body on a given day was dissolved and discharged from the surface water body the same day. That is, the surface waters do not act as on-site storage areas for nitrogen. With typical performance guarantees from SCR vendors and catalyst suppliers, the potential range at maximum ammonia slip is $50-100 \mathrm{ppm}$. To be conservative, a source concentration of ammonia that ranged from 50 to 200 milligrams/kilogram ( $\mathrm{mg} / \mathrm{kg}$ ) was used in the surface water quality predictions.

\section{Site Description}

Three sites were selected for analyses based on the characteristics of the sites. These sites are considered typical for power stations located throughout the eastern United States. These stations burn low-volatility Central Appalachian bituminous coal and produce fly ash with a relatively low $\mathrm{pH}$ in the range of 4.0 to 5.25 . 
Site A currently uses a wet ash disposal system which is described below. Fly ash is sluiced into an impoundment where the solids settle out of the solution. The resulting solution is discharged into a local stream and this discharge is regulated by an existing NPDES permit. The average daily discharge from the impoundment is approximately 9 million gallons per day and the impoundment receives 200,000 tons of fly ash per year which is exposed to the SCR. Existing pre-SCR ammonia as $\mathrm{N}$ and Nitrate as $\mathrm{N}$ concentrations in the impoundment are 0.12 and $0.32 \mathrm{ppm}$, respectively. The ash is periodically removed from the pond and placed into a landfill.

Site B currently uses a dry ash handling system and disposes ash in a landfill having a two foot thick cohesive soil liner. Ash is trucked to the disposal site. The landfill receives an average of 570,000 tons of fly ash per year. The portion of the landfill which will receive the fly ash from the SCR equipped unit discharges approximately 108,000 gallons of leachate per day. Leachate generated at the site is diverted to a surface treatment system. Effluent from the treatment system is discharged under an existing NPDES permit. Runoff from the site and the haul roads is diverted into a low volume waste treatment impoundment where the suspended fly ash settles out of solution and the resulting water is discharged to local surface water under an existing NPDES permit. The low volume waste treatment impoundment receives an average of 9,600 tons of fly ash per year and this impoundment discharges an average of 7 million gallons per day.

Site $\mathrm{C}$ uses a dry fly ash handling system with a synthetic liner that collects leachate generated at the facility. Fly ash is trucked to the disposal site and the site receives an average of 124,500 tons of dry fly ash per year. The collected leachate from the facility is diverted into a nearby ash impoundment and it eventually discharges into a local stream under an existing NPDES permit. The average total discharge from this ash impoundment is 0.8 million gallons per day. Runoff from the site is diverting into the same ash impoundment that receives the site's leachate. The receiving ash impoundment receives an average of 60 tons of fly ash per year and 3,700 gallons of leachate per day.

\section{Results}

Table 6 summarizes the surface water quality predictions for the wet disposal system at Site A. As shown in Table 6 the addition of SCR units is predicted to increase ammonia as $\mathrm{N}$ concentrations from $0.12 \mathrm{mg} / \mathrm{L}$ to $0.8 \mathrm{mg} / \mathrm{L}$, which is well below the applicable acute and chronic surface water quality standards for ammonia. Ammonia as $\mathrm{N}$ loading is predicted to increase from approximately 9 pounds per day to approximately 60 pounds per day. Nitratenitrogen concentrations are predicted to increase from 0.3 to $2.1 \mathrm{mg} / \mathrm{L}$ with the addition of SCR technology. Existing limits associated with nitrate-nitrogen as $\mathrm{N}$ at the ash settling pond outfall are not predicted to be exceeded. Nitrate-nitrogen loading as $\mathrm{N}$ is predicted to increase from approximately 24 to 160 pounds per day.

Table 7 summarizes the predicted leachate concentrations for the landfill at Site B. As shown on Table 7, ammonia as $\mathrm{N}$ concentrations in the leachate are predicted to increase from an estimated concentration of $0.25 \mathrm{mg} / \mathrm{L}$ to $425 \mathrm{mg} / \mathrm{L}$ and nitrate as $\mathrm{N}$ concentrations are predicted to increase from an estimated concentration of $0.1 \mathrm{mg} / \mathrm{L}$ to $100 \mathrm{mg} / \mathrm{L}$. These 
predicted increases in concentrations will translate to increased concentrations and increased loading of nitrogen-containing compounds at the treatment system and at the treatment system discharge.

Table 8 summarizes the surface water quality predictions for an impoundment that receives runoff from ash handling areas at Site $\mathrm{B}$. As shown on Table 8 , ammonia as $\mathrm{N}$ and nitrate as $\mathrm{N}$ concentrations are not predicted to increase significantly as a result of the addition of SCR at Site B. No significant increases are predicted because the flow into and out of this impoundment is high relative the volume of ash that this impoundment receives.

Table 9 summarizes the surface water quality predictions for the impoundment that receives runoff and leachate at Site $\mathrm{C}$. As shown on Table 9, ammonia as $\mathrm{N}$ concentrations are predicted to increase from 0.2 to $4.9 \mathrm{mg} / \mathrm{L}$ and nitrate as $\mathrm{N}$ concentrations are expected to increase from $0.6 \mathrm{mg} / \mathrm{L}$ to $13 \mathrm{mg} / \mathrm{L}$. Ammonia as $\mathrm{N}$ loading is predicted to increase from approximately 1.4 pounds per day to 32 pounds per day and nitrate as $\mathrm{N}$ loading is predicted to increase from approximately 4 pounds per day to 86 pounds per day.

The predicted concentrations reported are equilibrium concentrations based on the best available data. These equilibrium concentrations may take as much as three to six months to be achieved within a particular system. Likewise, if ash exposed to the SCR process is not introduced to a particular system for an extended period of time, the concentrations of nitrogen within the system related to the SCR process will dissipate.

\section{Ground Water}

\section{Discussion}

Nitrate $\left(\mathrm{NO}_{3}{ }^{-}\right)$is typically the dominant form of nitrogen in ground water and nitrate is a common ground water contaminant, especially in areas that have substantial agricultural landuse. Nitrogen also exists in natural environments in the form of ammonium $\left(\mathrm{NH}_{4}^{+}\right)$, ammonia $\left(\mathrm{NH}_{3}\right)$, nitrite $\left(\mathrm{NO}_{2}{ }^{-}\right)$, nitrogen $(\mathrm{N})$, nitrous oxide $\left(\mathrm{N}_{2} \mathrm{O}\right)$, cyanide $(\mathrm{CN})$, and organic nitrogen.

Nitrate moves with ground water with no transformation and little or no retardation and in oxidized ground water $\mathrm{NO}_{3}{ }_{3}^{-}$is the stable form of dissolved nitrogen. Shallow ground water in highly permeable sediment or fractured rock commonly contains considerable dissolved $\mathrm{O}_{2}$ and these ground waters will therefore allow for the existence and migration of $\mathrm{NO}_{3}{ }^{-}$. Nitrate can be reduced to $\mathrm{N}_{2} \mathrm{O}$ and then $\mathrm{N}_{2}$ with a lowering of the water's redox potential (anaerobic conditions - the ground water is devoid of dissolved oxygen). This process is called denitrification. Denitrification in the unsaturated zone has been observed in numerous systems if there is an ample supply of $\mathrm{NO}_{3}{ }^{-}$and organic matter. A portion of the $\mathrm{N} \varrho$ and/or the $\mathrm{N}_{2}$ can be lost to the atmosphere by off-gassing to the soil air if the ground water moves into the unsaturated zone. From a water quality standpoint, denitrification is a desirable process because $\mathrm{N}_{2} \mathrm{O}$ and $\mathrm{N}_{2}$ are not detrimental to drinking water. Nitrate concentrations above $45 \mathrm{mg} / \mathrm{L}$ ( $10 \mathrm{mg} / \mathrm{L}$ as N) makes water unfit for consumption by infants and $450 \mathrm{mg} / \mathrm{L}$ is not suitable for livestock. 
Ammonium has been shown to be retarded due to absorption (exchange) onto negativelycharged solid surfaces. The ammonium displaced may displace other cations, such as calcium and magnesium, that had been absorbed onto solid surfaces. Therefore, ammonium adsorption may result in the increased concentration of metals that are currently immobile a subsurface environment. Ammonium will remain immobile as long as anaerobic conditions prevail (Mohan et al., 2000). If aerobic conditions prevail the ammonium is transformed to nitrate which is an anion and it is mobile in the subsurface (Mohan et al., 2000).

The three sites evaluated in the surface water quality section were evaluated with respect to potential ground water contamination resulting from the addition of SCR units. The generalized characteristics of the ground water at Site A and Site B and the results of the ground water quality investigation are presented below.

Site $A$ is situated in the Coastal Plains Physiographic Province and it is completely surrounded by surface water bodies. Surface elevations at this site are a few feet above mean sea level and ground water occurs in an alluvial and/or a marine unconsolidated aquifer. The unconsolidated aquifer overlies relatively impermeable bedrock formations. Ground water flow rates in the unconsolidated aquifer range from approximately 1 to 400 feet per year.

Site B is situated in the eastern portion of the Appalachian Plateau Physiographic Province. There is extensive surface and deep coal mining in the region in which Site B is located. Unconsolidated materials at the site tend to be relatively thin and they overlie gently dipping Pennsylvanian-aged sedimentary rocks. Ground water at the site typically flows through the unconsolidated materials at the unconsolidated material-bedrock interface or through nearsurface fractured bedrock. Ground water velocities in the aquifers at the site typically range from less than 1 foot per year to 10 feet per year.

The first aquifer beneath the site is near surface saturated fine sand deposits which were deposited in marine-estuarine environments and are somewhat heterogenious and discontinuous. The ground water within this aquifer is unconfined. The average ground water velocity within this aquifer is 17 feet per year.

Site $\mathrm{C}$ is part of the Coastal Plains Physiographic Province and the site is underlain by silt loams and clay loams grading to fine sands at depths of 3 to 4 feet or more. The water table at the site varies from approximately 6 feet below the ground surface to near the ground surface water bodies. The average ground water velocity in the vicinity of Site $\mathrm{C}$ is estimated at 17 feet per year.

\section{Results}

Because the ground water associated with the disposal systems at Sites A, B, and C are predicted to be relatively shallow and relatively well oxygenated, nitrate has been assumed to be the dominant form of nitrogen in these systems. As discussed previously, nitrate moves through a saturated porous media without retardation at virtually the same rate of ground water. At Site A, nitrate is predicted to migrate at a rate of 1 to 400 feet per year and the concentrations of nitrate as $\mathrm{N}$ in ground water resulting from the wet disposal site are 
predicted to range from 0.8 to $2.1 \mathrm{mg} / \mathrm{L}$. Therefore, exceedances of the USEPA's current nitrate as $\mathrm{N}$ drinking water standard of $10 \mathrm{mg} / \mathrm{L}$ are not anticipated.

Nitrate is predicted to migrate at a rate of less than 1 foot per year to 10 feet per year at Site $\mathrm{B}$ and nitrate as $\mathrm{N}$ concentrations of $25 \mathrm{mg} / \mathrm{L}$ to $100 \mathrm{mg} / \mathrm{L}$ are predicted. These predicted nitrate as $N$ concentrations exceed the current USEPA drinking water standard of $10 \mathrm{mg} / \mathrm{L}$ nitrate as $\mathrm{N}$.

Nitrate is predicted to migrate at an average rate of 17 feet per year at Site $\mathrm{C}$ and nitrate as $\mathrm{N}$ concentrations of 4 to $13 \mathrm{mg} / \mathrm{L}$ are predicted. The predicted nitrate as $\mathrm{N}$ concentration with $200 \mathrm{mg} / \mathrm{kg}$ of ammonia on the ash exceeds the current USEPA drinking water standard of $10 \mathrm{mg} / \mathrm{L}$ nitrate as N. Predicted nitrate as N concentrations at 50 and $100 \mathrm{mg} / \mathrm{kg}$ of ammonia on the ash do not exceed this standard. 


\section{CONCLUSIONS}

Here follows a summary of the significant findings of this investigation based on the information presently available. The mechanism of ammonia adsorption on fly ash and the consequential effects on plant equipment and operations continues to be a subject of much industry interest and research activity. More operating experience with SCR systems is needed in the United States, with different plant configurations, firing conditions, and coal sources, before the effects of ammonia adsorption on fly ash can be predicted with certainty.

\section{Ammonia Adsorption and Release}

- Most of the ammonia present on fly ash is highly water soluble, and is completely dissolved into solution within several hours.

- $\mathrm{pH}$ exerts the dominant influence on ammonia speciation in solutions of fly ash and water.

- The effect of temperature on ammonia species in solution was much less pronounced than $\mathrm{pH}$, although it did exert a strong influence on the rate of ammonia loss from solution.

- SCR/SNCR fly ash that produces a high $\mathrm{pH}$ in aqueous solution can potentially produce ammonia odors when wetted. Ammonia odors from fly ashes that produce a low $\mathrm{pH}$ solution will be negligible.

- $\mathrm{NH}_{4}{ }^{+}$ion is stable in fly ash/water mixtures at low $\mathrm{pH}$ and is not out-gassed. However, conversion of at least a portion of it to $\mathrm{NO}_{3}{ }^{2-}$ and $\mathrm{NO}_{2}{ }^{2}$ is likely in the natural environment because of the presence of nitrifying bacteria.

\section{Thermal Analysis}

- TG-MS can be used to detect ammonia release from fly ash upon heating by monitoring the ratio of amu $17 / 18$.

- Evolution of high temperature ammonia is typically associated with amu 44 release, which probably represents $\mathrm{CO}_{2}$ evolution, suggesting that the ammonia may be bound by unburned carbon in the ash. 
- When heated in an oxidizing atmosphere, "high temperature ammonia" appeared to be susceptible to $\mathrm{NO}_{x}$ conversion, usually in association with amu 44 release, suggesting a possible catalytic role of the carbon in the ammonia-to- $\mathrm{NO}_{x}$ conversion

\section{Process Implications - Air Preheater}

- Early SCR installations experienced significant air preheater plugging and corrosion resulting from formation and deposition of ammonium bisulfate.

- These problems can be resolved by proper system configuration and by limiting ammonia slip to less than 2 ppm, although some industry experts advocate even lower levels.

\section{Process Implications - CEMS}

- Operators at several U.S. installations have had difficulty in maintaining CEMS at the operating conditions before the SCR (hot, dirty, etc.).

- Stack NOx measurements used to determine ammonia injection levels are not an effective means to optimize performance.

\section{Process Implications - Catalyst}

- Catalyst deactivation can result from arsenic poisoning, ammonia salt deposition, alkaline metal poisoning, calcium sulfate masking, and fly ash plugging.

- Catalyst masking by calcium sulfate has become a major issue with Powder River Basin coal due to the concentration and form of calcium it contains.

- Limestone addition has been used to limit arsenic poisoning for coal burning facilities with low available calcium.

- Units with high carbon fly ash may have a potential for fire as the unit is brought down from normal operation.

\section{Process Implications - ESP, FGD}

- Addition of SCR has had minimal impact on ESP performance at operating systems.

- Operators of FGD systems do not currently experience odor problems, although this can become a concern if the $\mathrm{pH}$ rises above approximately 9 and ammonia slip levels are elevated. 


\section{Process Implications - Ash Handling and Use}

- Well-designed SCR installations have efficient ammonia distribution and NOx removal systems. This results in low ammonia slip $(0-2$ ppmv) and yields a corresponding ammonia on ash concentration at the lower range of those studied (- $50-100 \mathrm{ppm})$.

- Operators of new SCR systems have not had to change ash-handling systems.

- Odor has not become a problem at landfills or impoundments.

- Fly ash uses involving the addition of alkaline material, such as concrete, have been impacted by ammonia odors. Although ammonia does not affect the performance of concrete, the aversion to ammonia odor can limit ash sales.

\section{Air Quality Impacts}

- Stack releases of ammonia are expected to have minimal impact.

- Ammonia release to the air from ash ponds, landfills and storage piles appears to be driven almost solely by the $\mathrm{pH}$ of the aqueous solution. In general, no odors or significant releases occur at $\mathrm{pH} 7$ - 8 or lower.

\section{Water Quality Impacts}

- Moisture is the controlling factor in the rate and amount of ammonia that will desorb from fly ash. In cases where the ash is placed in ponds most or all of the ammonia will desorb into the pond water.

- Leachate and/or runoff at ash landfills will contain increased concentrations of ammonia. If and when these salts are contacted with water, they will most likely be dissolved and the resulting aqueous concentration of nitrogen-containing compounds will increase in the waters associated with the ash.

A mass balance model applied to three eastern power plants burning central Appalachian high-volatile coal and producing a relatively low-pH ash determined the following:

- The predicted increase in ammonia as $\mathrm{N}$ concentrations in surface water due to installation of SCR systems may be of concern depending on site specific factors such as the assimilative capacity of receiving surface waters and regulatory permitting procedures.

- The predicted increase in ammonia as $\mathrm{N}$ and nitrate as $\mathrm{N}$ concentrations in landfill leachate and surface water runoff will translate to increased concentrations and increased loading of nitrogen-containing compounds at treatment ponds. 
- Predicted concentrations of nitrate as $\mathrm{N}$ in ground water, which is hydraulically connected with disposal sites that will receive ash from SCR units, may exceed the current USEPA drinking water standard of $10 \mathrm{mg} / \mathrm{L}$ whenever the ammonia concentration on the ash approaches $200 \mathrm{mg} / \mathrm{kg}$. 


\section{REFERENCES}

American Petroleum Institute The Sources, Chemistry, Fate, and Effects of Ammonia in Aquatic Environments, 131 pp, 1981.

Babcock and Wilcox, Steam - Its Generation and Use, $40^{\text {th }}$ Edition.

Bates, R.G. and Pinching, G.D. Dissociation Constant of Aqueous Ammonia at 0 to 50E from E.M.F. Studies of the Ammonium Salt of a Weak Acid, J. American Chemical Society, Vol. 72, pp. 1393-1396, 1950.

Becker, et al. The Case for Low Ammonia Slip, DOE 2000 Conference on Selective Catalytic \& Non-Catalytic Reduction for NOx Control, Pittsburgh, PA, May, 2000.

Bondurant, Louis P., Ammonia Slip Issues and the Impact on the Ljungstrom Air Preheater, ICAC Forum 2000 Cutting NOx Emissions, Arlington, VA, March, 2000.

Bower, C.E. and Bidwell, J.P. Ionization of Ammonia in Seawater: Effects of Temperature, pH, and Salinity, J. Fish. Res. Board Can., Vol. 35, pp. 1012-1016, 1978.

Chen, R.L., Keeney, D.R. and Konrad, J.G. Nitrification in Sediments of Selected Wisconsin Lakes, Journal of Environmental Quality, Vol. 1, No. 2, pp. 151-154, 1972.

Cichanowicz, J. E., Emissions Control - What You Should Know Before Specifying SCR, Power, May/June 1999.

Cichanowicz, J. E., What You Should Know Before Specifying SCR, Power, Volume 143, No. 3, pp. 77-82.

Coffee, R.C. and Bartholemew, W.V. Some Aspects of Ammonia Sorption by Soil Surfaces, Soil Science Society Proceedings, Vol. 28 (4), pp. 485-490, 1964.

Cooper, et al. Airheater Operating Experience on a Utility Boiler Firing International Market Coals after the Retrofit of Selective Catalytic NOx Reduction Equipment, Power-Gen International, New Orleans, LA, December, 1999. 
CRC Handbook of Chemistry and Physics, $73^{\text {rd }}$ Edition, CRC Press, Boca Raton, 1992-1993.

Dasgupta, P. G. and Dong, S. Solubility of Ammonia in Liquid Water and Generation of Trace Levels of Standard Gaseous Ammonia, Atmospheric Environment, Vol. 20, pp. 565-570, 1986.

Delwiche, C.C. The Nitrogen Cycle, in The Biosphere. Freeman, San Francisco, pp.69-80, 1970.

Elliot, et al., Standard Handbook of Powerplant Engineering - NOx Controls, Second Edition.

Emerson, K., Russo, R.C., Lund, R.E. and Thurston, R.V. Aqueous Ammonia Equilibrium Calculations: Effect of $\mathrm{pH}$ and Temperature, J. Fish. Res. Board Canada, Vol. 32, pp. 23792383, 1975.

EPA. Hazards of Ammonia Releases at Ammonia Refrigeration Facilities, U.S. Environmental Protection Agency, EPA 550-F-98-017, August 1998.

EPA, Update of Ambient Water Quality Criteria for Ammonia (1999 Ammonia Update), EPA-822-R-99-014, December 1999.

Faure, G. Principles and Applications of Inorganic Geochemistry, MacMillan, New York, $626 \mathrm{pp}$.

Freeze, R. H. and Cherry, J. A., 1979. "Groundwater," Prentice-Hall, Inc, Englewood, NJ.

Golden, D.M. Ammonia Adsorption onto Ash and Ammonia Removal from Fly Ash, Presentation at ACAA Workshop, San Diego, CA, January 25, 2000.

Gutberlet, et al., Deactivation of SCR Catalyst, DOE 2000 Conference on Selective Catalytic \& Non-Catalytic Reduction for NOx Control, Pittsburgh, PA, May, 2000.

Gutberlet, et al., Long Term Experience With SCR Honeycomb Catalyst, Power-Gen International, New Orleans, LA, December, 1999.

Hales, J.M. and Drewes, D.R. Solubility of Ammonia in Water at Low Concentrations, Atmospheric Environment, Vol 13, pp. 1133-1147, 1979.

Hathaway, et.al. Procter and Hughes' Chemical Hazards of the Workplace, Third Edition, Van Nostrand Reinhold, 1991.

Hem, J. D. "Study and Interpretation of the Chemical Characteristics of Natural Water," Third Edition, United States Geological Survey Water Supply Paper 2254. 
Jansen, R.J.J. and van Bekkum, H., Amination and Ammoxidation of Activated Carbons, Carbon, Vol. 32, No. 8, pp. 1507-1516, 1994.

Jones, Cate, Emissions Control - SCR Takes Industry By Storm, Power, May/June 1999.

Jordan, T.D. and Casper, M.A. SNCR Experience with Coal-Fired Boilers, PWR-Vol. 29, 1995 Joint Power Generation Conference, Vol. 4, ASME 1995, pp. 147-151.

Keeney, D.R. The Fate of Nitrogen in Aquatic Ecosystems, The University of Wisconsin, Water Resource Center, Literature Review No. 3, 1972.

Kholdebarin, B. and Oertli, J.J. (a) Effect of Suspended Particles and Their Sizes on Nitrification in Surface Water, J. Water Pollution Control Fed., Vol. 49, No. 1, pp. 693-697, 1977.

Kholdebarin, B. and Oertli, J.J. (b) Effect of $\mathrm{pH}$ and Ammonia on the Rate of Nitrification in Surface Water, J. Water Pollution Control Fed., Vol. 49, No. 1, pp. 688-692, 1977.

Lang, W., Block, T.M. and Zander, R. Solubility of $\mathrm{NH}_{3}$ and Apparent pK of $\mathrm{NH}_{4}^{+}$in Human Plasma, Isotonic Salt Solutions and Water at 37EC, Clinica Chimica Acta, Vol. 273, pp. 43-58, 1998.

Mohan, V. S., Bonasa, Lakshmi, S. R., Hugo, D., 2000. "Scrape-and Replace-Method to Minimize Ammonium Transport from Animal Waste Lagoons", Practical Periodical of Hazardous, Toxic, and Radioactive Wastes Management, V. 4, No. 2.

Muzio, Larry, Personal Communications.

O'Connor, D.O., Larrimore, L., Dodgen, D., Monroe, L., Cushing, K., Hinton, S. and Turner, J. The Effects of Ammonia-Based NOx Reduction on Fly Ash: Ammonia Adsorption on Ash, EPRI Symposium 1999, pp. 16-33 to 16-42.

OSHA, Ammonia in Workplace Atmospheres - Solid Sorbent, Method No. ID-188, 1991.

NIOSH, Ammonia by IC, Manual of Analytical Methods, Method 6016, Issue 1, 1996.

NIOSH, Ammonia, Manual of Analytical Methods, Method 6015, Issue 2, 1994.

NIOSH 1974. Criteria for a Recommended Standard ... Occupational Exposure to Ammonia, U.S. Department of Health, Education and Welfare, National Institute for Occupational Safety and Health, 1974. 
Sander, R. Compilation of Henry's Law Constant for Inorganic and Organic Species of Potential Importance in Environmental Chemistry, http://www.mpchmainz.mpg.de/ sander/res/henry.html, Version 3, 1999.

Sanyal, Anupam, SCR Performance Improvement From US Coal Quality Evaluation, DOE 2000 Conference on Selective Catalytic \& Non-Catalytic Reduction for NOx Control, Pittsburgh, PA, May, 2000.

Thurston, R.V., Russo, R.C. and Emerson, K. Aqueous Ammonia Equilibrium Calculations, Technical Report No. 74-1, Fisheries Bioassay Laboratory, Montana State University, Bozeman, Montana, 18pp, 1977.

Turner, J.R., Choné, S. and DudukoviÉ, P. Ammonia/Flyash Interactions and Their Impact on Flue Gas Treatment Technologies, Chemical Engineering Science, Vol. 49, No. 24A, pp. 4315-4325, 1994.

Weiler, R. R. Rate of Loss of Ammonia from Water to the Atmosphere, J. Fish. Res. Board Canada, Vol. 36, pp. 685-689, 1979. 


\section{TABLES}


Table 1. Ammonia Solubility

\begin{tabular}{|l|c|c|c|}
\hline \multicolumn{1}{|c|}{ Name } & Formula & $\begin{array}{c}\text { Cold Water Sol. } \\
(\mathbf{g} / \mathbf{1 0 0} \mathbf{~ m l})\end{array}$ & $\begin{array}{c}\text { Hot Water Sol. } \\
(\mathbf{g} / \mathbf{1 0 0} \mathbf{~ m l})\end{array}$ \\
\hline Ammonia & $\mathrm{NH}_{3}$ & 89.9 & 7.4 \\
\hline Ammonium carbonate & $\left(\mathrm{NH}_{4}\right)_{2} \mathrm{CO}_{3} \cdot \mathrm{H}_{2} \mathrm{O}$ & $100^{15}$ & $\mathrm{~d}$ \\
\hline Ammonium bicarbonate & $\mathrm{NH}_{4} \mathrm{HCO}_{3}$ & $11.9^{0}$ & $\mathrm{~d}$ \\
\hline Ammonium chloride & $\mathrm{NH}_{4} \mathrm{Cl}$ & $29.7^{0}$ & $75.8^{100}$ \\
\hline Ammonium nitrate & $\mathrm{NH}_{4} \mathrm{NO}_{3}$ & $118.3^{0}$ & $871^{100}$ \\
\hline Ammonium sulfate & $\left(\mathrm{NH}_{4}\right)_{2} \mathrm{SO}_{4}$ & $70.6^{0}$ & $103.8^{100}$ \\
\hline Ammonium bisulfate & $\mathrm{NH}_{4} \mathrm{HSO}_{4}$ & 100 & vs \\
\hline Ammonium sulfite & $\left(\mathrm{NH}_{4}\right)_{2} \mathrm{SO}_{3} \cdot \mathrm{H}_{2} \mathrm{O}$ & $32.4^{0}$ & $60.4^{100}$ \\
\hline Ammonium bisulfite & $\mathrm{NH}_{4} \mathrm{HSO}_{3}$ & $71.8^{0}$ & $84.6^{60}$ \\
\hline
\end{tabular}

Solubility data from CRC Handbook (1992-1993)

Superscript numbers refer to temperature; $d=$ decomposes, vs = very soluble

Table 2. Properties of "Pre-SCR" Fly Ash Samples

\begin{tabular}{|l|c|c|c|c|c|c|c|c|c|}
\hline Ash & $\begin{array}{c}\mathrm{LOI} \\
(\%)\end{array}$ & $\begin{array}{c}\mathrm{SiO}_{2} \\
(\%)\end{array}$ & $\begin{array}{c}\mathrm{Al}_{2} \mathrm{O}_{3} \\
(\%)\end{array}$ & $\begin{array}{c}\mathrm{Na}_{2} \mathrm{O} \\
(\%)\end{array}$ & $\begin{array}{c}\mathrm{K}_{2} \mathrm{O} \\
(\%)\end{array}$ & $\begin{array}{c}\mathrm{MgO} \\
(\%)\end{array}$ & $\begin{array}{c}\mathrm{CaO} \\
(\%)\end{array}$ & $\begin{array}{c}\mathrm{Fe}_{2} \mathrm{O}_{3} \\
(\%)\end{array}$ & pH \\
\hline $\mathrm{C} 1$ & 13.4 & 46.13 & 25.56 & 0.46 & 2.93 & 1.02 & 1.02 & 14.76 & 4.10 \\
\hline $\mathrm{C} 2$ & 20.0 & 54.31 & 30.69 & 0.36 & 2.14 & 0.93 & 1.12 & 8.48 & 4.20 \\
\hline $\mathrm{MT}$ & 11.2 & 52.09 & 28.15 & 0.27 & 2.41 & 0.9 & 1.57 & 10.86 & 5.23 \\
\hline
\end{tabular}


Table 3. Ash Properties for Selected Plants with SCR/SNCR Systems

\begin{tabular}{|l|c|c|c|c|c|c|c|c|c|c|}
\hline Ash & $\begin{array}{c}\mathrm{LOI} \\
(\%)\end{array}$ & $\begin{array}{c}\mathrm{SiO}_{2} \\
(\%)\end{array}$ & $\begin{array}{c}\mathrm{Al}_{2} \mathrm{O}_{3} \\
(\%)\end{array}$ & $\begin{array}{c}\mathrm{Na}_{2} \mathrm{O} \\
(\%)\end{array}$ & $\begin{array}{c}\mathrm{K}_{2} \mathrm{O} \\
(\%)\end{array}$ & $\begin{array}{c}\mathrm{MgO} \\
(\%)\end{array}$ & $\begin{array}{c}\mathrm{CaO} \\
(\%)\end{array}$ & $\begin{array}{c}\mathrm{Fe}_{2} \mathrm{O}_{3} \\
(\%)\end{array}$ & $\mathbf{p H}$ & $\begin{array}{c}\mathrm{NH}_{3} \\
(\mathbf{m g} / \mathbf{k g})\end{array}$ \\
\hline $\mathrm{P} 1$ & 4.8 & 43.5 & 23.4 & 1.5 & 2.5 & 1.0 & 3.3 & 16.4 & 3.66 & 680 \\
\hline $\mathrm{W}$ & 0.5 & 33.9 & 17.9 & 1.8 & 0.4 & 4.5 & 24.5 & 4.7 & 12.25 & 600 \\
\hline $\mathrm{L}$ & 7.4 & 30.5 & 15.0 & 0.1 & 1.2 & 0.4 & 2.6 & 36.4 & 12.11 & 92 \\
\hline $\mathrm{S}$ & 31.6 & 60.5 & 22.2 & 0.5 & 1.6 & 1.6 & 2.1 & 8.3 & 11.67 & 60 \\
\hline $\mathrm{O}$ & 9.2 & 51.1 & 29.1 & 0.5 & 2.5 & 1.0 & 1.8 & 11.0 & 4.27 & 72 \\
\hline $\mathrm{H}$ & 32.9 & 64.3 & 20.0 & 0.4 & 1.7 & 1.9 & 2.5 & 7.9 & 10.16 & 2020 \\
\hline $\mathrm{B}$ & 2.6 & 55.7 & 30.0 & 0.4 & 2.4 & 1.0 & 1.6 & 5.7 & 10.55 & 184 \\
\hline
\end{tabular}

Table 4. Onset Temperature for Ammonia Evolution from Ammonia Salts

\begin{tabular}{|l|c|c|}
\hline \multicolumn{1}{|c|}{ Salt } & $\begin{array}{c}\text { He Onset Temp. } \\
\text { EC }\end{array}$ & $\begin{array}{c}\mathbf{O}_{2} / \text { He Onset Temp. } \\
\text { EC }\end{array}$ \\
\hline$\left(\mathrm{NH}_{4}\right)_{2} \mathrm{CO}_{3}$ & 106 & 112 \\
\hline$\left(\mathrm{NH}_{4}\right) \mathrm{HCO}_{3}$ & 114 & 143 \\
\hline $\mathrm{NH}_{4} \mathrm{Cl}$ & 330 & 387 \\
\hline$\left(\mathrm{NH}_{4}\right)_{2} \mathrm{SO}_{4}$ & 356 & 362 \\
\hline$(\mathrm{NH} 4)_{2} \mathrm{SO}_{3}{ }^{*} \mathrm{H}_{2} \mathrm{O}$ & 120 & 142 \\
\hline$\left(\mathrm{NH}_{4}\right) \mathrm{HSO}_{4}$ & 214 & 230 \\
\hline
\end{tabular}


Table 5. Onset Temperature for Low- and High-Temperature Ammonia Evolution from SCR/SNCR Fly Ash Samples

\begin{tabular}{|c|c|c|}
\hline Ash & $\begin{array}{c}\text { Onset, EC } \\
\text { Low Temperature }\end{array}$ & $\begin{array}{c}\text { Onset, EC } \\
\text { High Temperature }\end{array}$ \\
\hline H & 187 & 706 \\
\hline O & 268 & 628 \\
\hline W & 242 & 518 \\
\hline L & 387 & --- \\
\hline P1 & 347 & --- \\
\hline S & --- & 626 \\
\hline B & --- & 578 \\
\hline
\end{tabular}

Table 6. Summary of Surface Water Quality Predictions for Site A

\begin{tabular}{|c|c|c|c|c|}
\hline & Existing & $50 \mathrm{mg} / \mathrm{kg}$ & $100 \mathrm{mg} / \mathrm{kg}$ & $200 \mathrm{mg} / \mathrm{kg}$ \\
\hline \multicolumn{5}{|l|}{ Ammonia as $\mathrm{N}(\mathrm{mg} / \mathrm{L})$} \\
\hline Ash Settling Pond & 0.12 & 0.3 & 0.5 & 0.8 \\
\hline Acute Water Quality Standard & 7.5 & & & \\
\hline Chronic Water Quality Standard & 1.7 & & & \\
\hline Groundwater Standard & $0.025^{*}$ & & & \\
\hline \multicolumn{5}{|l|}{ Ammonia as N Loading (pounds/day) } \\
\hline Ash Pond Loading & 9 & 22 & 34 & 60 \\
\hline \multicolumn{5}{|l|}{ Nitrate - Nitrogen as N (mg/L) } \\
\hline Ash Settling Pond & 0.3 & 0.8 & 1.2 & 2.1 \\
\hline Groundwater Quality Standard & 5 & & & \\
\hline \multicolumn{5}{|l|}{ Nitrate - Nitrogen as N Loading } \\
\hline Ash Settling Pond Loading & 24 & 60 & 90 & 160 \\
\hline
\end{tabular}

* Where the existing groundwater concentration is greater than the standard, no additional degradation of groundwater quality is allowed. 
Table 7. Summary of Predicted Leachate Concentrations for Landfill Site B

\begin{tabular}{|l|c|c|c|c|}
\hline & $\begin{array}{c}\text { Estimated } \\
\text { Existing }\end{array}$ & $\mathbf{5 0} \mathbf{~} \mathbf{~ g / k g}$ & $\mathbf{1 0 0} \mathbf{~} \mathbf{g} / \mathbf{k g}$ & $\mathbf{2 0 0} \mathbf{~} \mathbf{~ g / \mathbf { k g }}$ \\
\hline Ammonia as N (mg/L) & $0.25^{*}$ & 106 & 212 & 425 \\
\hline Nitrate - Nitrogen as N (mg/L) & $0.1^{*}$ & 25 & 50 & 100 \\
\hline
\end{tabular}

*Existing concentrations based on existing ground water concentrations. Data for leachate is not available.

Table 8. Summary of Surface Water Quality Predictions for Site B

\begin{tabular}{|l|r|r|r|r|}
\hline & $\begin{array}{c}\text { Existin } \\
\mathbf{g}\end{array}$ & $\mathbf{5 0} \mathbf{~ m g / k g}$ & $\mathbf{1 0 0} \mathbf{~ m g / k g}$ & $\mathbf{2 0 0} \mathbf{~ m g / k g}$ \\
\hline Ammonia as N (mg/L) & \multicolumn{5}{|l|}{} \\
\hline Low Volume Waste Treatment Ponds & 0.054 & 0.054 & 0.054 & 0.054 \\
\hline Acute Water Quality Standard & 1.66 & & & \\
\hline Chronic Water Quality Standard & 0.32 & & & \\
\hline Nitrate - Nitrogen as N (mg/L) & \multicolumn{1}{|c|}{} \\
\hline Low Volume Waste Treatment Ponds & 6 & 6 & 6 & 6 \\
\hline Groundwater Quality Standard & 10 & & & \\
\hline
\end{tabular}


Table 9. Summary of Surface Water Quality Predictions for Site C

\begin{tabular}{|l|c|c|c|c|}
\hline & Existing & $\mathbf{5 0 ~} \mathbf{~ m g} / \mathbf{k g}$ & $\mathbf{1 0 0} \mathbf{~ m g} / \mathbf{k g}$ & $\mathbf{2 0 0} \mathbf{~ m g} / \mathbf{k g}$ \\
\hline Ammonia as N (mg/L) & 0.2 & 1.4 & 2.6 & 4.9 \\
\hline Ash Impoundment & 8.5 & & & \\
\hline Acute Water Quality Standard & 1.2 & & & \\
\hline Chronic Water Quality Standard & $16.4^{* *}$ & & & \\
\hline Acute Wasteload Allocation & $60.0^{* *}$ & & & \\
\hline Chronic Wasteload Allocation & $0.025^{\star}$ & & & \\
\hline Ground Water Standard & 1.4 & 9 & 17 & 32 \\
\hline Ammonia as N Loading (pounds/day) & & & \\
\hline Ash Impoundment & 0.6 & 4 & 7 & 13 \\
\hline Nitrate - Nitrogen as N (mg/L) & 10 & & & \\
\hline Ash Impoundment & 4 & 24 & 45 & 86 \\
\hline Groundwater Standard &
\end{tabular}

* Where the existing ground water concentration is greater than the standard, no additional degradation of ground water quality is allowed.

** The acute and chronic wasteload allocations are maximum acceptable effluent concentrations for the protection of aquatic life based on current state permitting guidance. 


\section{FIGURES}




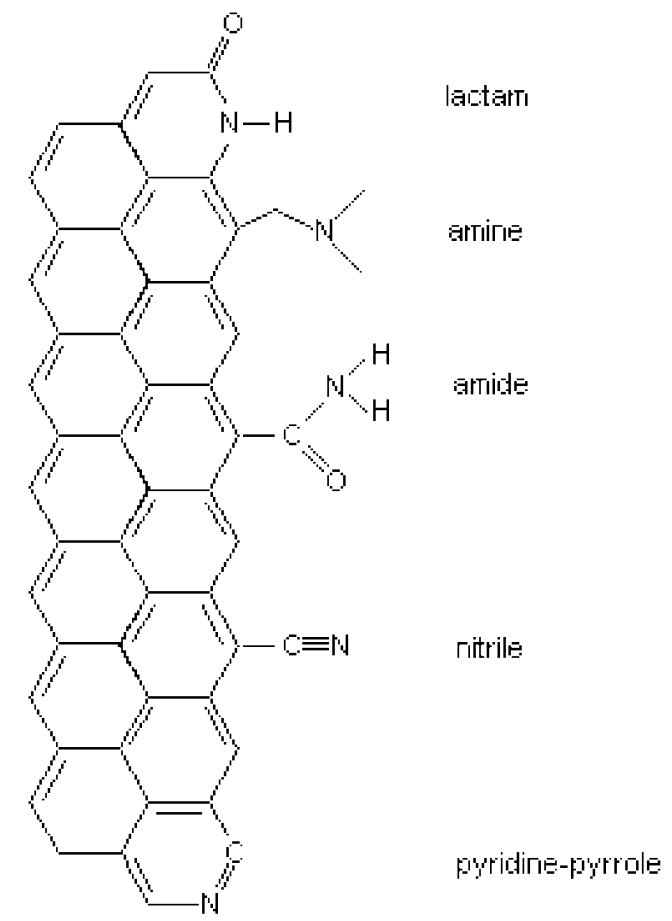

Figure 1. Nitrogen functional groups on a hypothetical carbon surface, introduced from treatment of the carbon with ammonia (adapted from Jansen and vanBekkum, 1994). 


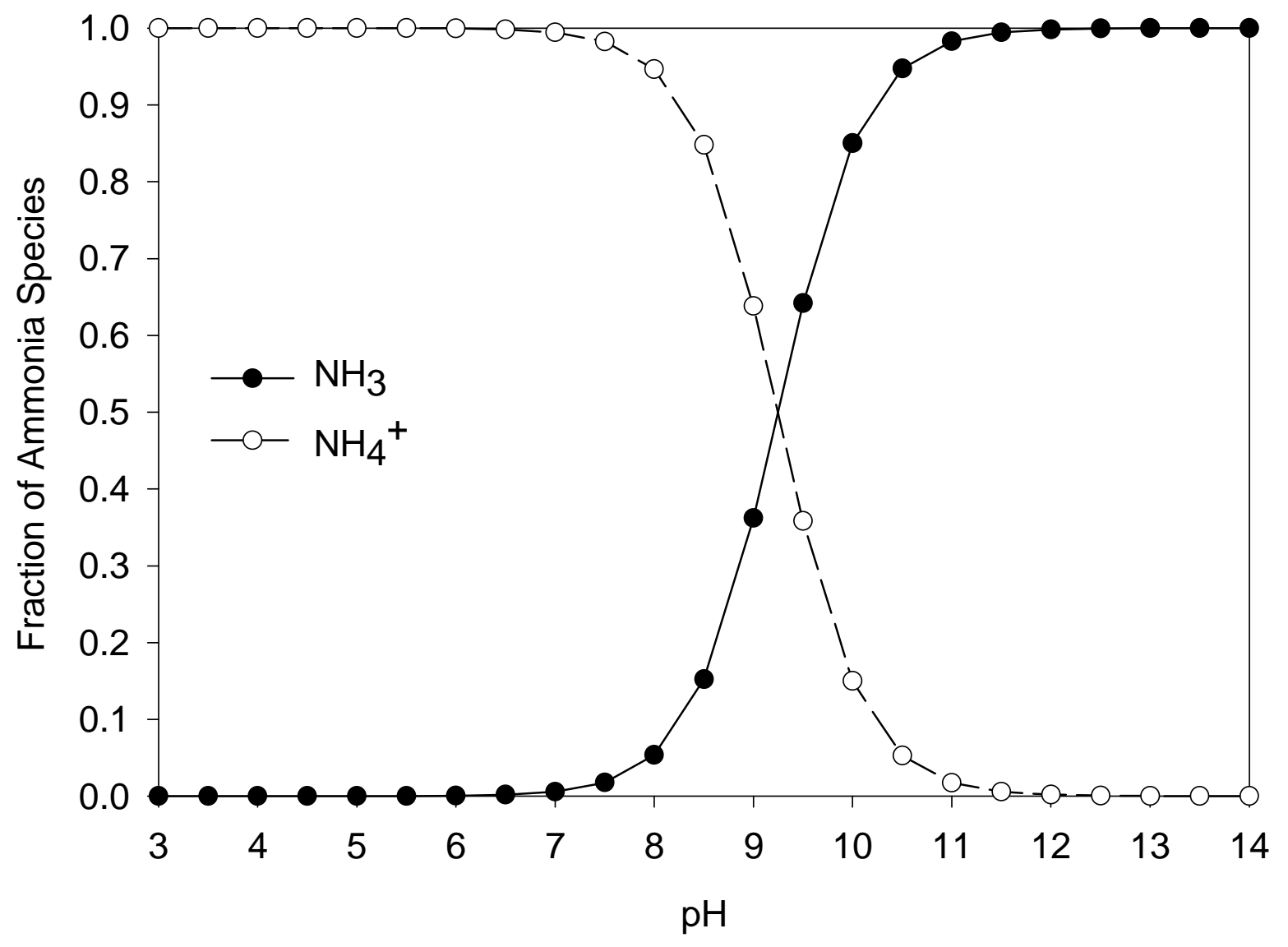

Figure 2. Ammonia species in aqueous solution as a function of $\mathrm{pH}$ at $25 \mathrm{EC}$ (calculated from Emerson et al., 1975). 


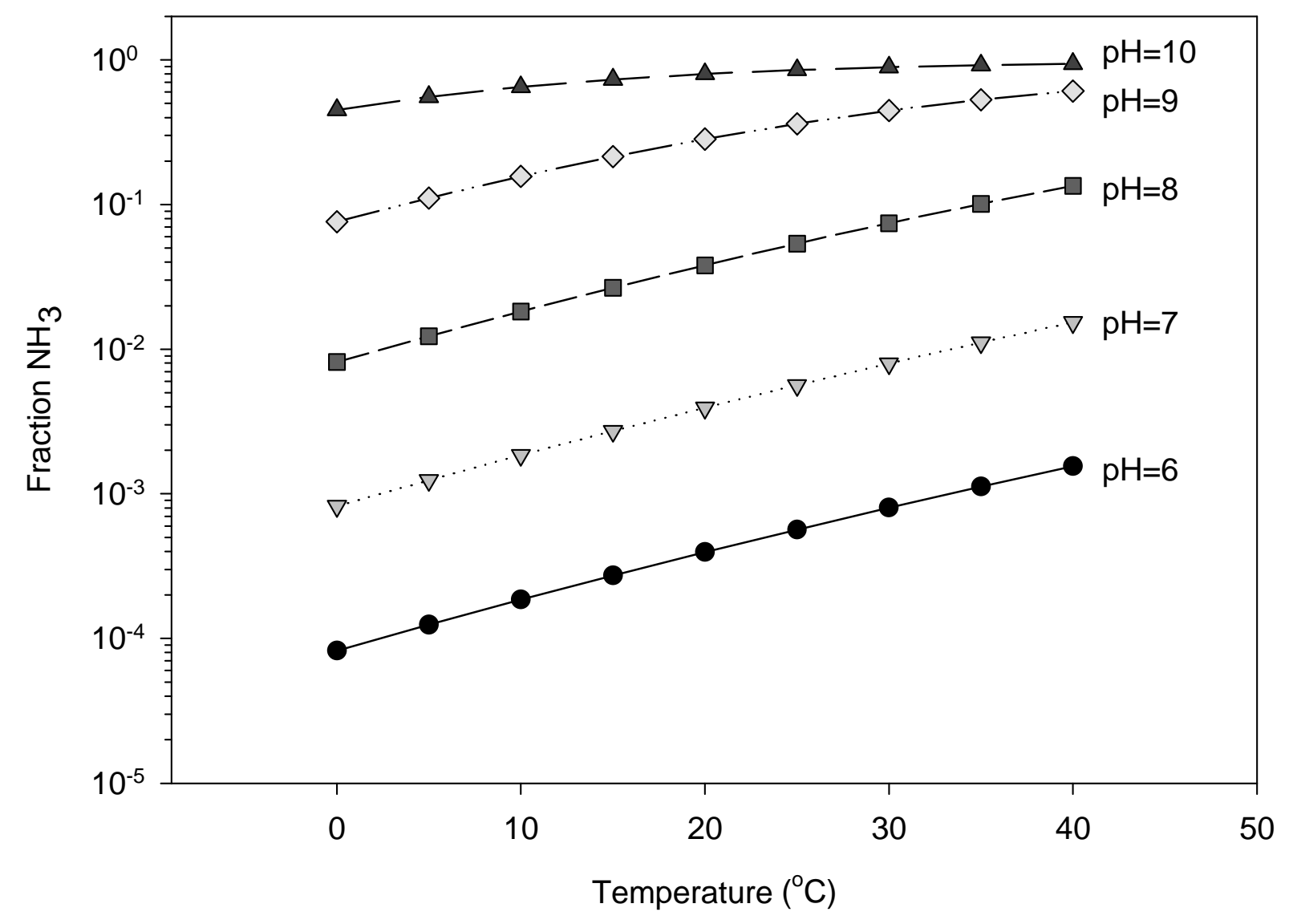

Figure 3. The effects of temperature on ammonia species distribution in aqueous solution at various $\mathrm{pH}$ levels (calculated from Emerson et al., 1975). 


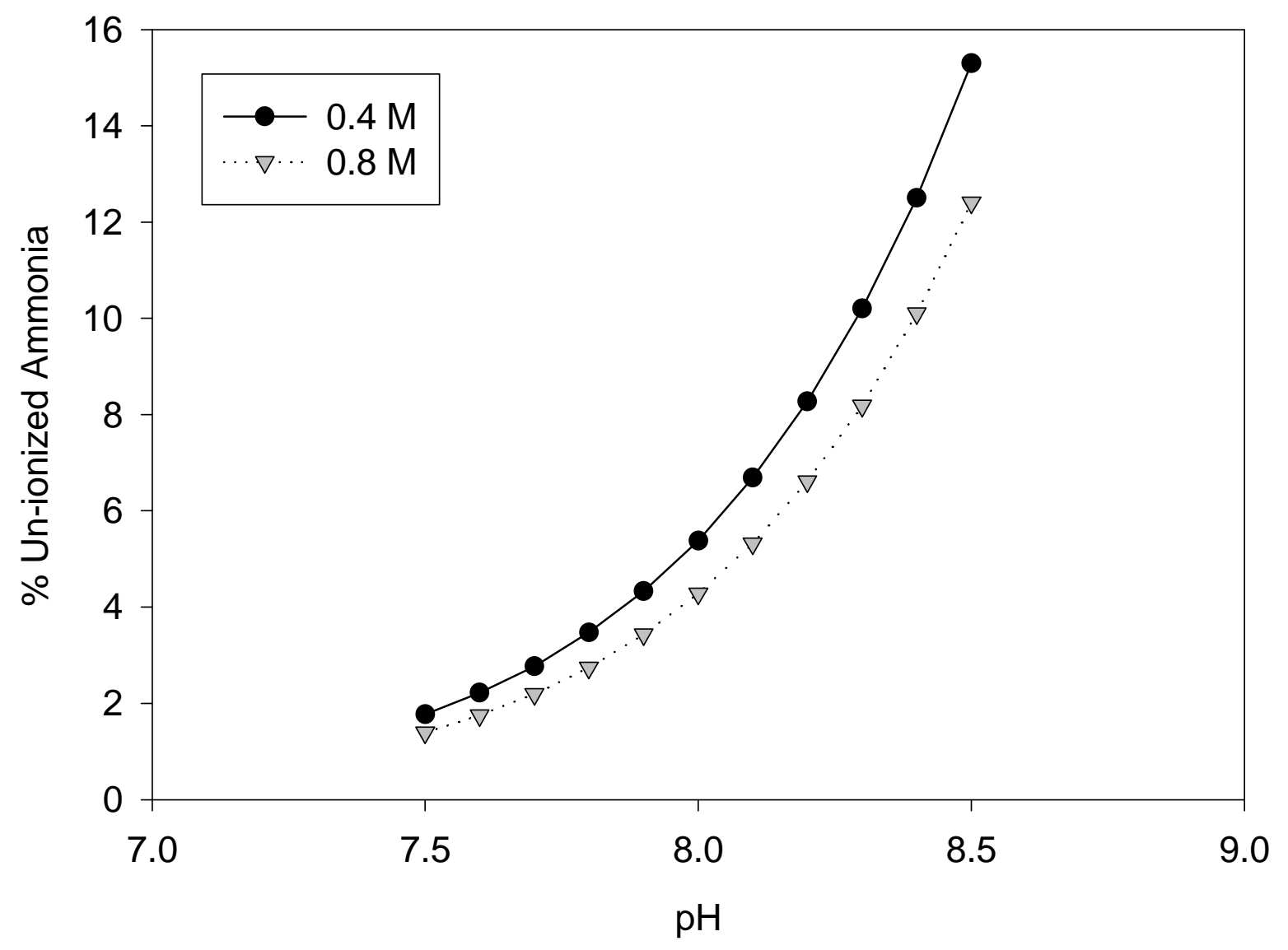

Figure 4. Effect of salinity (ionic strength) on the percent of un-ionized $\mathrm{NH}_{3}$ in aqueous solution at 25EC (from Bower and Bidwell, 1978). 


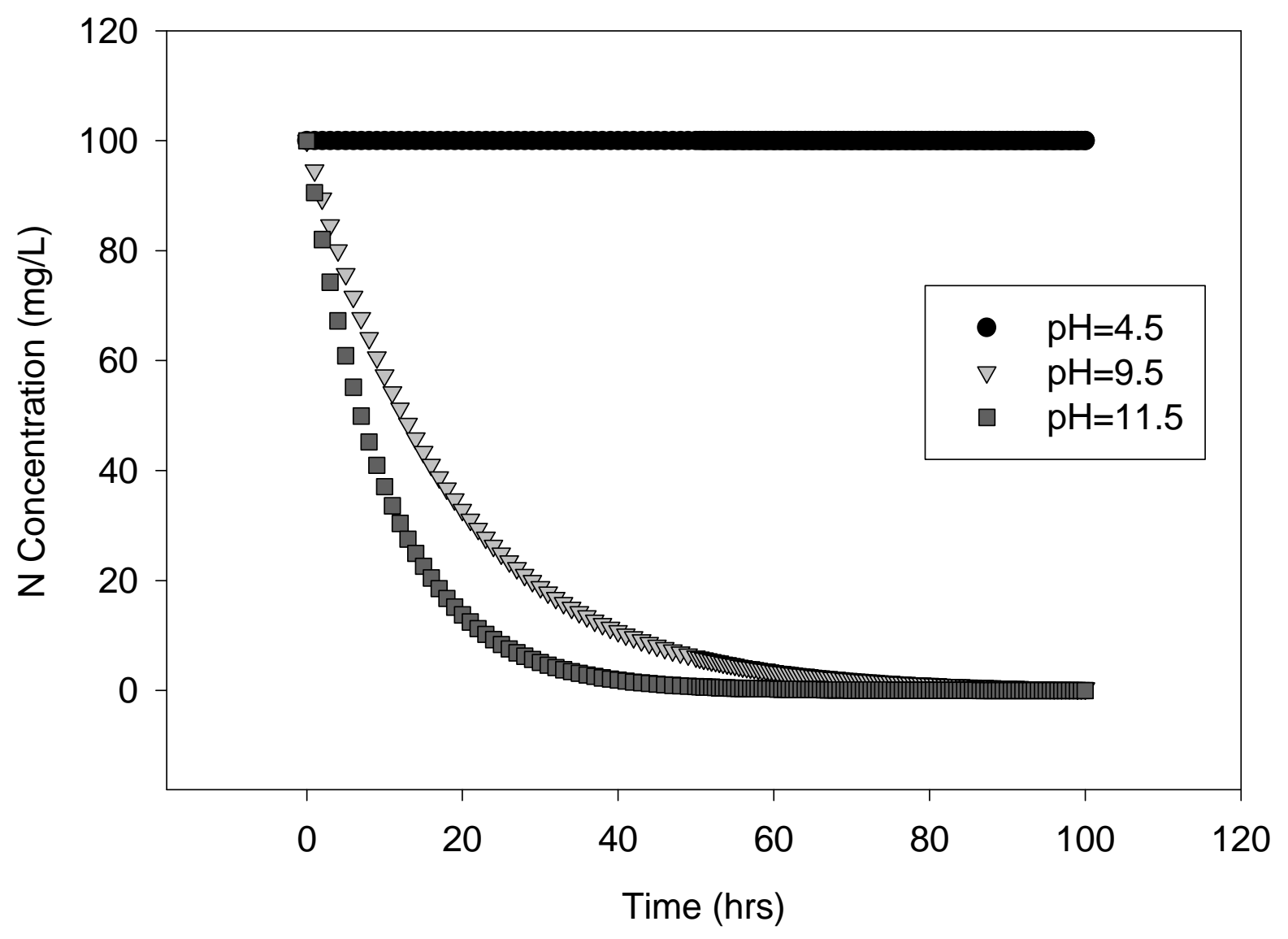

Figure 5. The effect of $\mathrm{pH}$ on the rate of ammonia loss from water at 20EC (calculated from Weiler, 1979). 


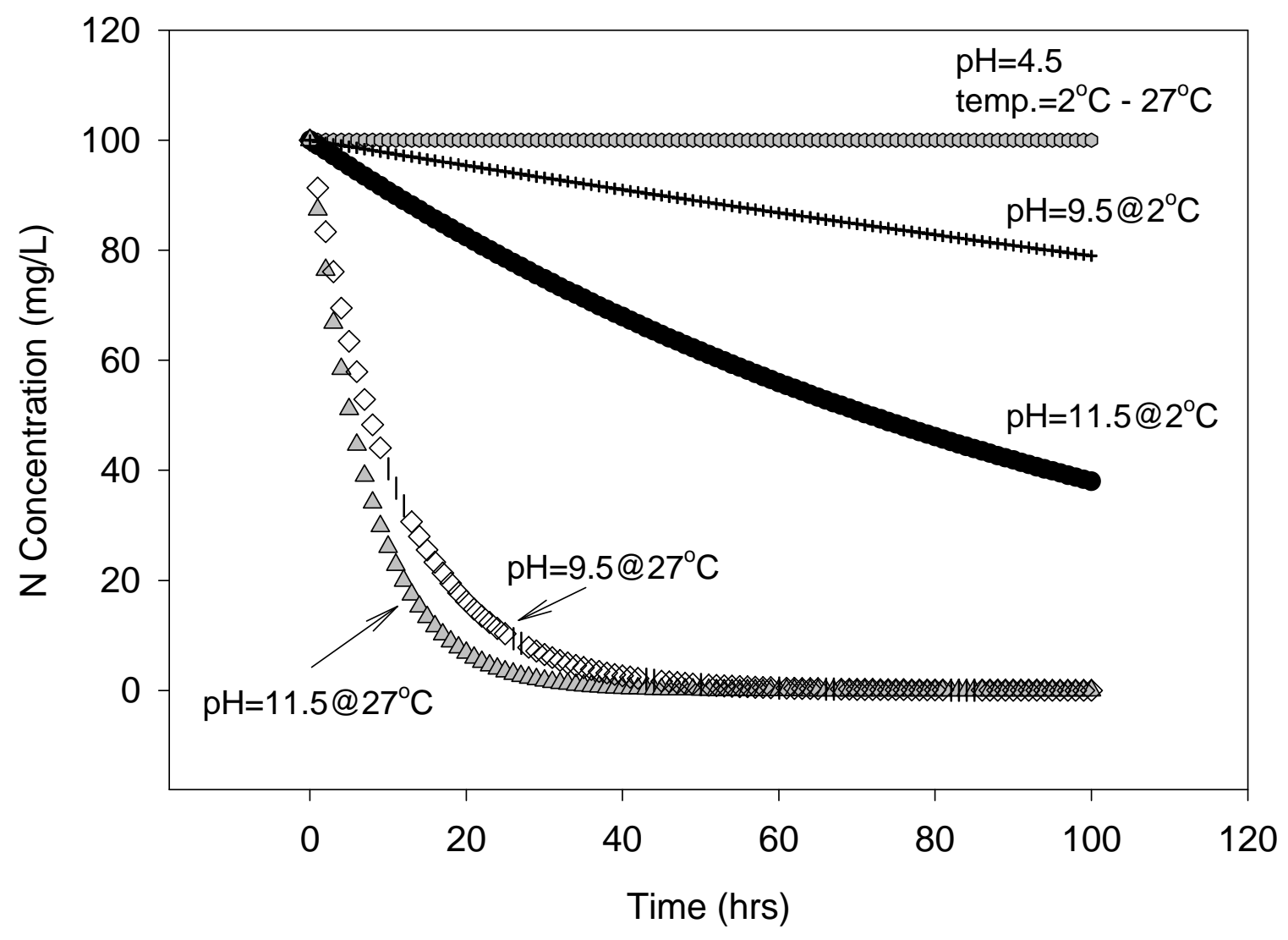

Figure 6. The effect of temperature on the rate of ammonia loss from water at different $\mathrm{pH}$ levels (calculated from Weiler, 1979). 


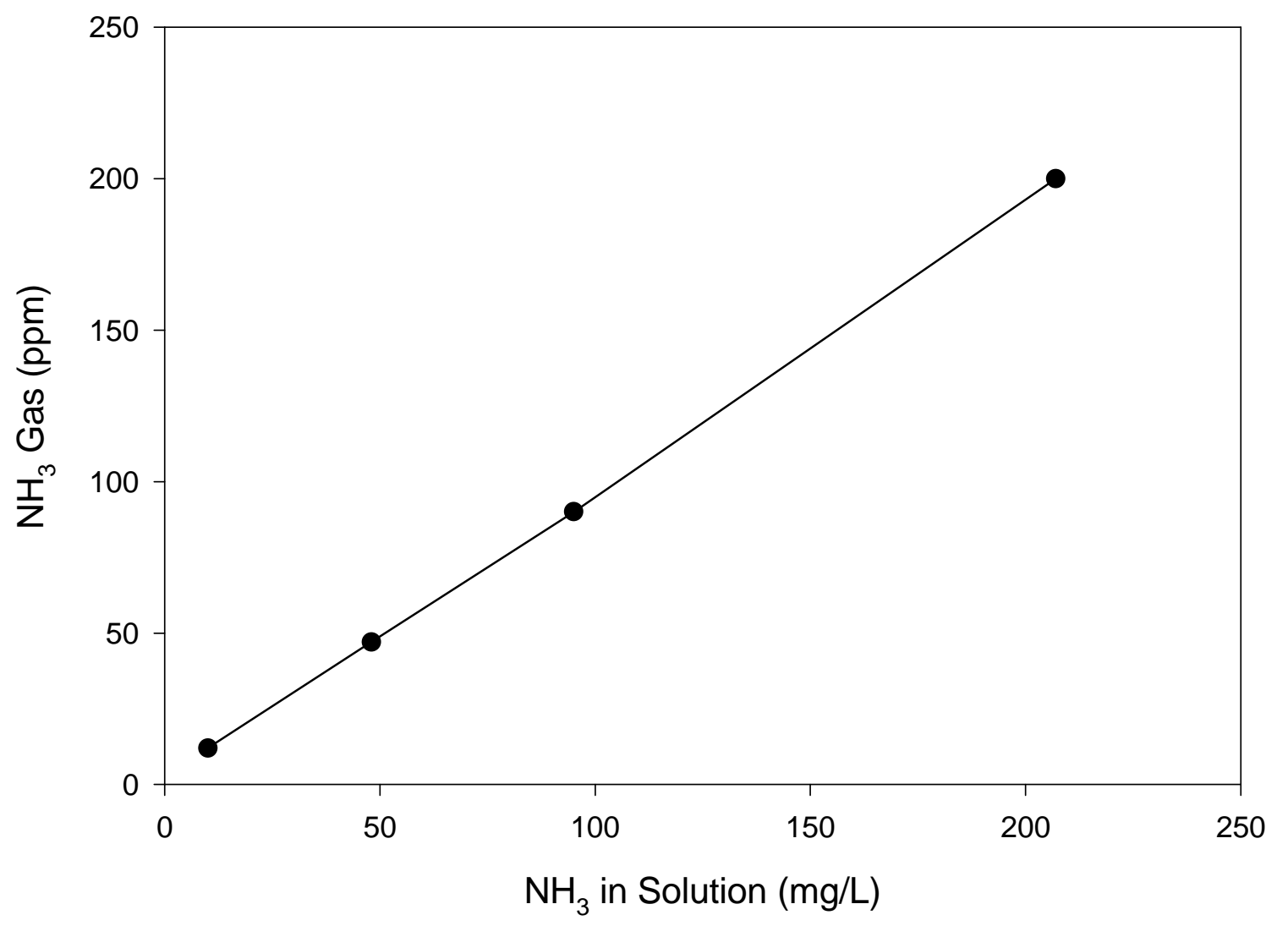

Figure 7. Calibration curve for the GasTec 3La ammonia detection tube. 


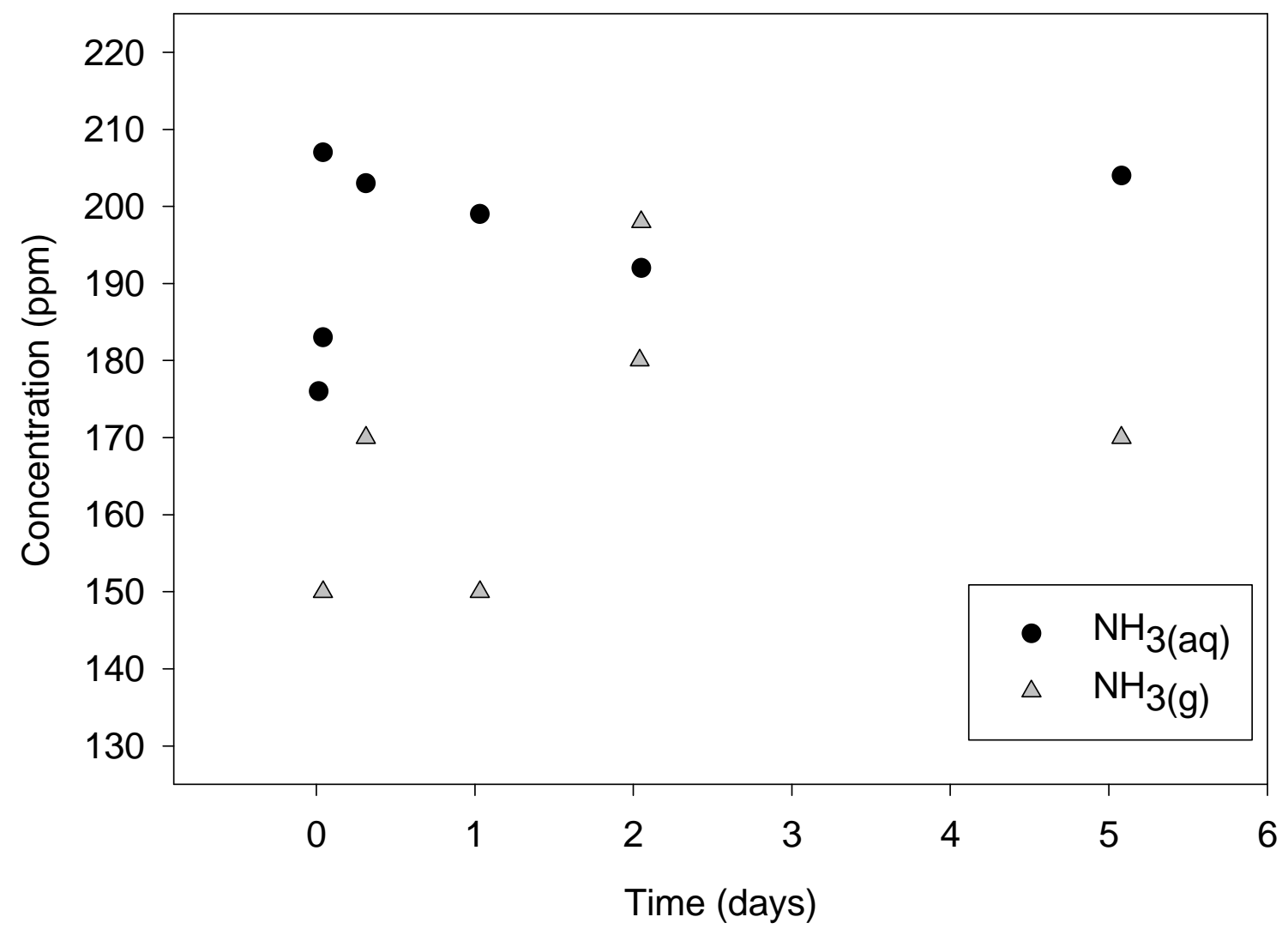

Figure 8. Ammonia release from fly ash "W" in distilled water under closed conditions. 


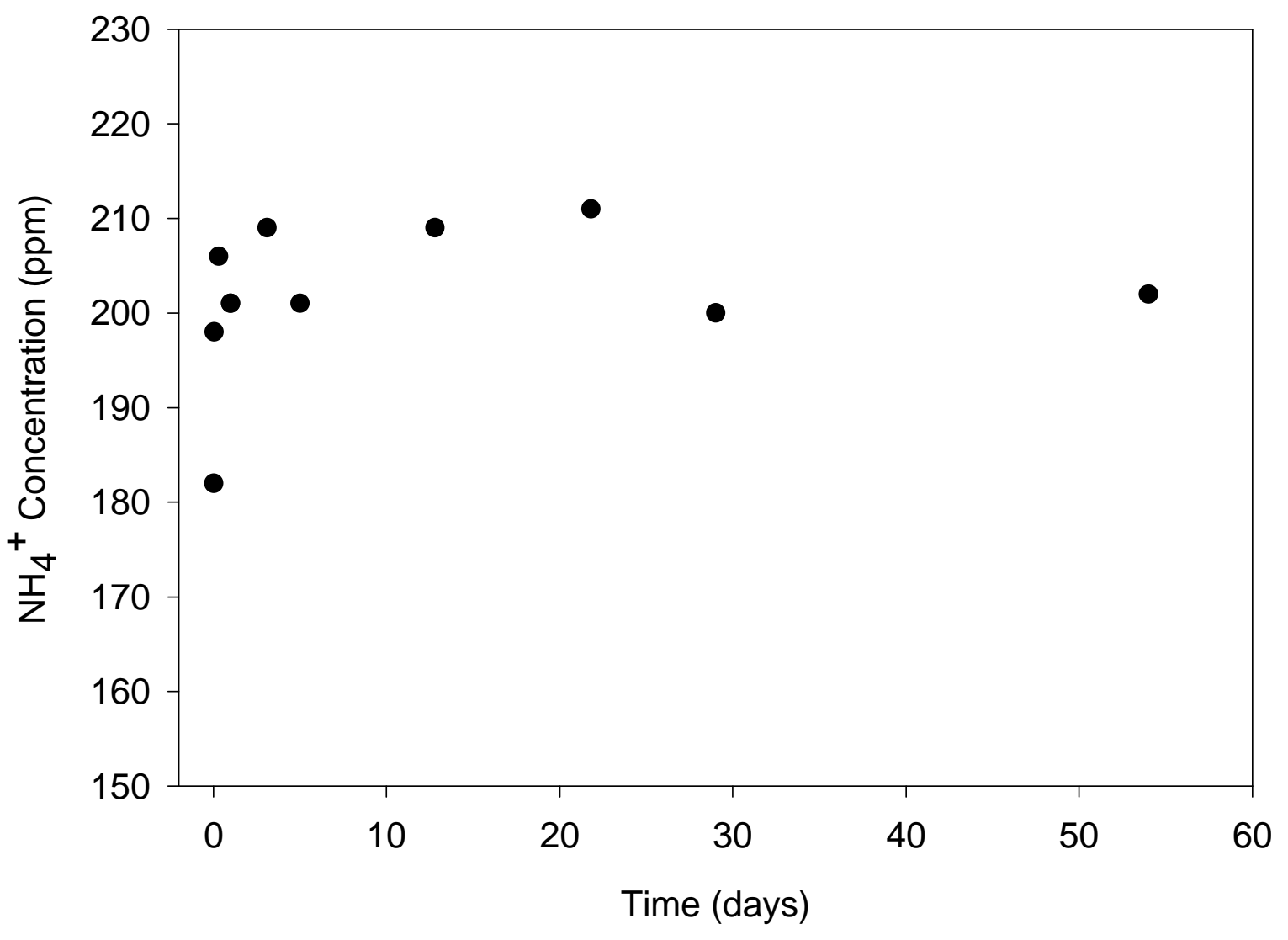

Figure 9. Ammonia release from fly ash "P1" in distilled water under closed conditions. 


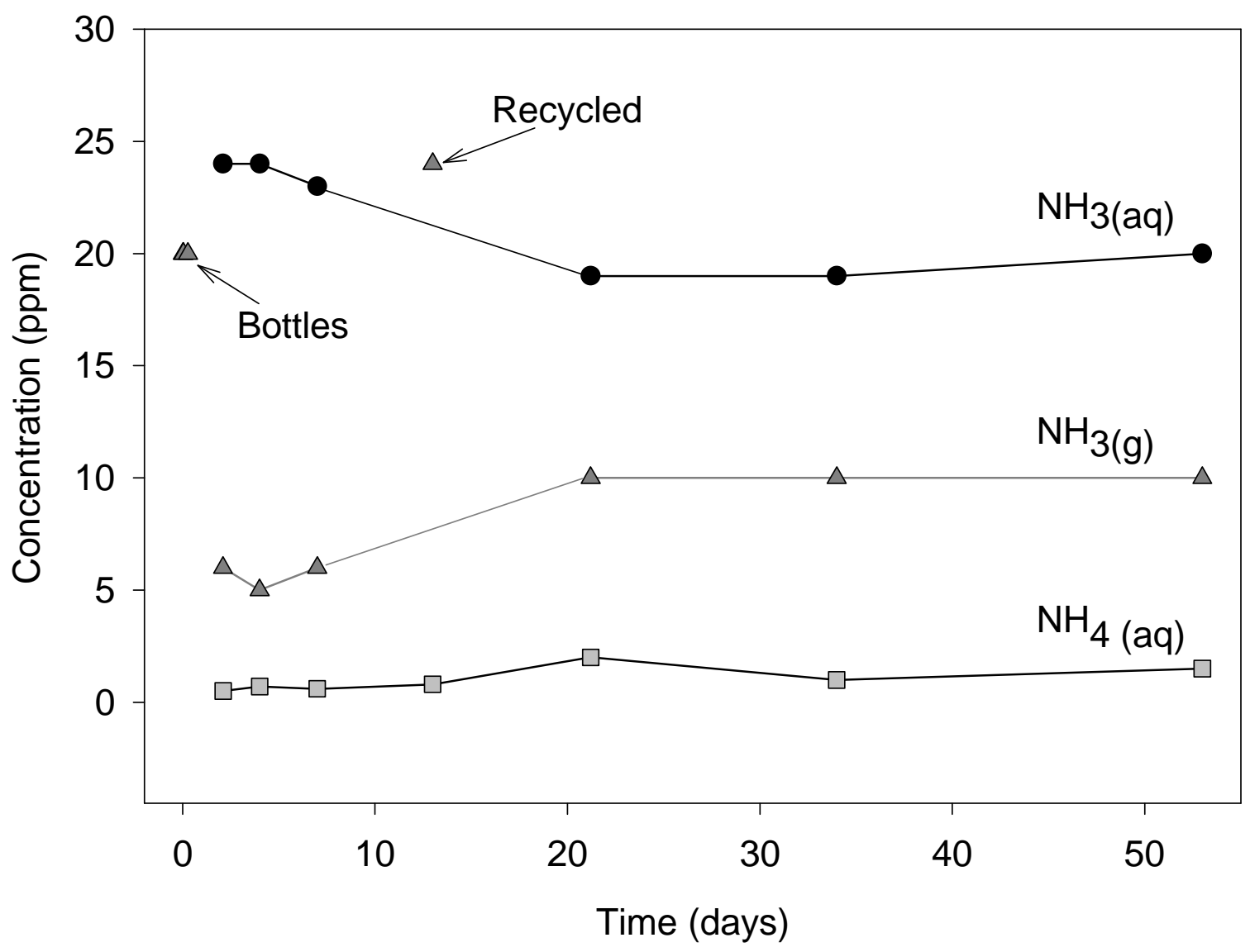

Figure 10. Ammonia release from fly ash "S" in distilled water under closed conditions. 


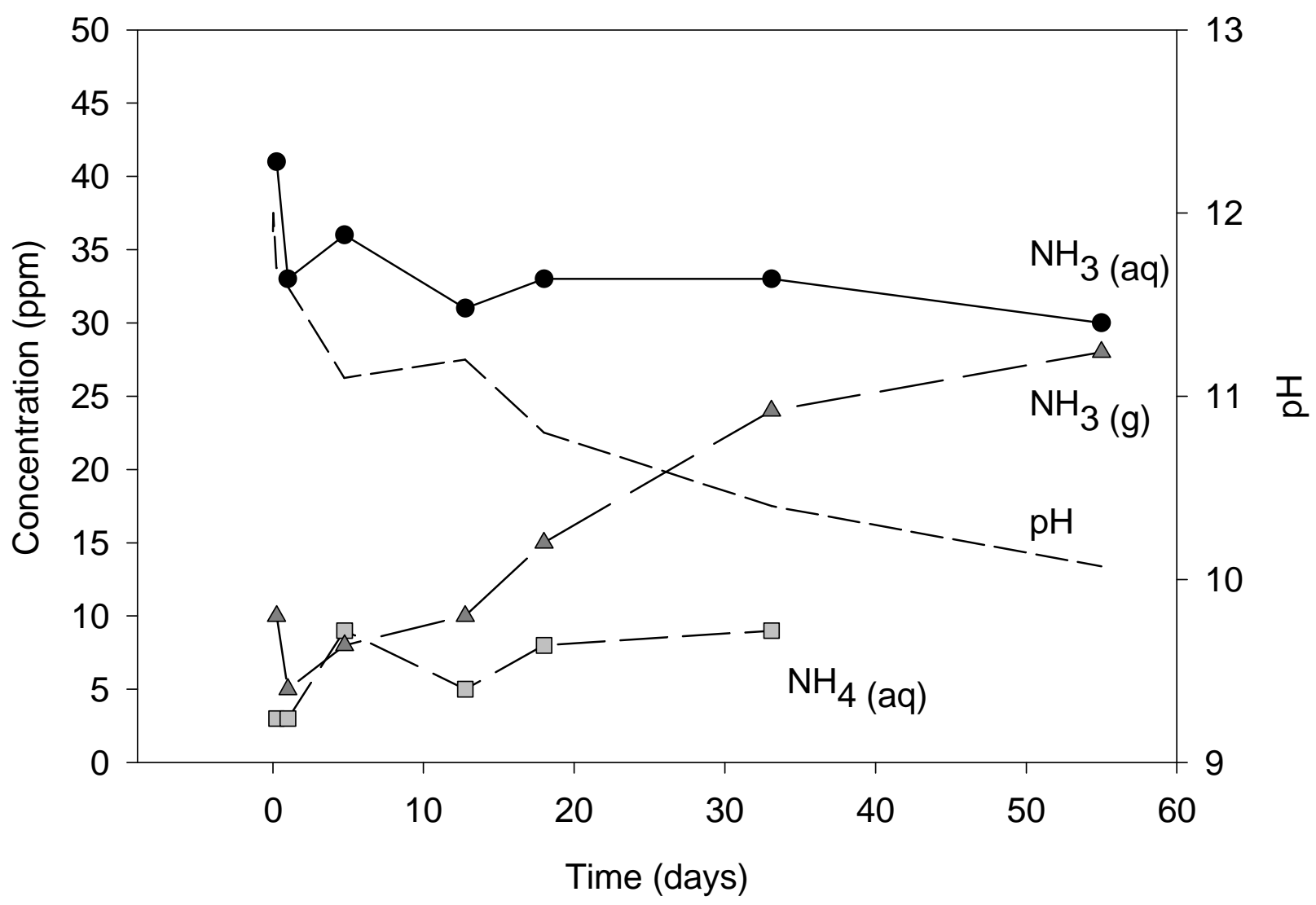

Figure 11. Ammonia release from fly ash "L" in distilled water under closed conditions. 


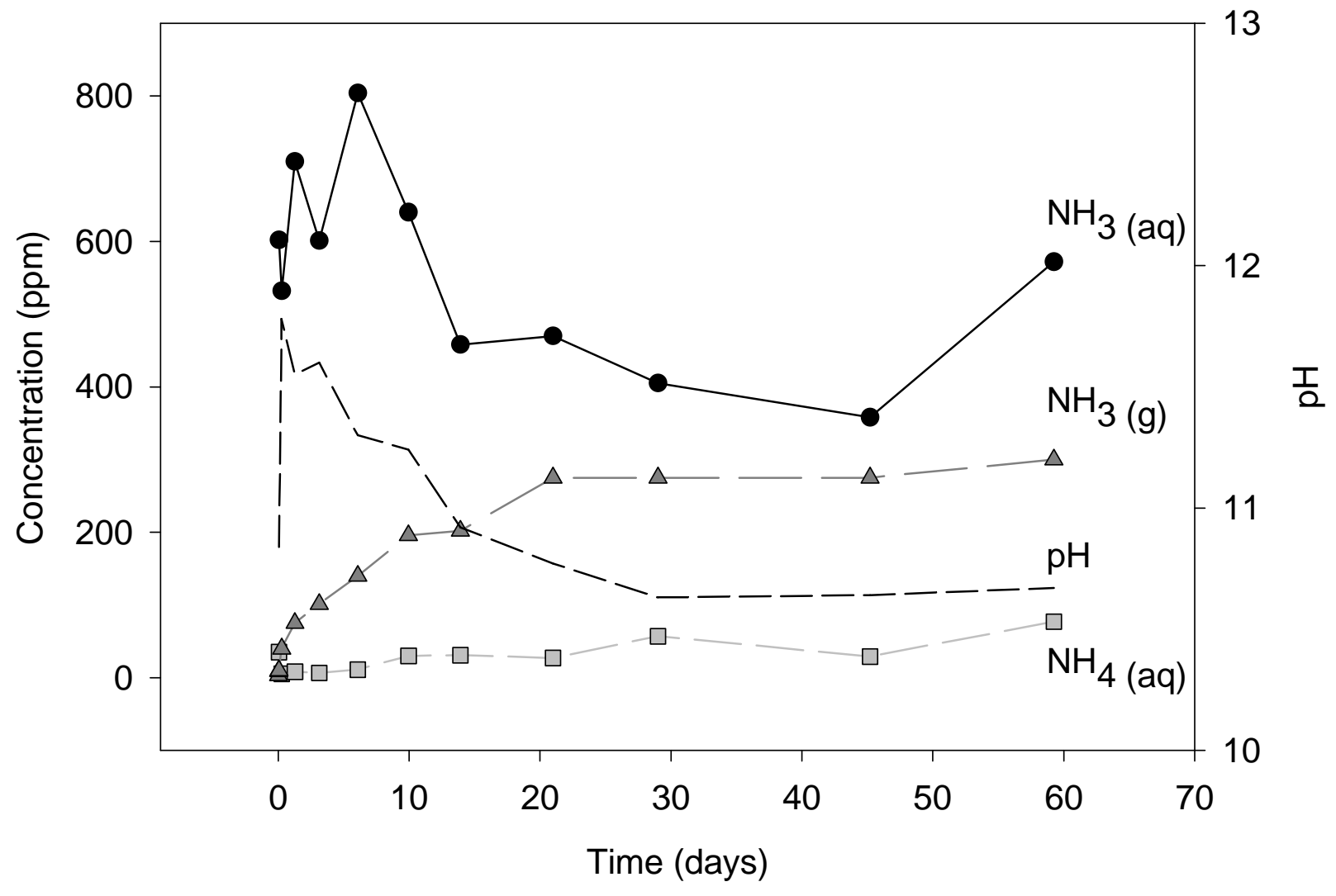

Figure 12. Ammonia release from fly ash "H" in distilled water under closed conditions. 


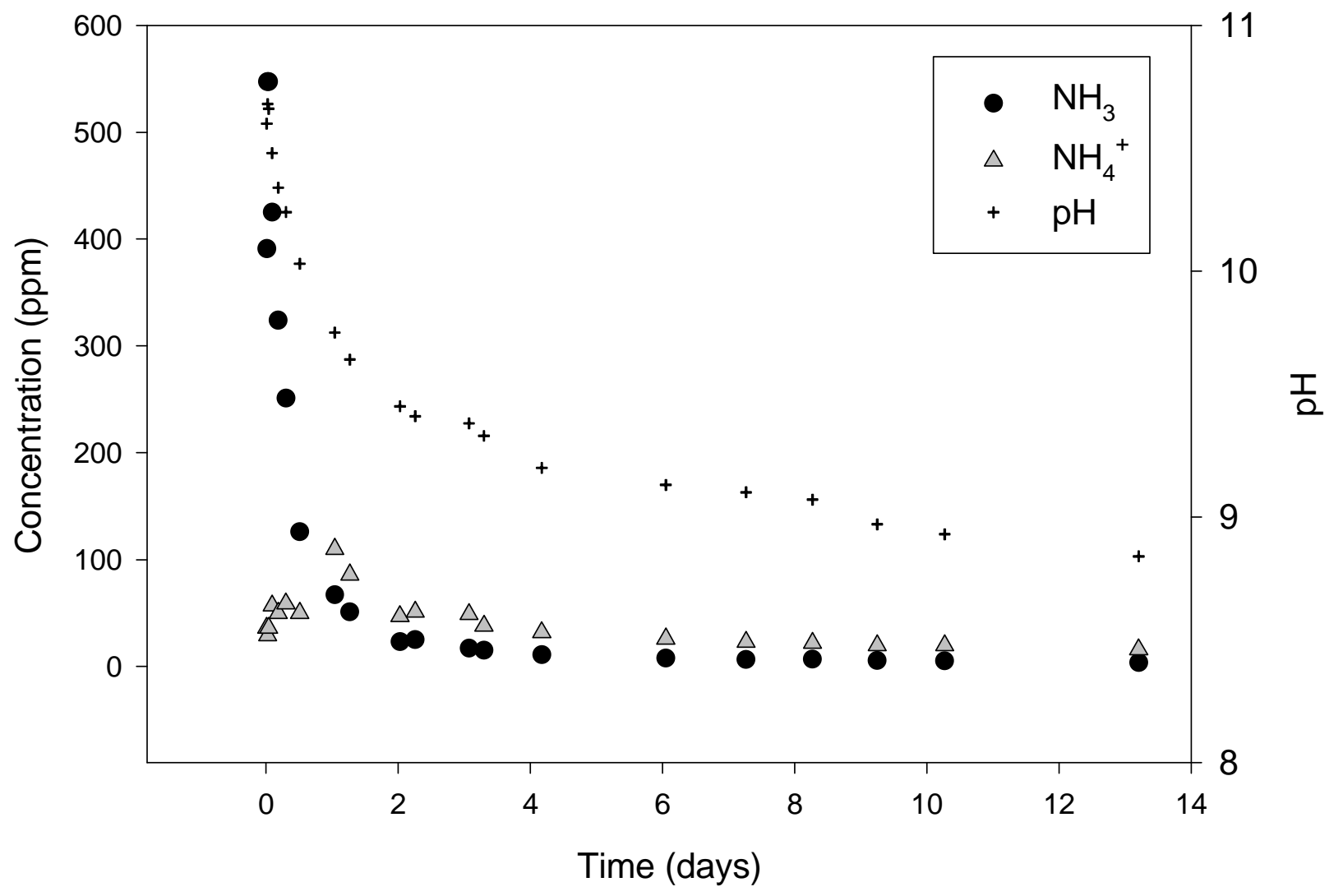

Figure 13. Ammonia release from fly ash "H" under open conditions at room temperature. 


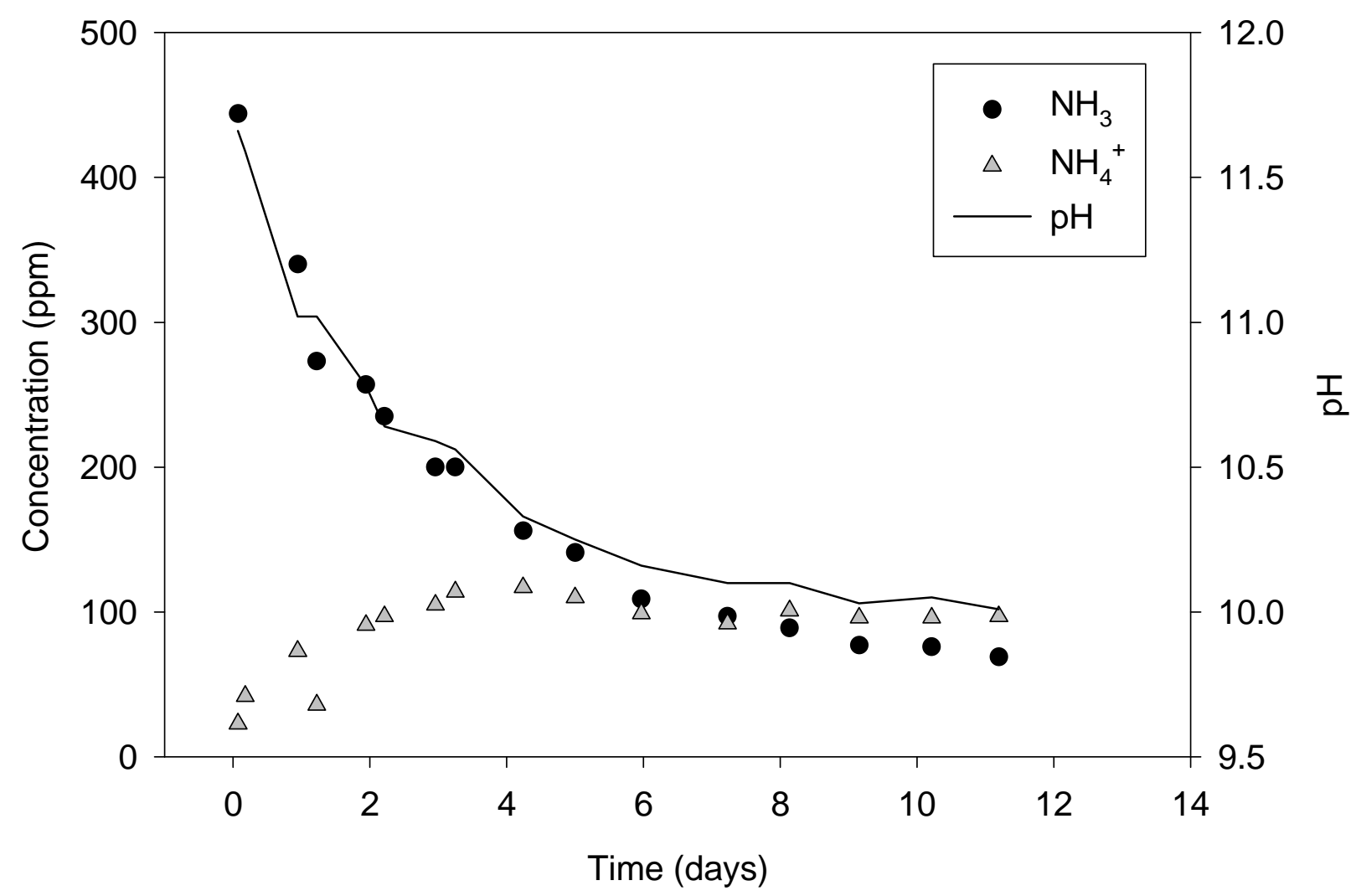

Figure 14. Ammonia release from fly ash "H" under open conditions at low temperature. 


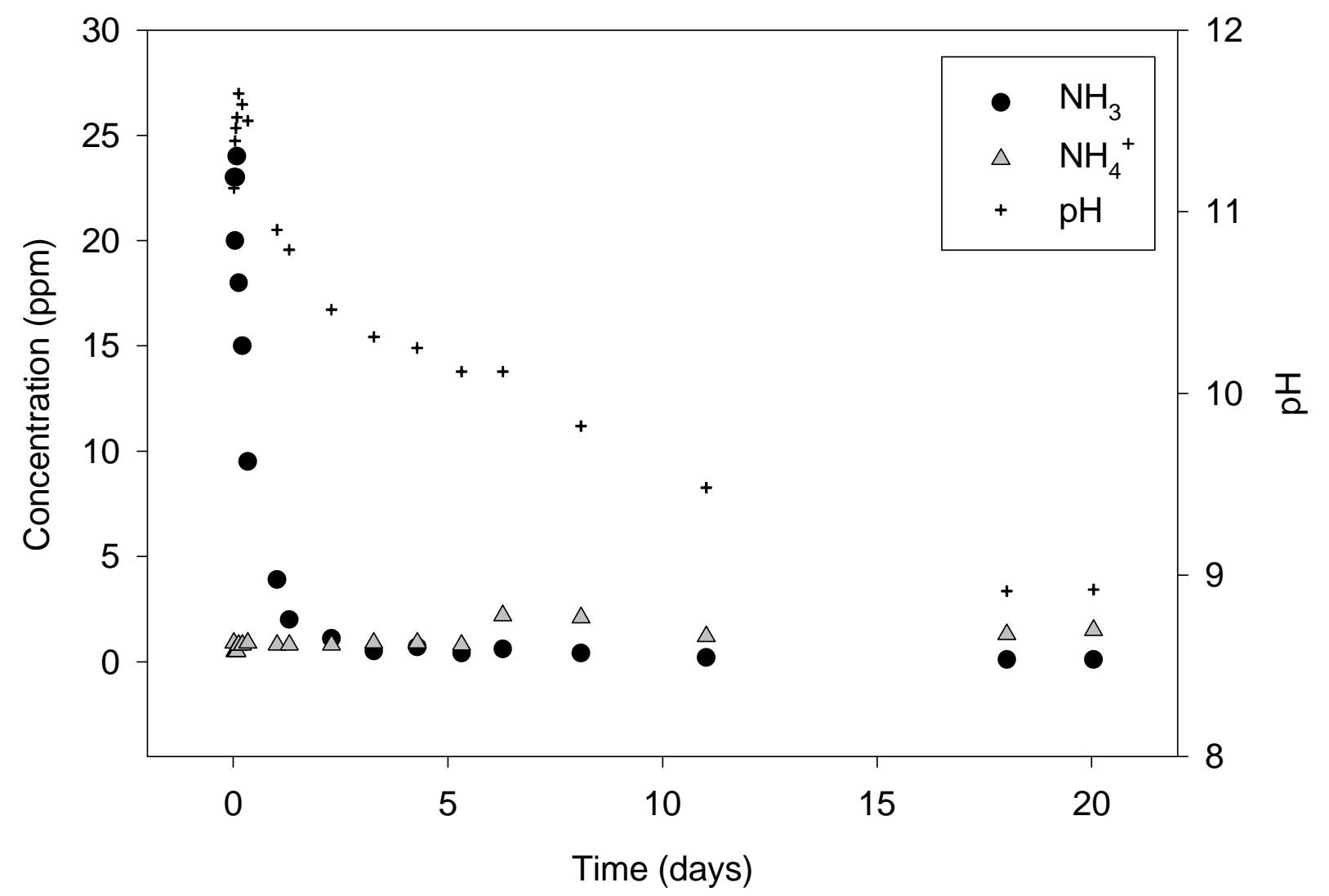

Figure 15. Ammonia release from fly ash "S" under open conditions at room temperature. 


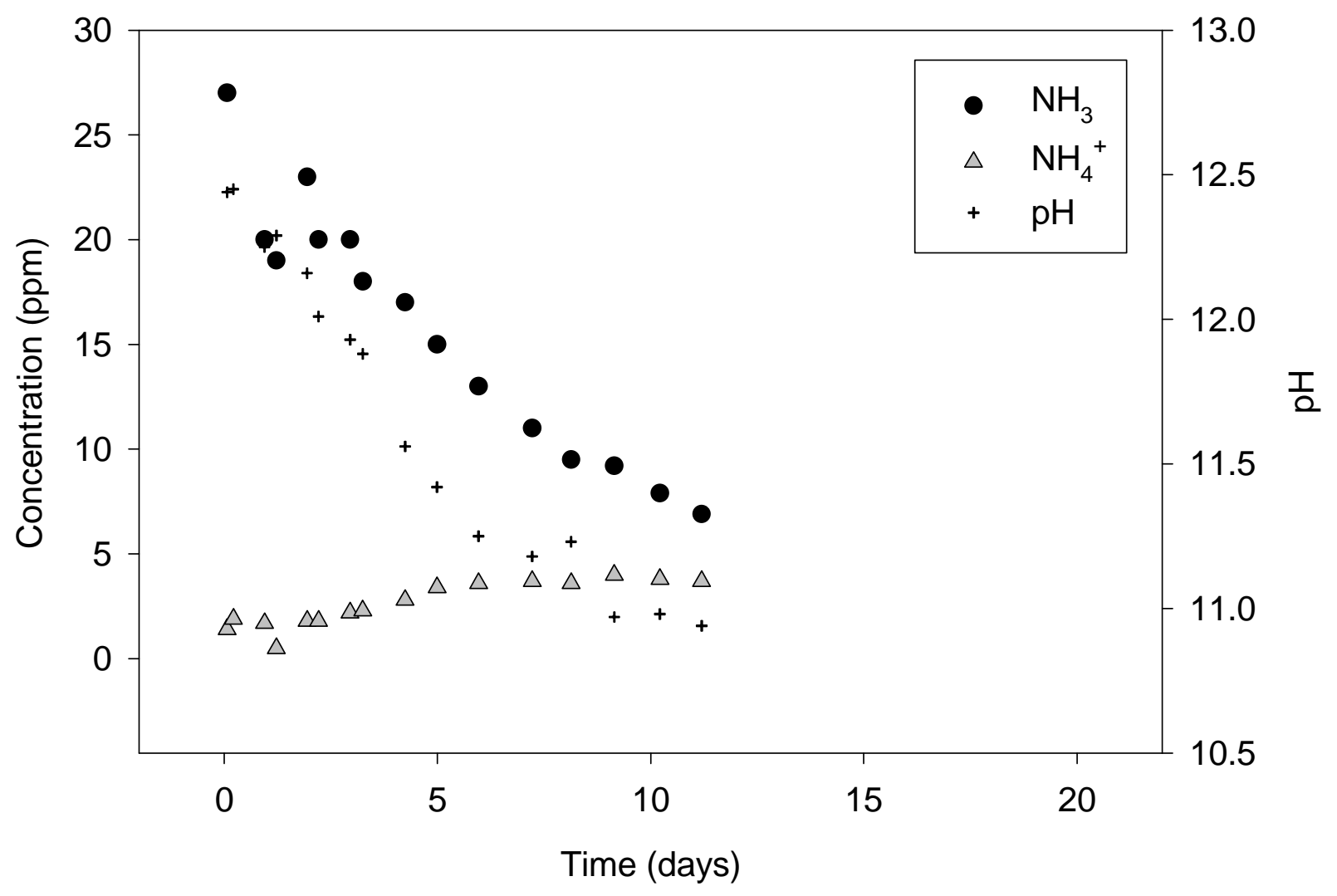

Figure 16. Ammonia release from fly ash "S" under open conditions at low temperature ( $\mathrm{x}$ axis scaled to correspond with room temperature experiment in Figure 15). 


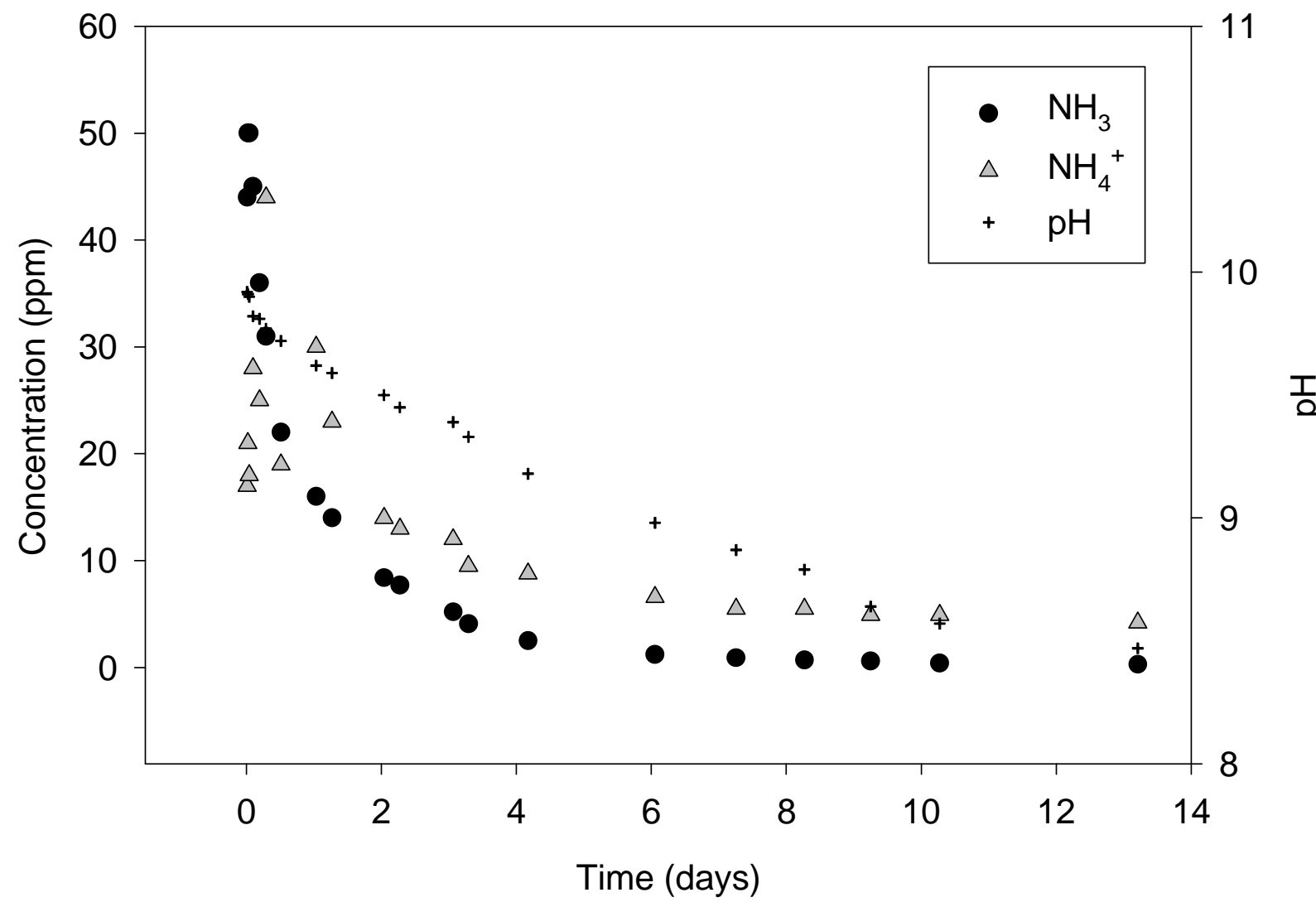

Figure 17. Ammonia release from fly ash "B" under open conditions at room temperature. 


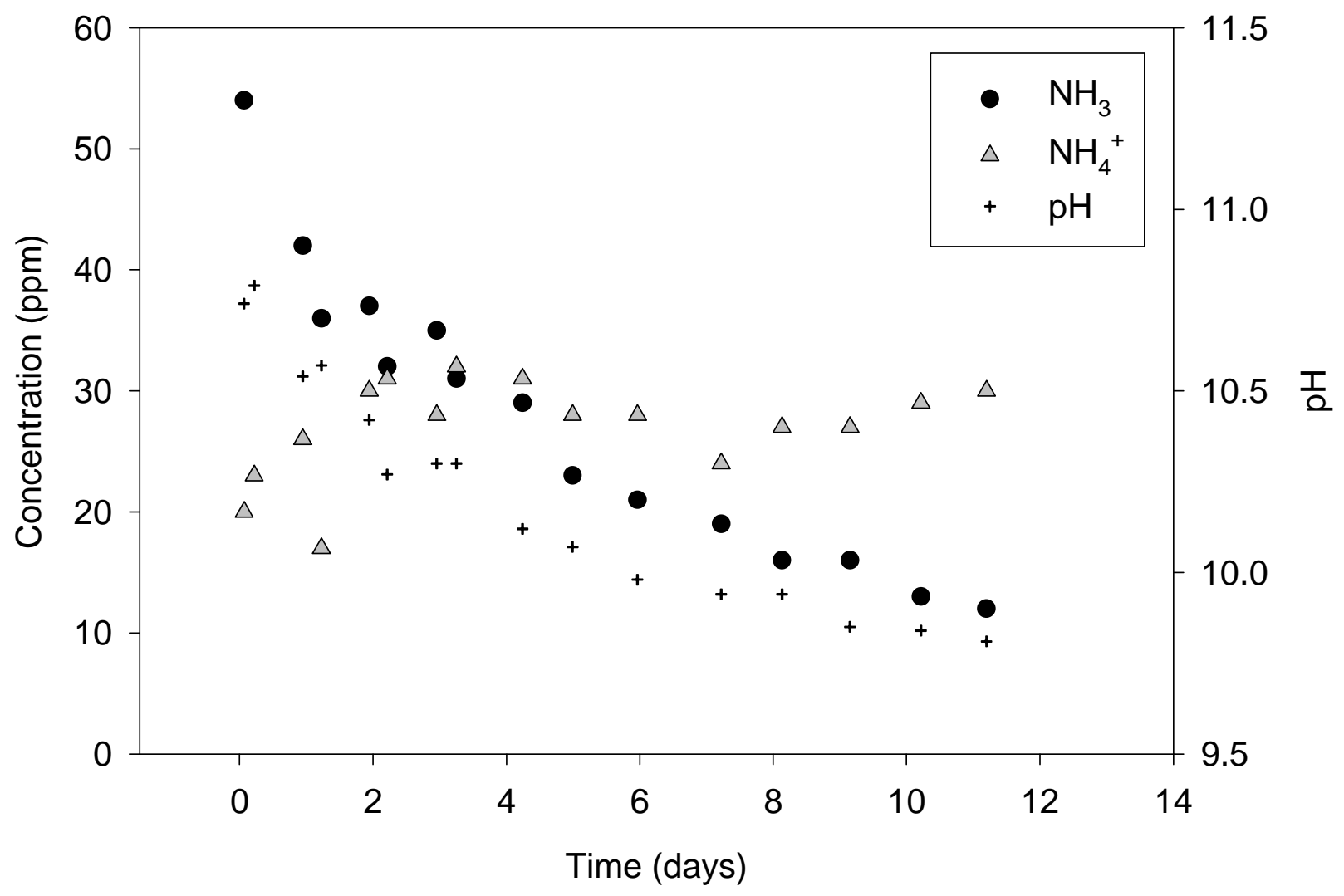

Figure 18. Ammonia release from fly ash "B" under open conditions at low temperature. 


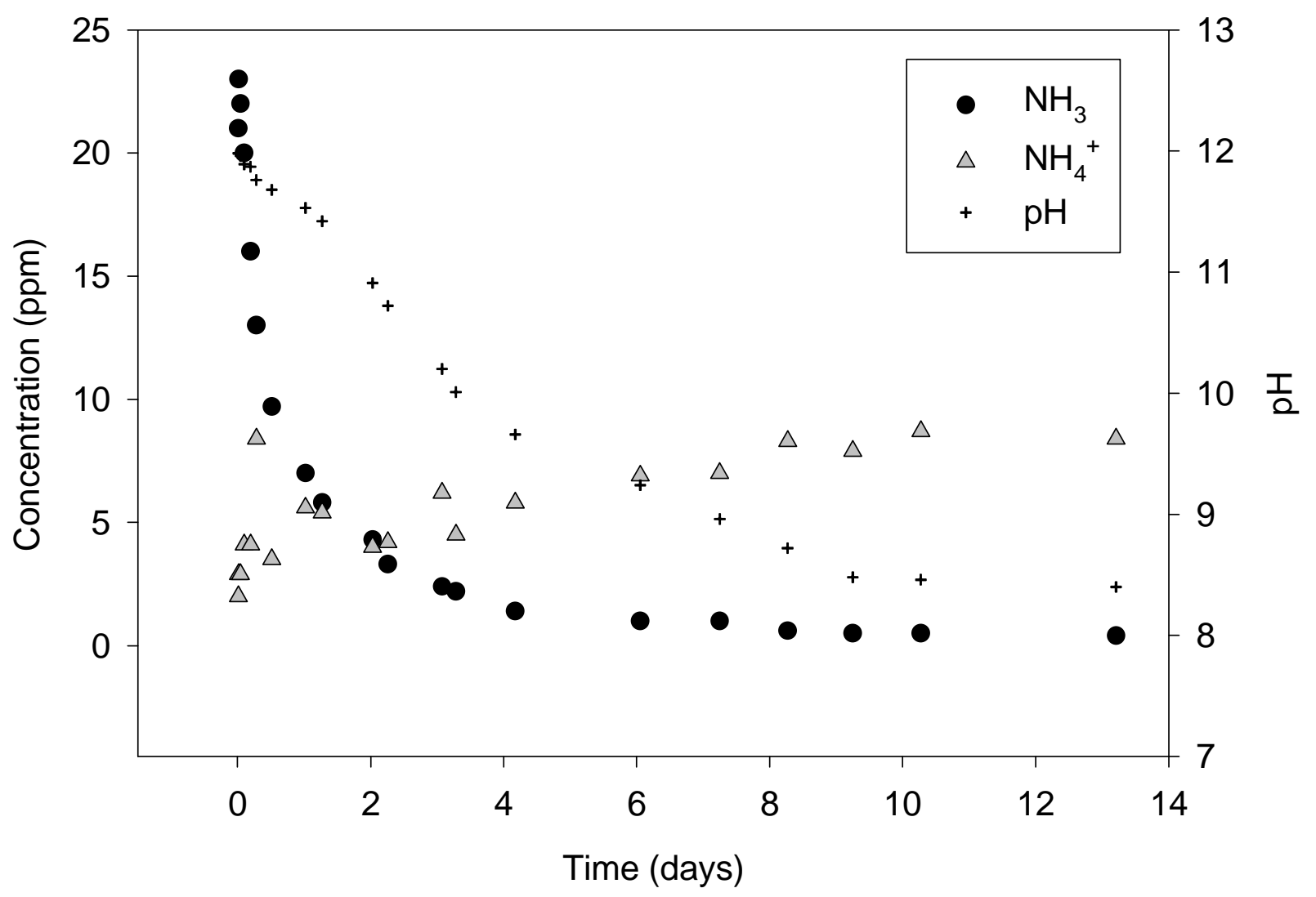

Figure 19. Ammonia release from fly ash "L" under open conditions at room temperature. 


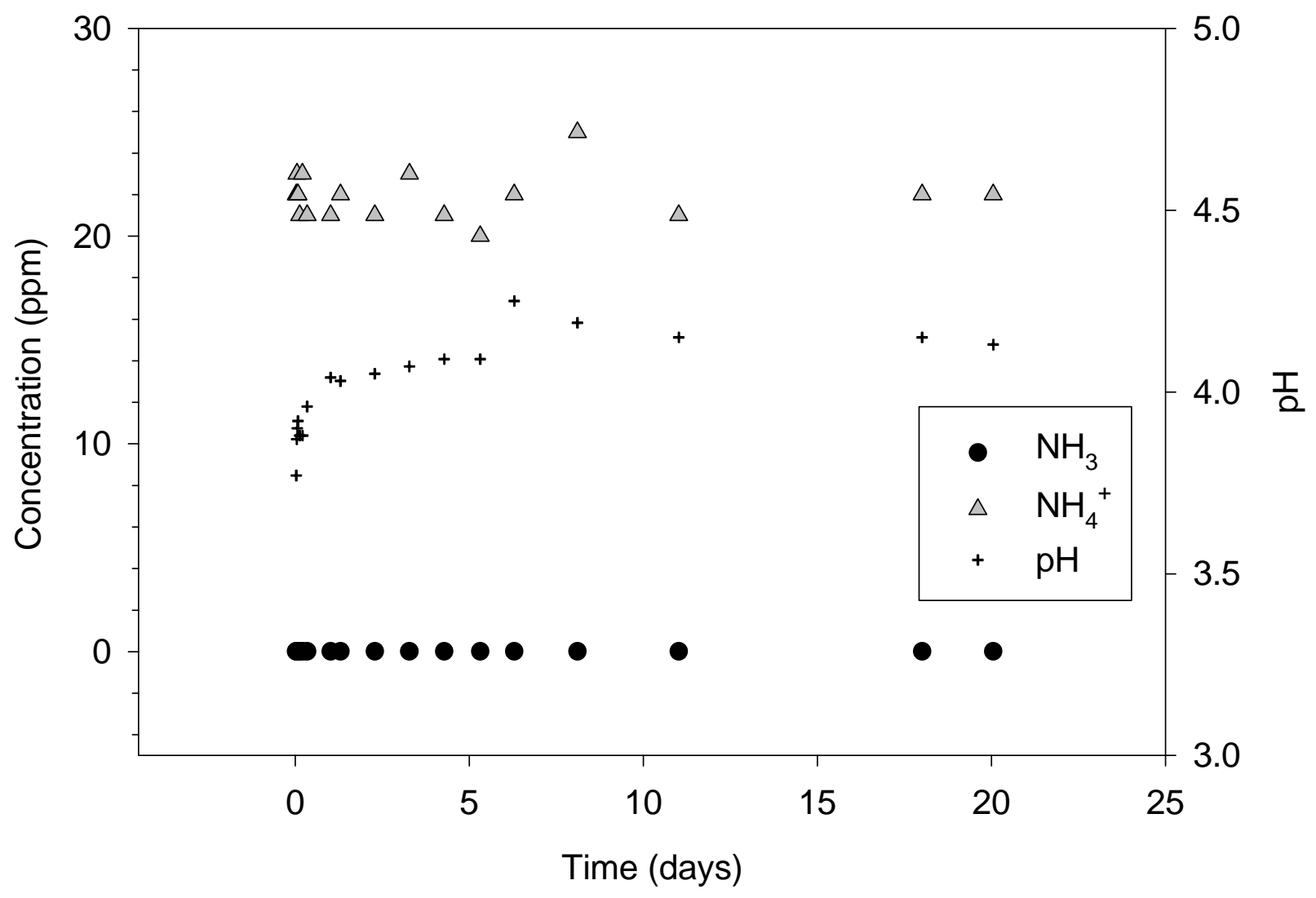

Figure 20. Ammonia release from fly ash "O" under open conditions at room temperature. 


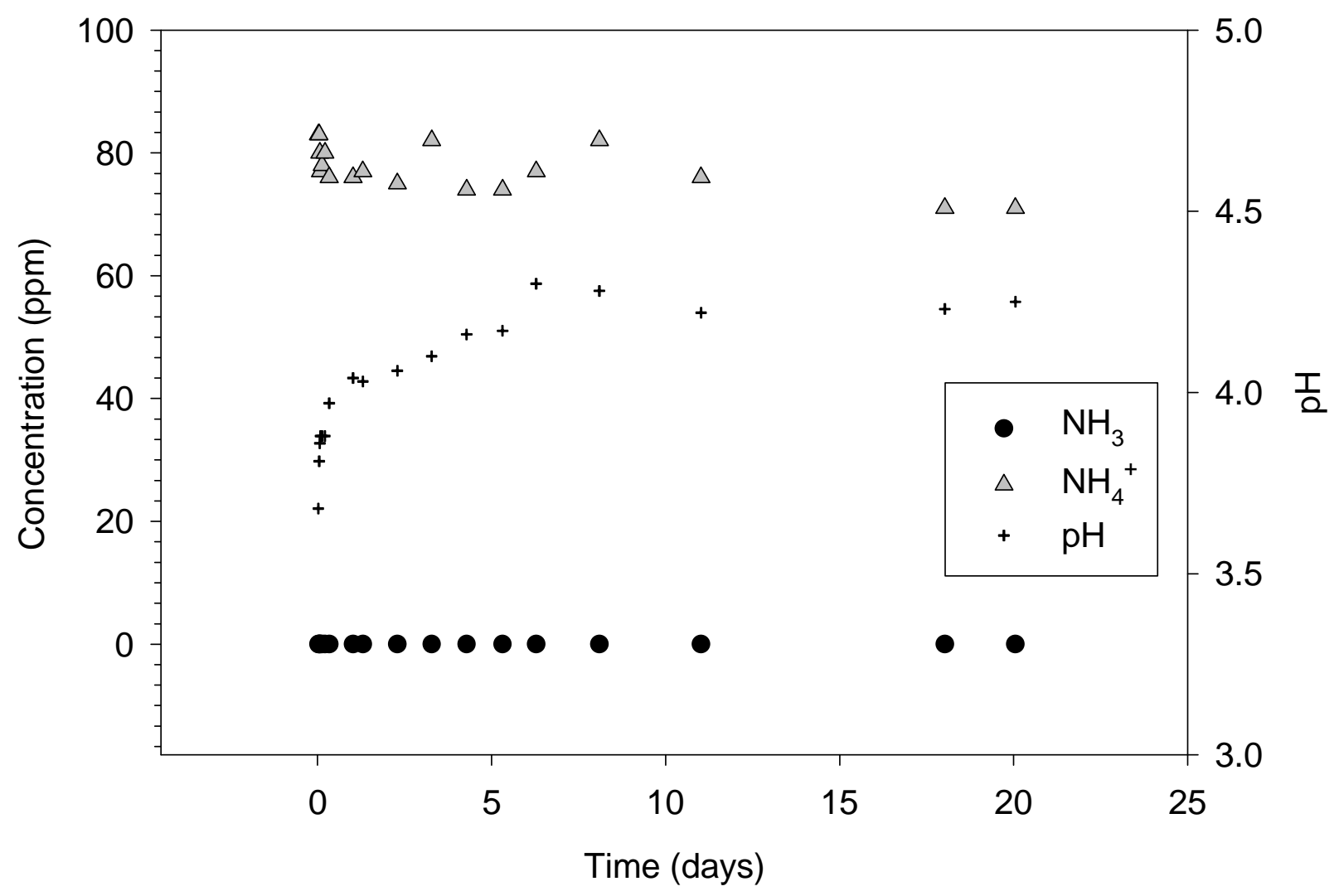

Figure 21. Ammonia release from a mixture of pre-SCR fly ash "C2" and water, to which approximately $67 \mathrm{mg} / \mathrm{L}$ (ppm) $\mathrm{NH}_{3}$ as $\left(\mathrm{NH}_{4}\right)_{2} \mathrm{SO}_{4}$ has been added, under open conditions at room temperature. 


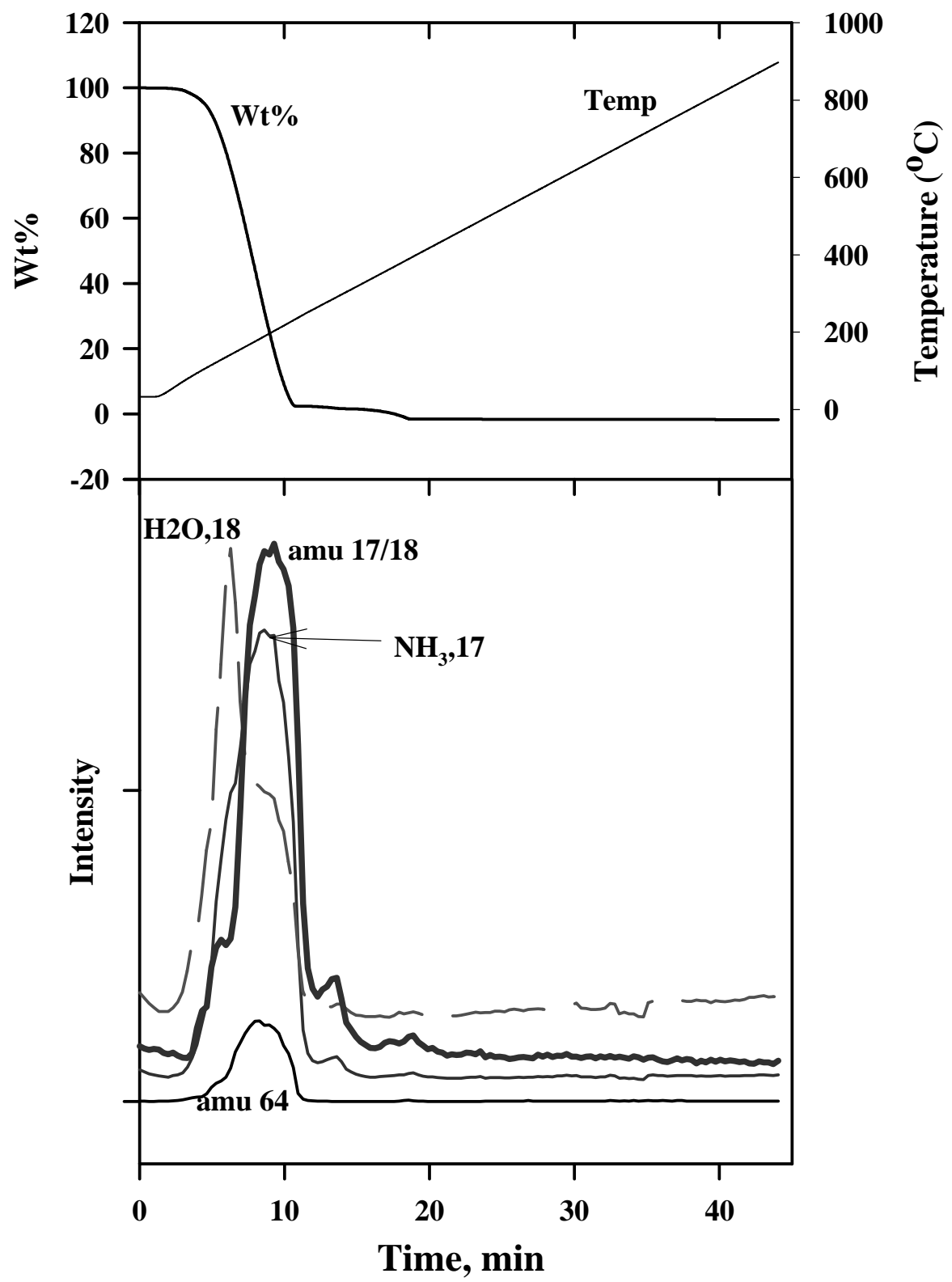

Figure 22. TG-MS results for ammonium sulfite in helium. 


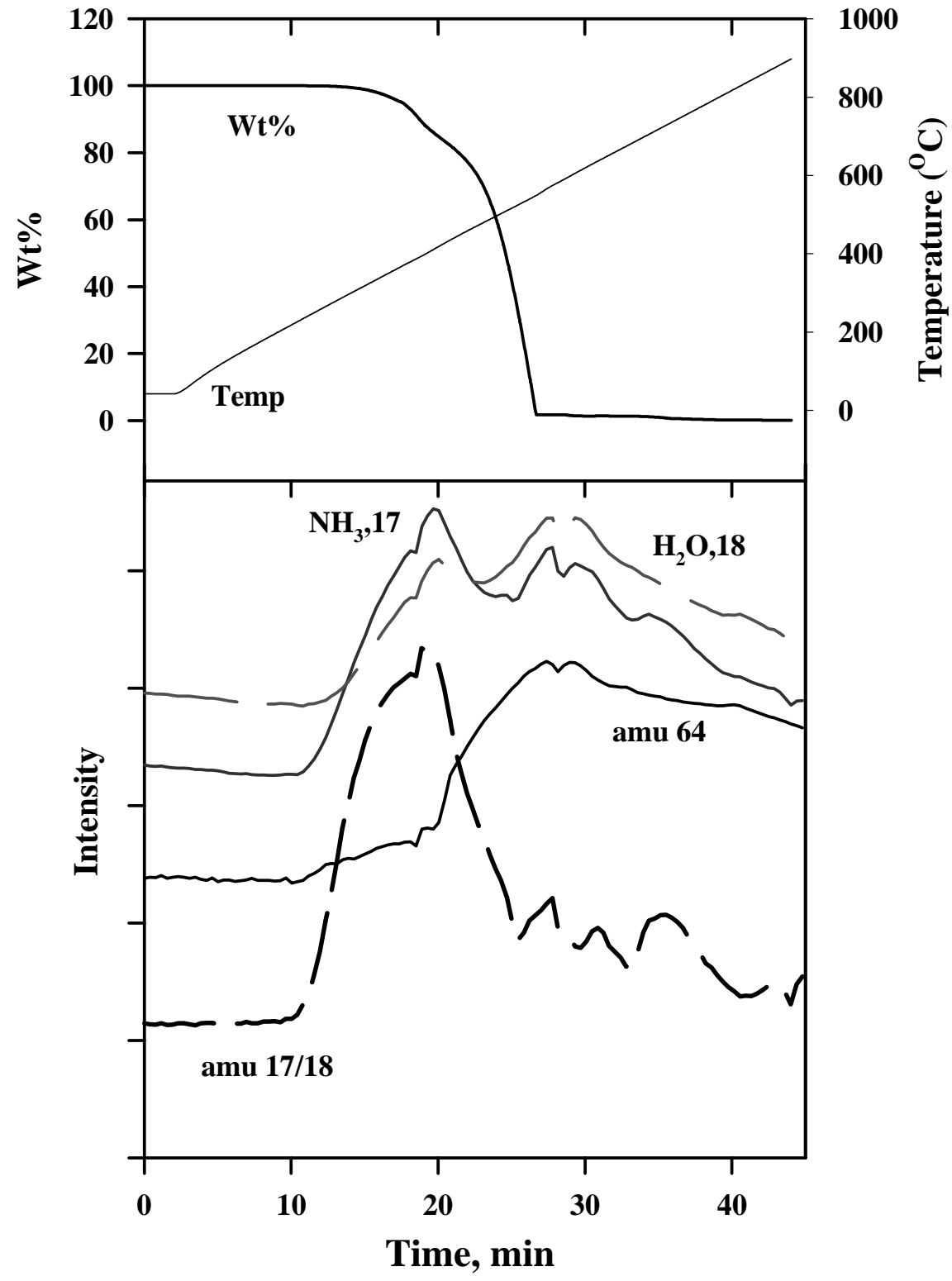

Figure 23. TG-MS results for ammonium sulfate in helium. 


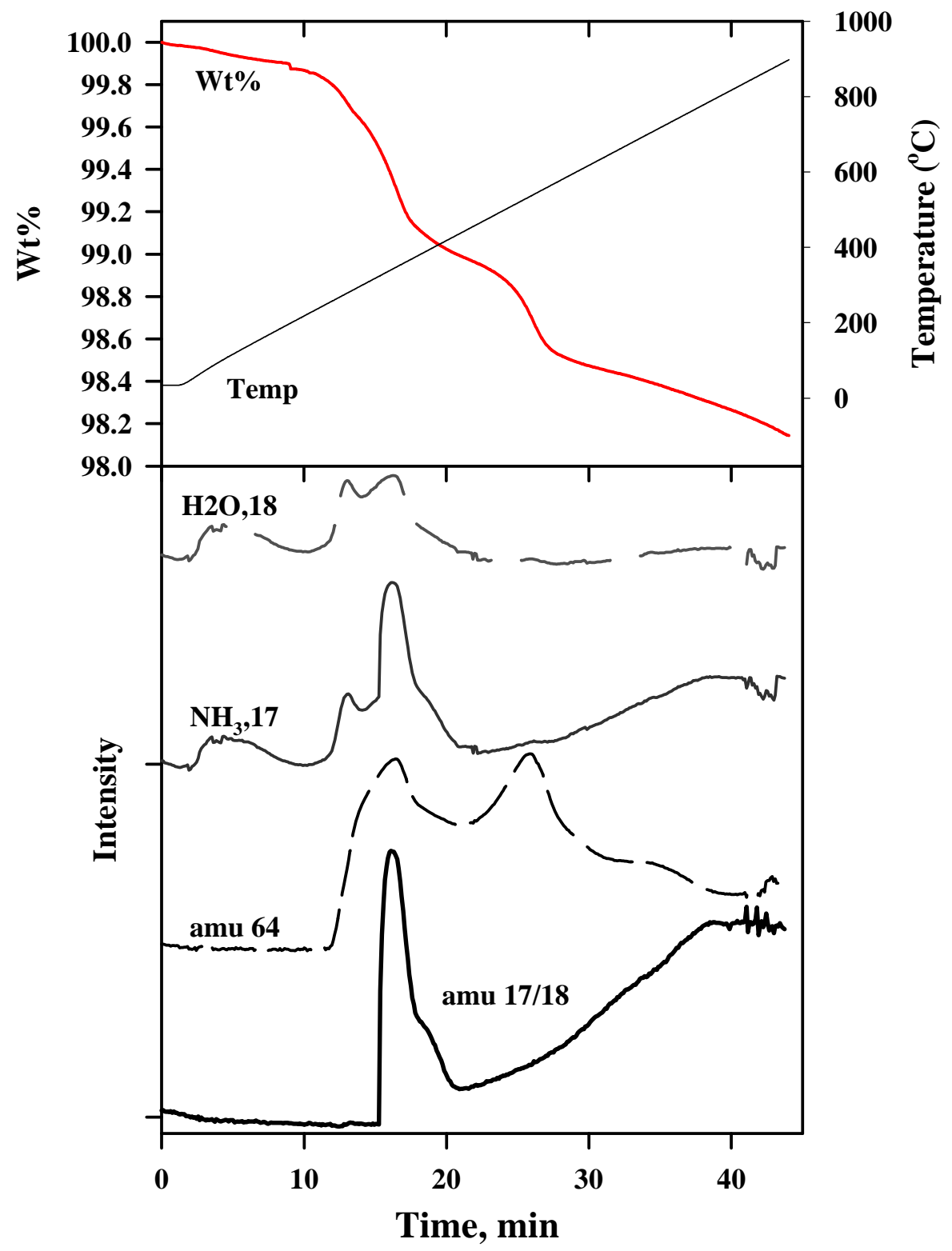

Figure 24. TG-MS results for ammonium sulfate and fly ash "MT" in helium. 


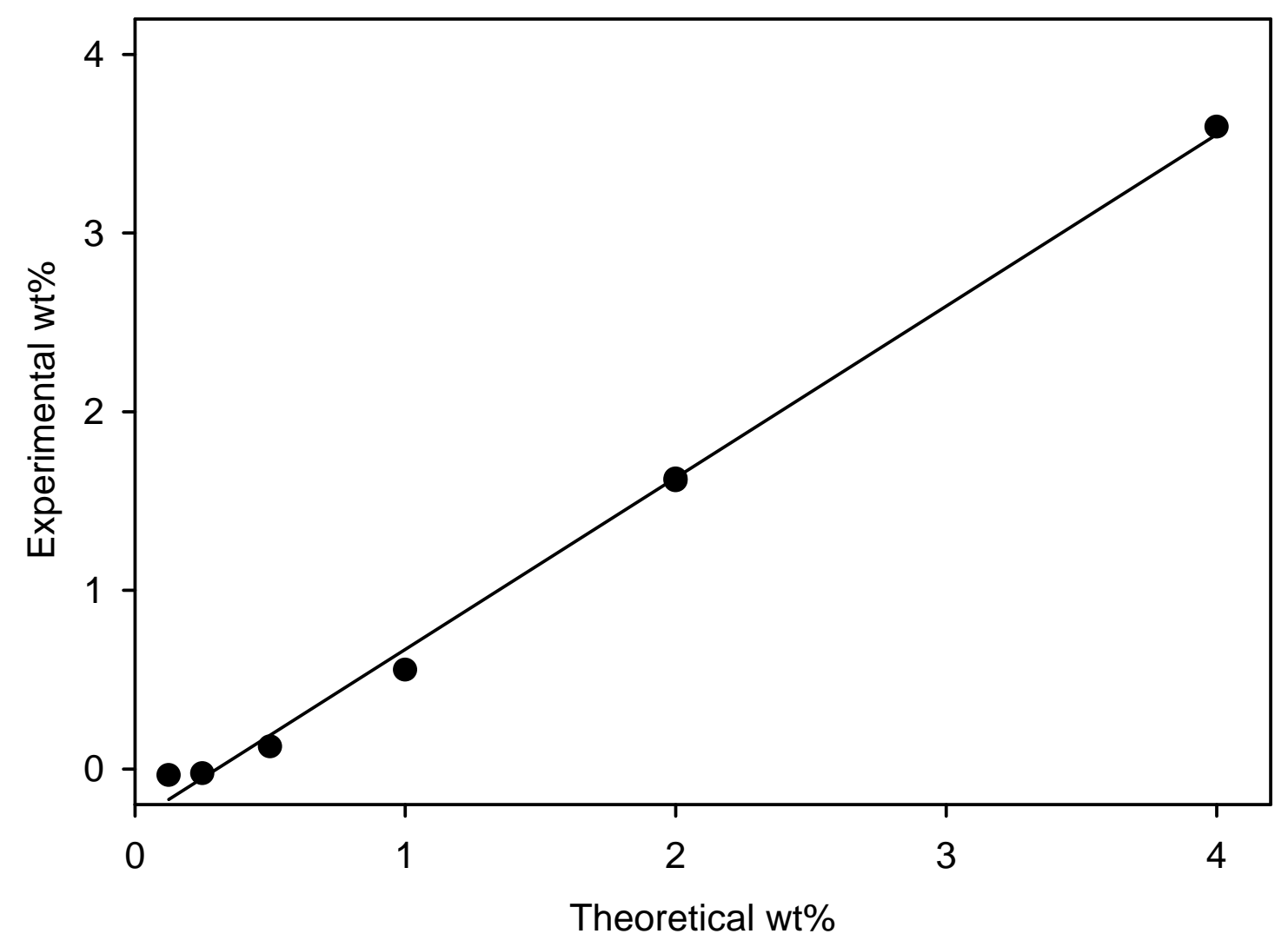

Figure 25. Theoretical weight loss vs. experimental weight loss for ammonium bicarbonate upon heating. 


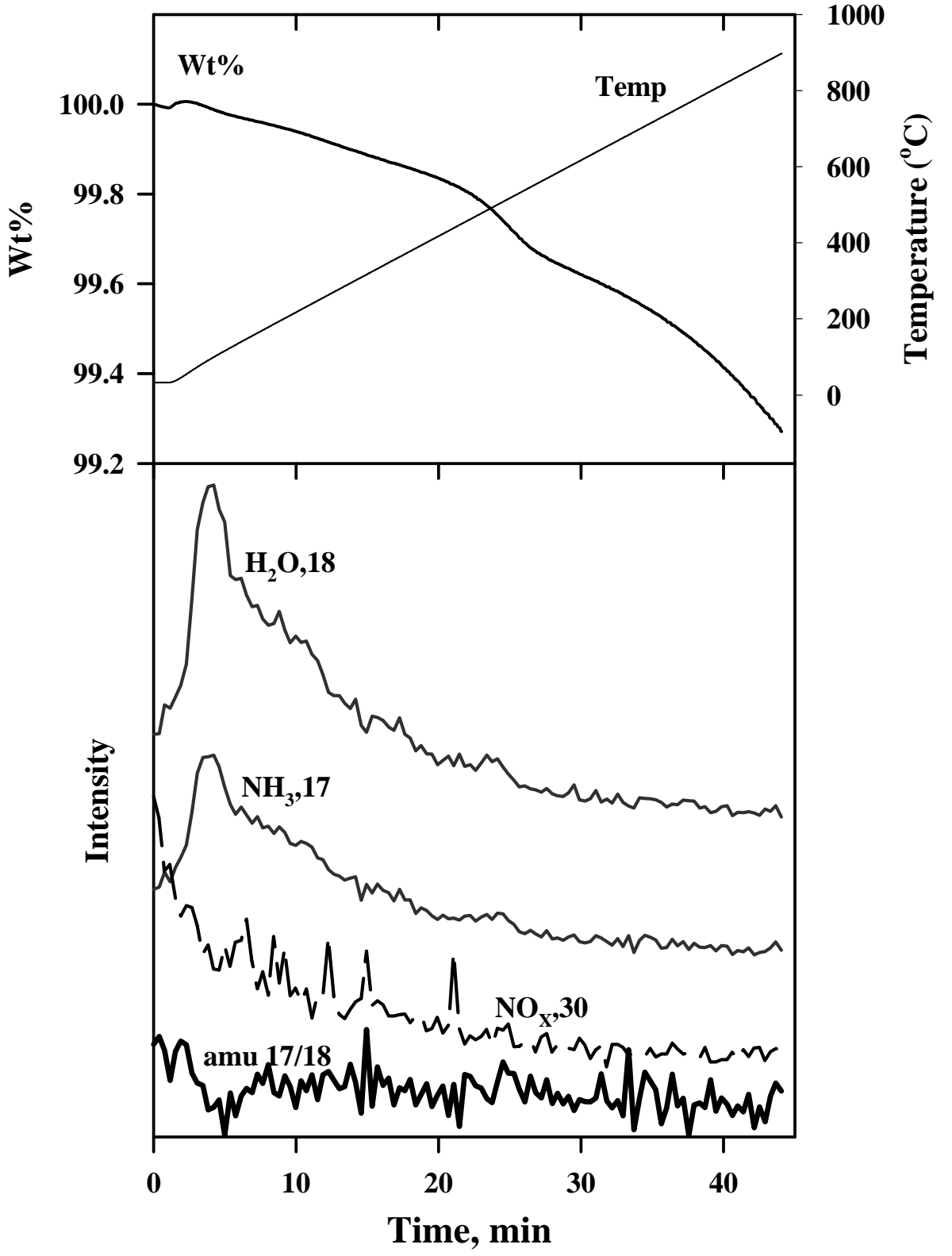

Figure 26. TG-MS spectra for fly ash "MT" heated in He atmosphere. 


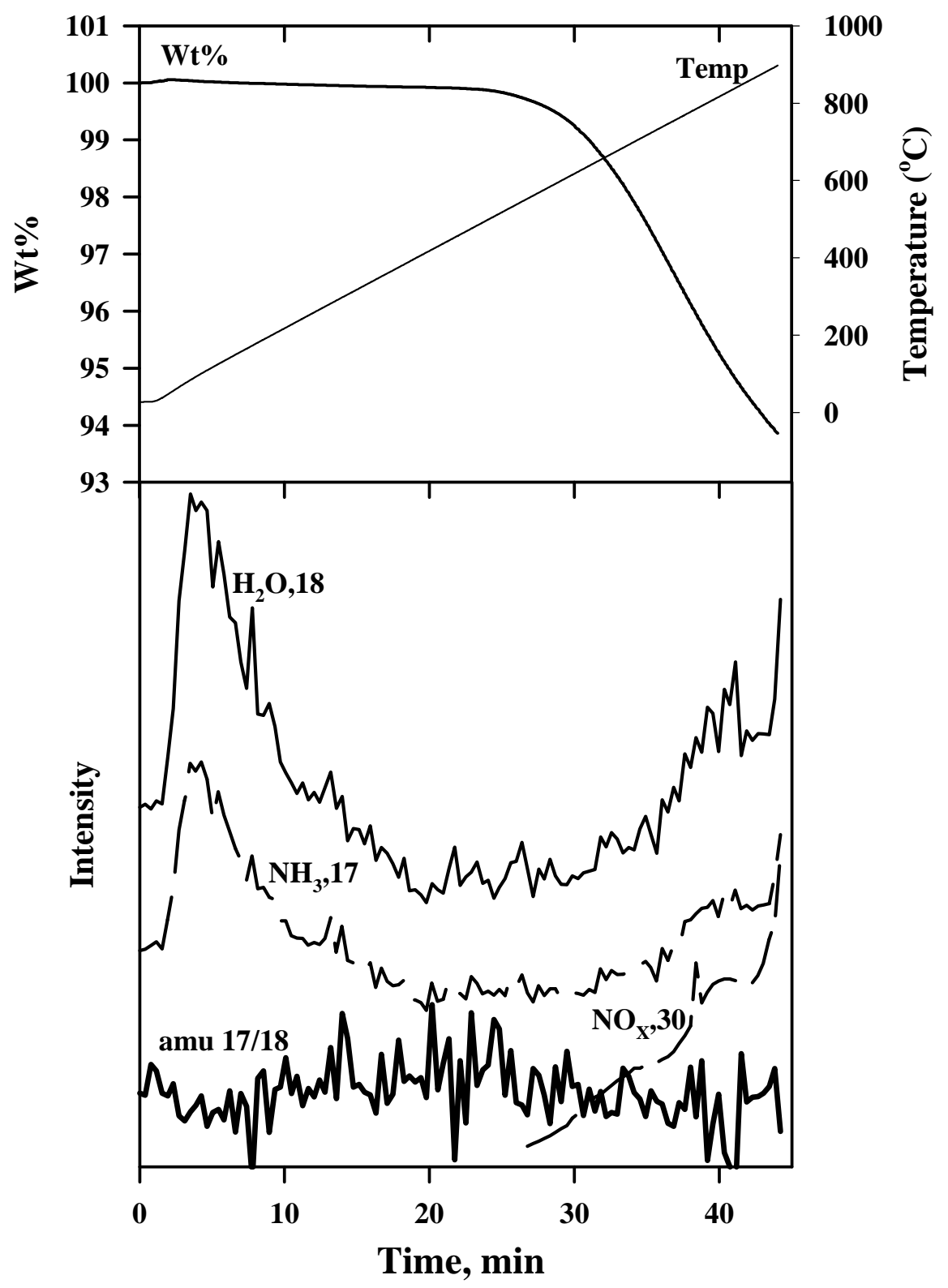

Figure 27. TG-MS spectra for fly ash "MT" heated in $\mathrm{He}-\mathrm{O}_{2}$ atmosphere. 


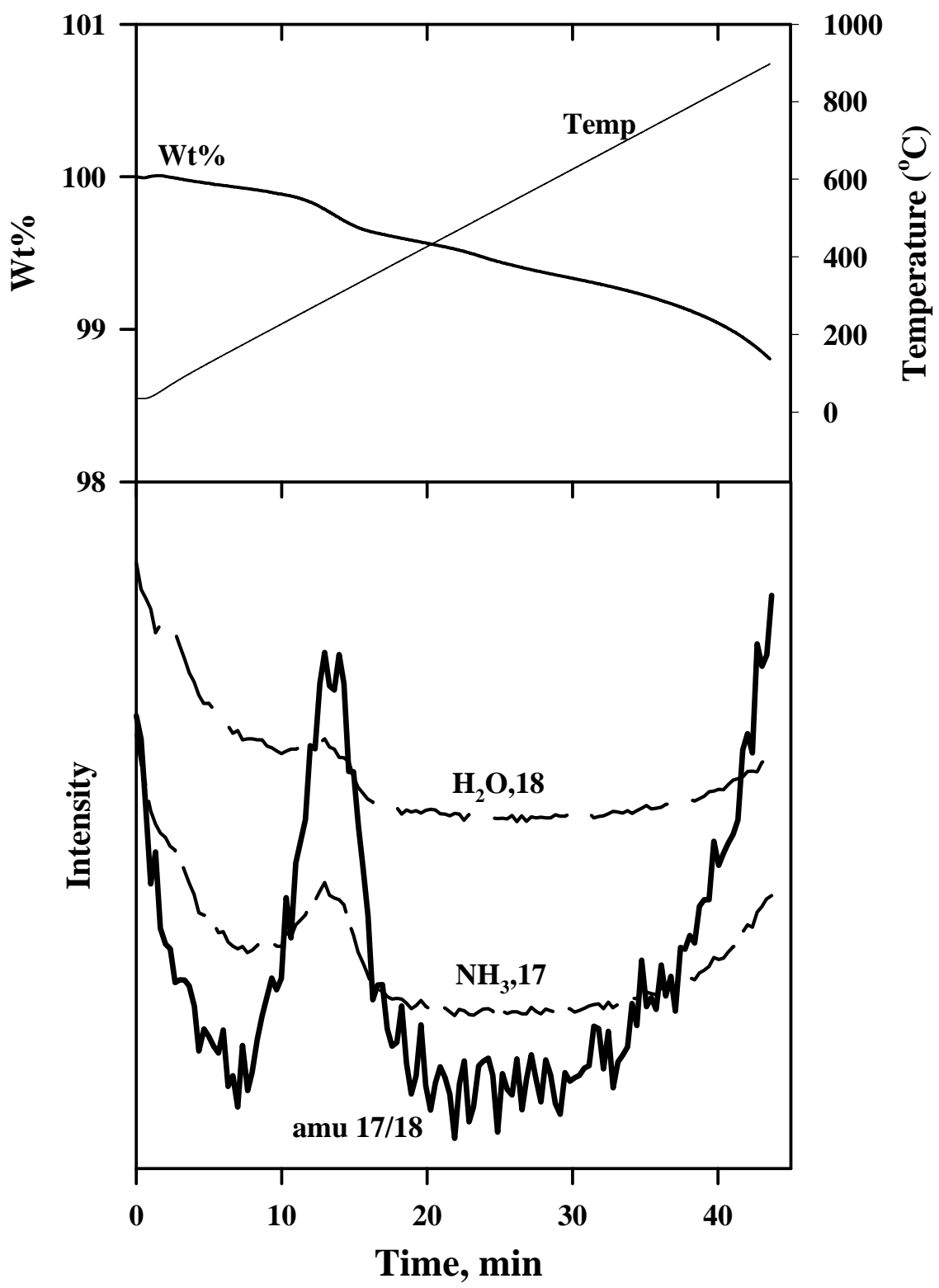

Figure 28. TG-MS spectra for fly ash "H" heated in He atmosphere. 


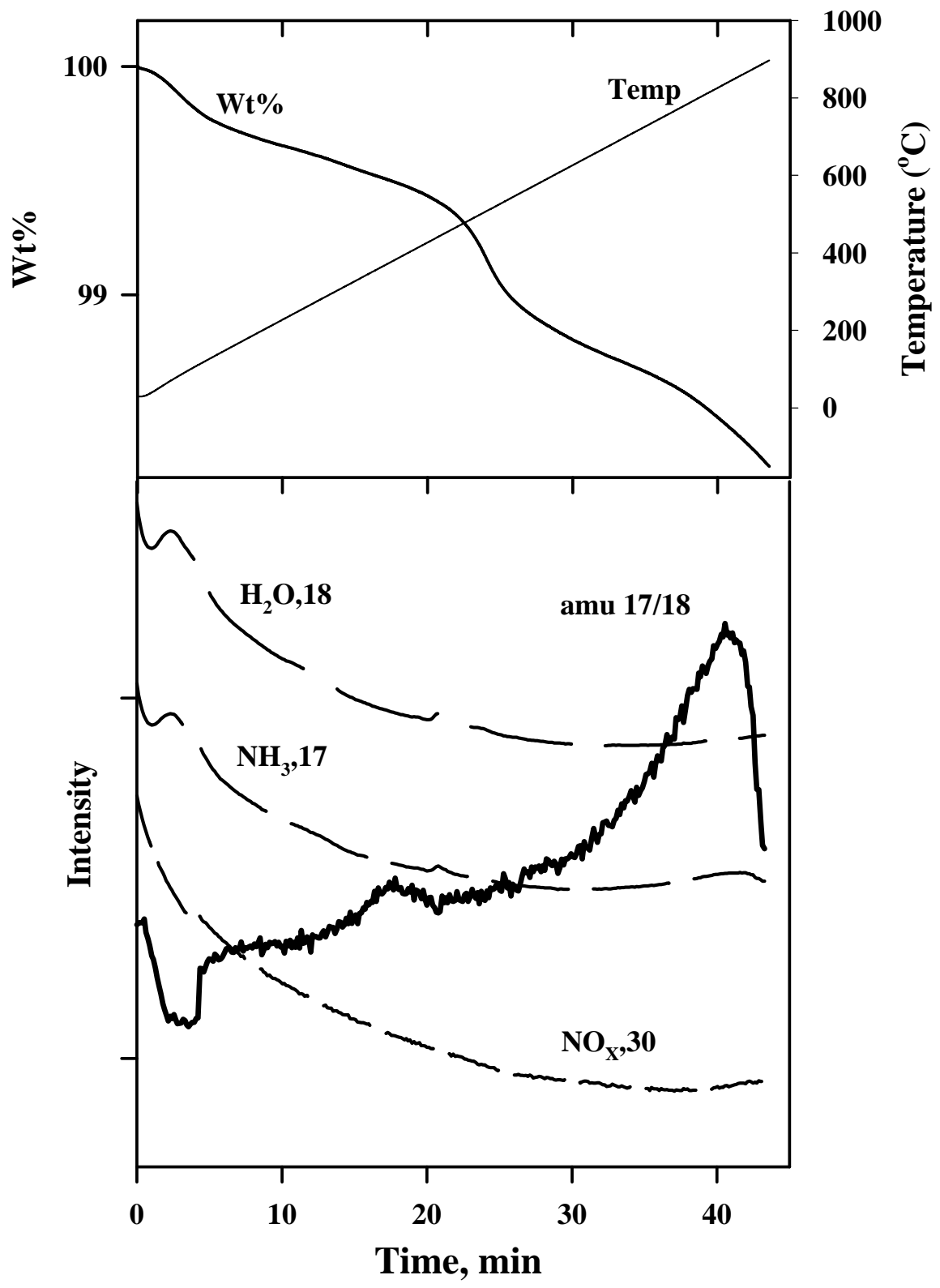

Figure 29. TG-MS spectra for fly ash "O" heated in He atmosphere. 


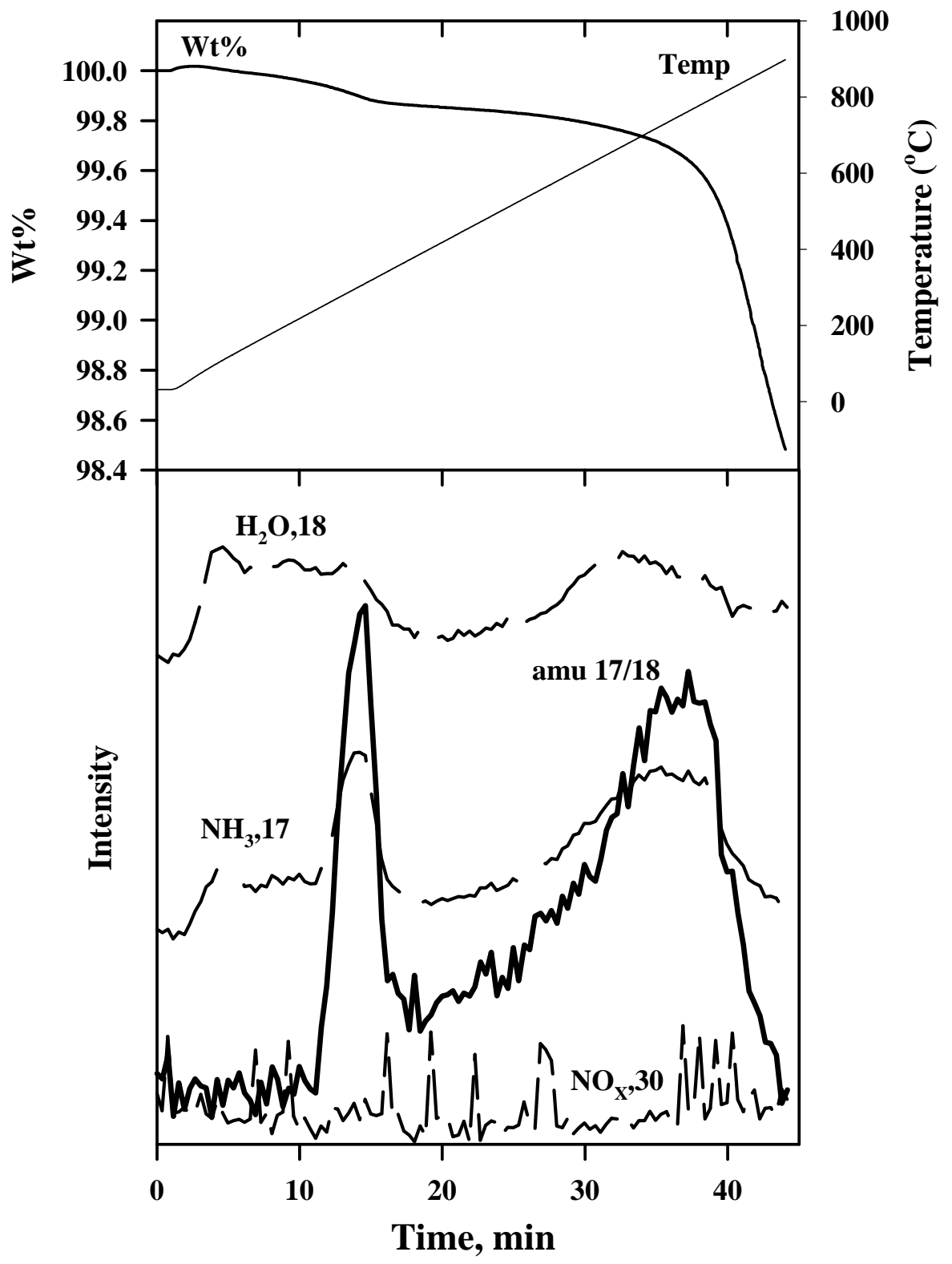

Figure 30. TG-MS spectra for fly ash "W" heated in He atmosphere. 


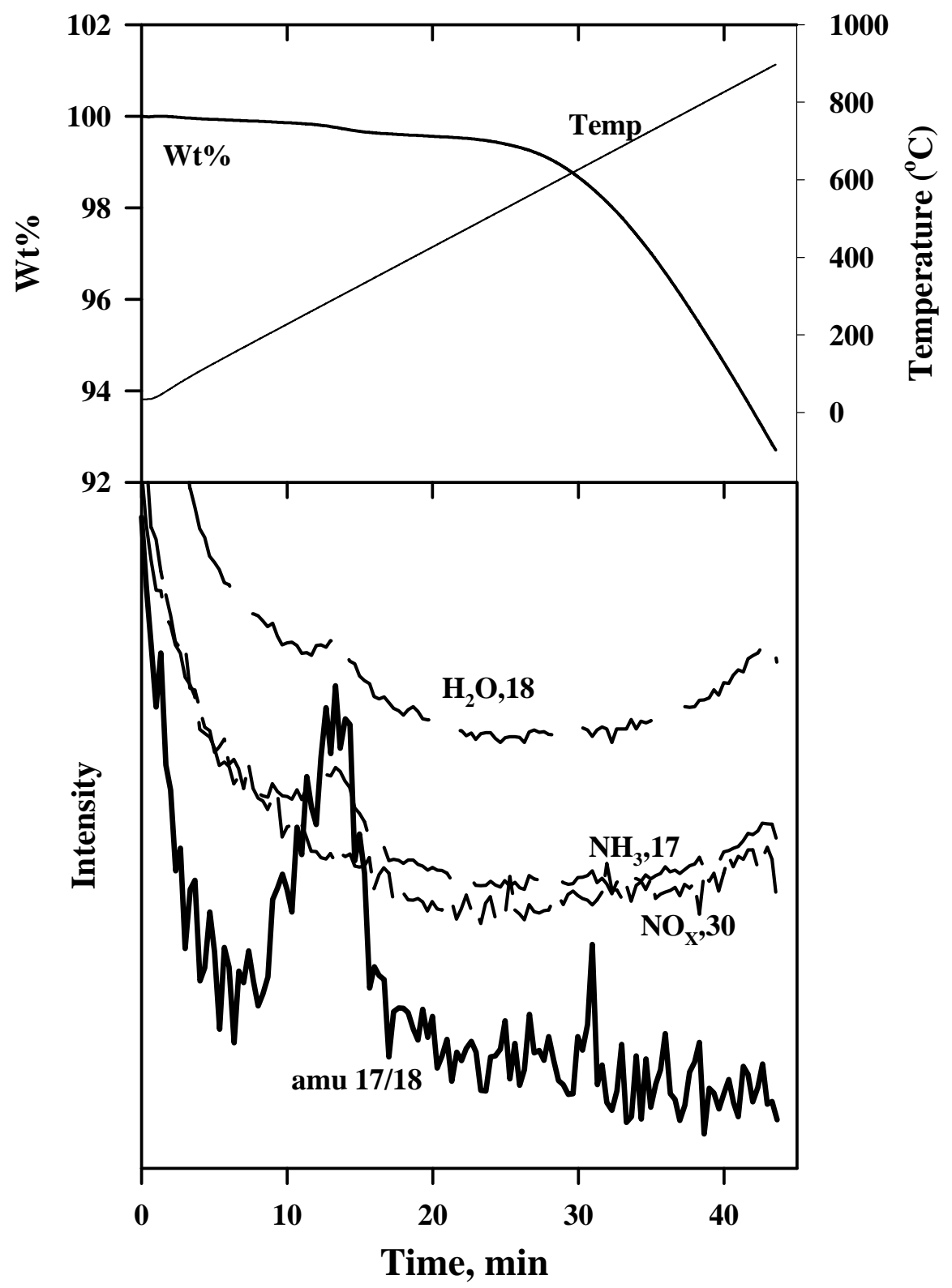

Figure 31. TG-MS spectra for fly ash "H" heated in $\mathrm{He}-\mathrm{O}_{2}$ atmosphere. 


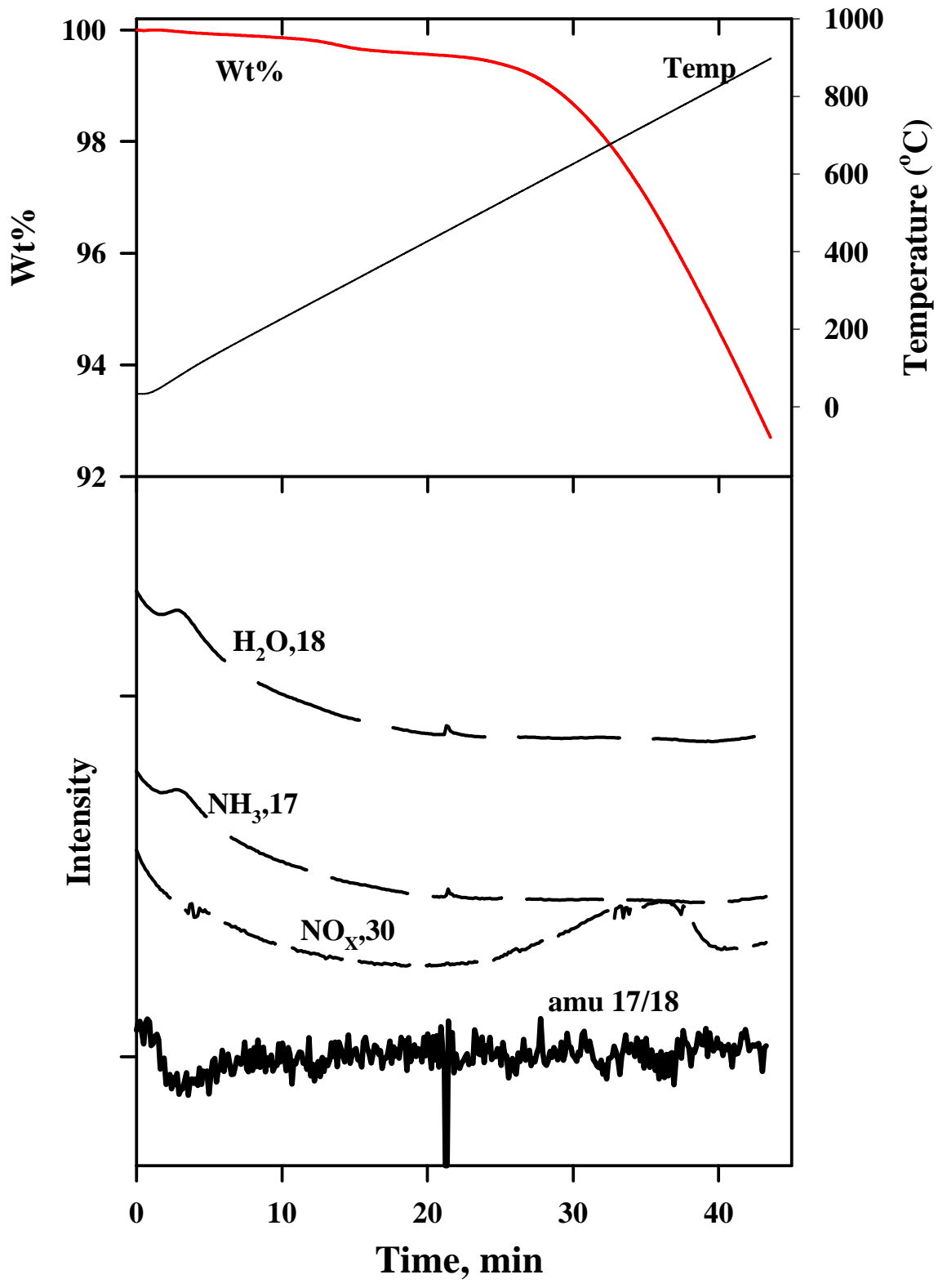

Figure 32. TG-MS spectra for fly ash "O" heated in $\mathrm{He}-\mathrm{O}_{2}$ atmosphere. 


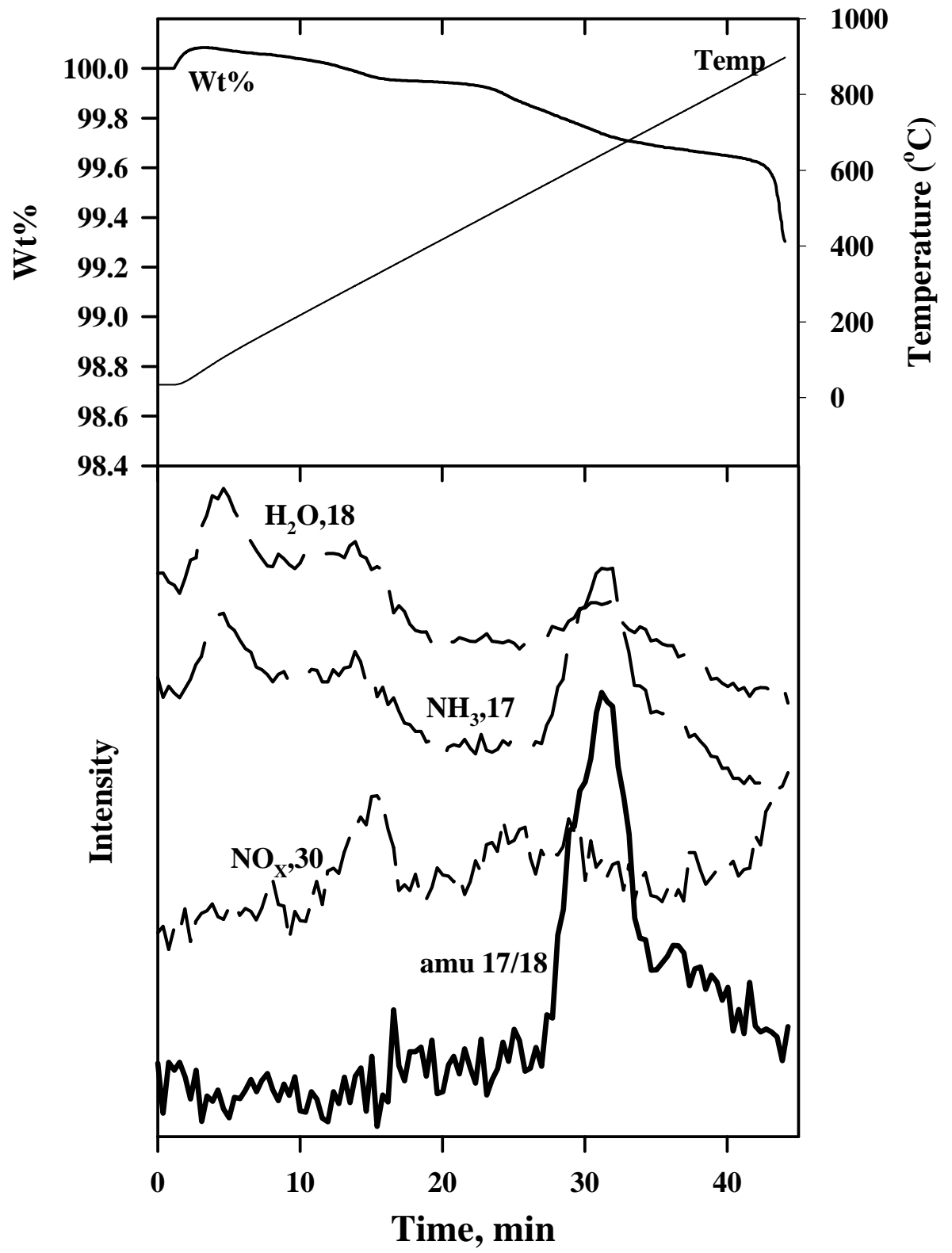

Figure 33. TG-MS spectra for fly ash "W" heated in $\mathrm{He}-\mathrm{O}_{2}$ atmosphere. 


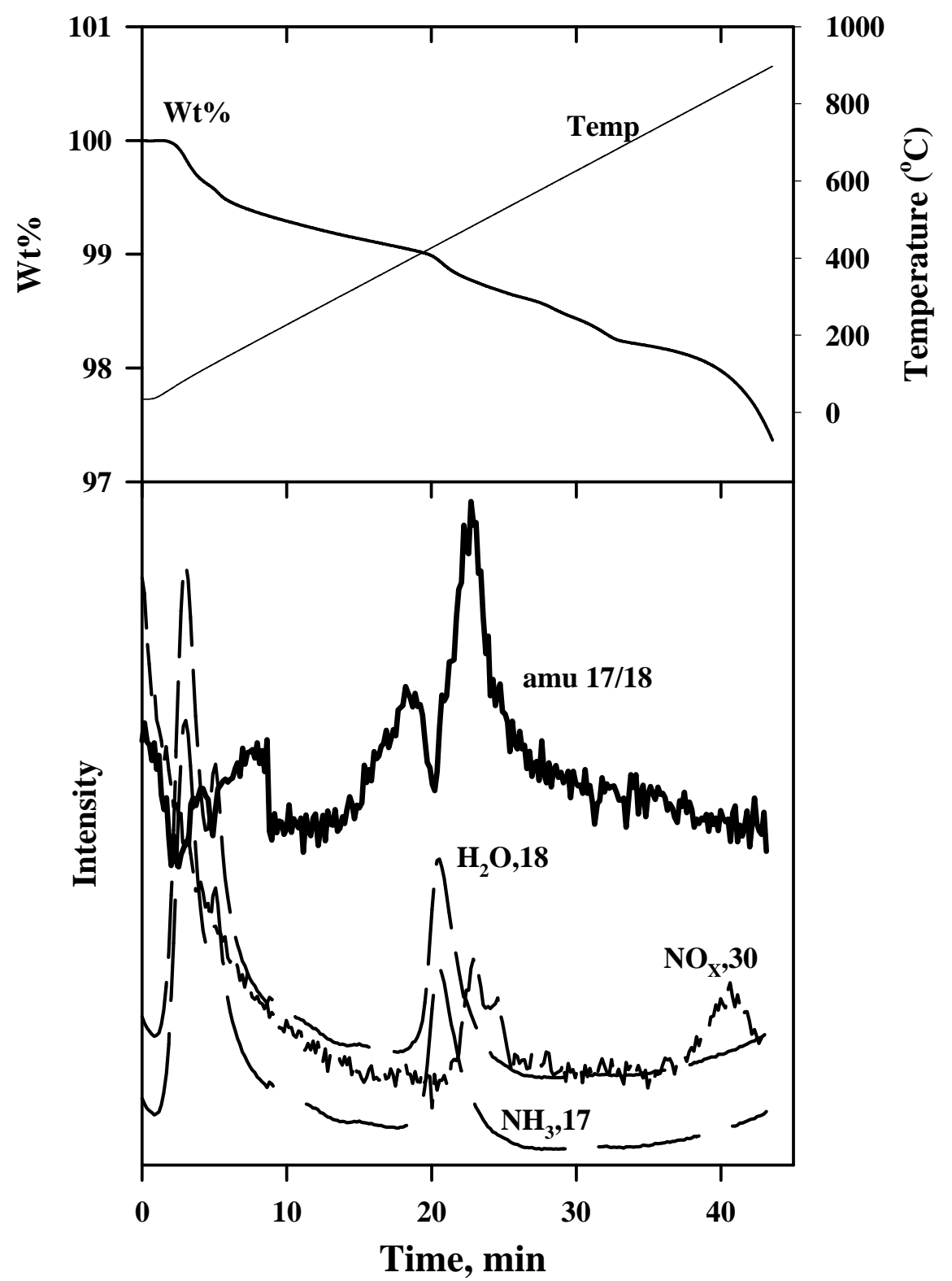

Figure 34. TG-MS spectra for fly ash "L" heated in He atmosphere. 


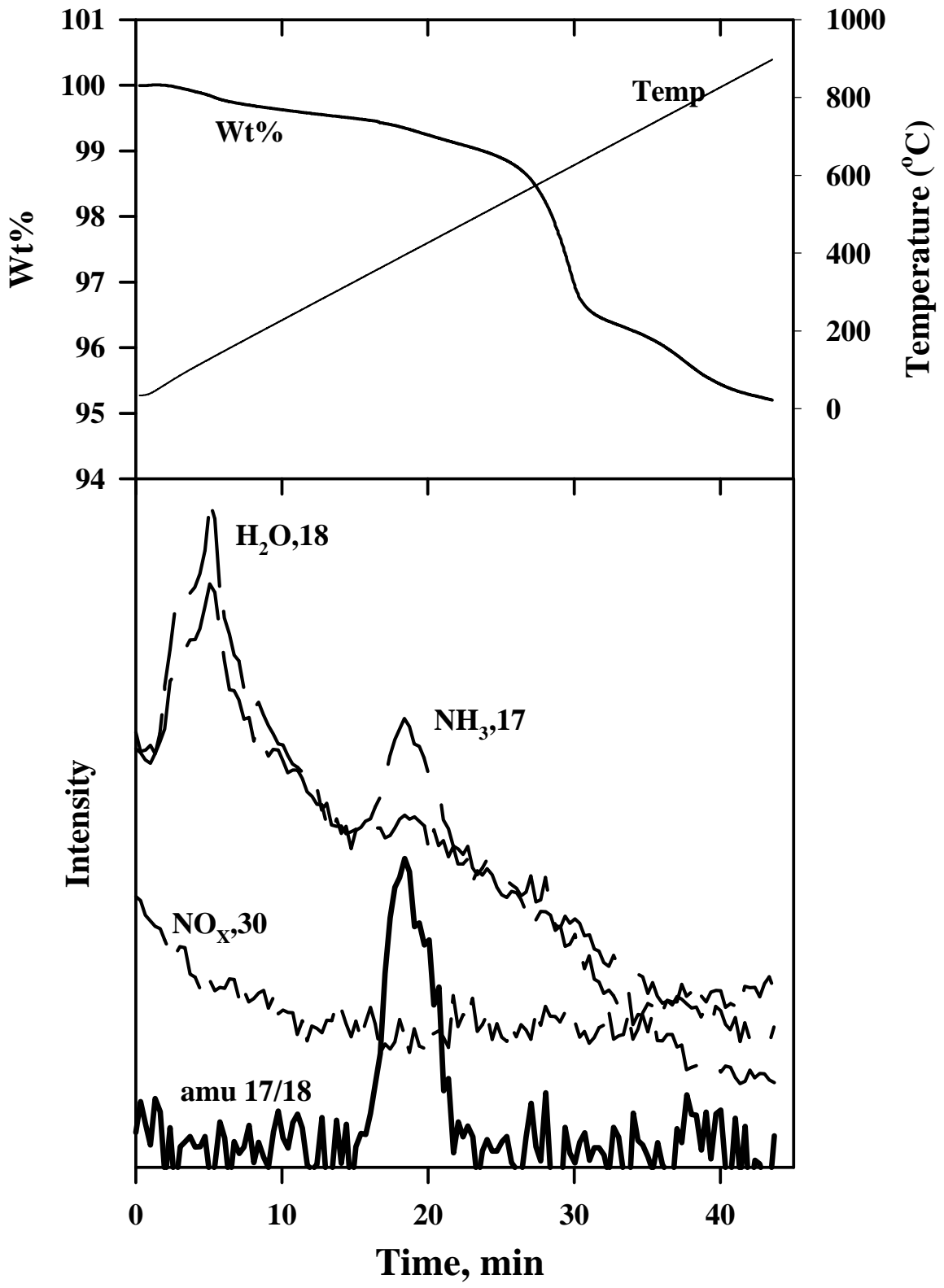

Figure 35. TG-MS spectra for fly ash "P1" heated in He atmosphere. 


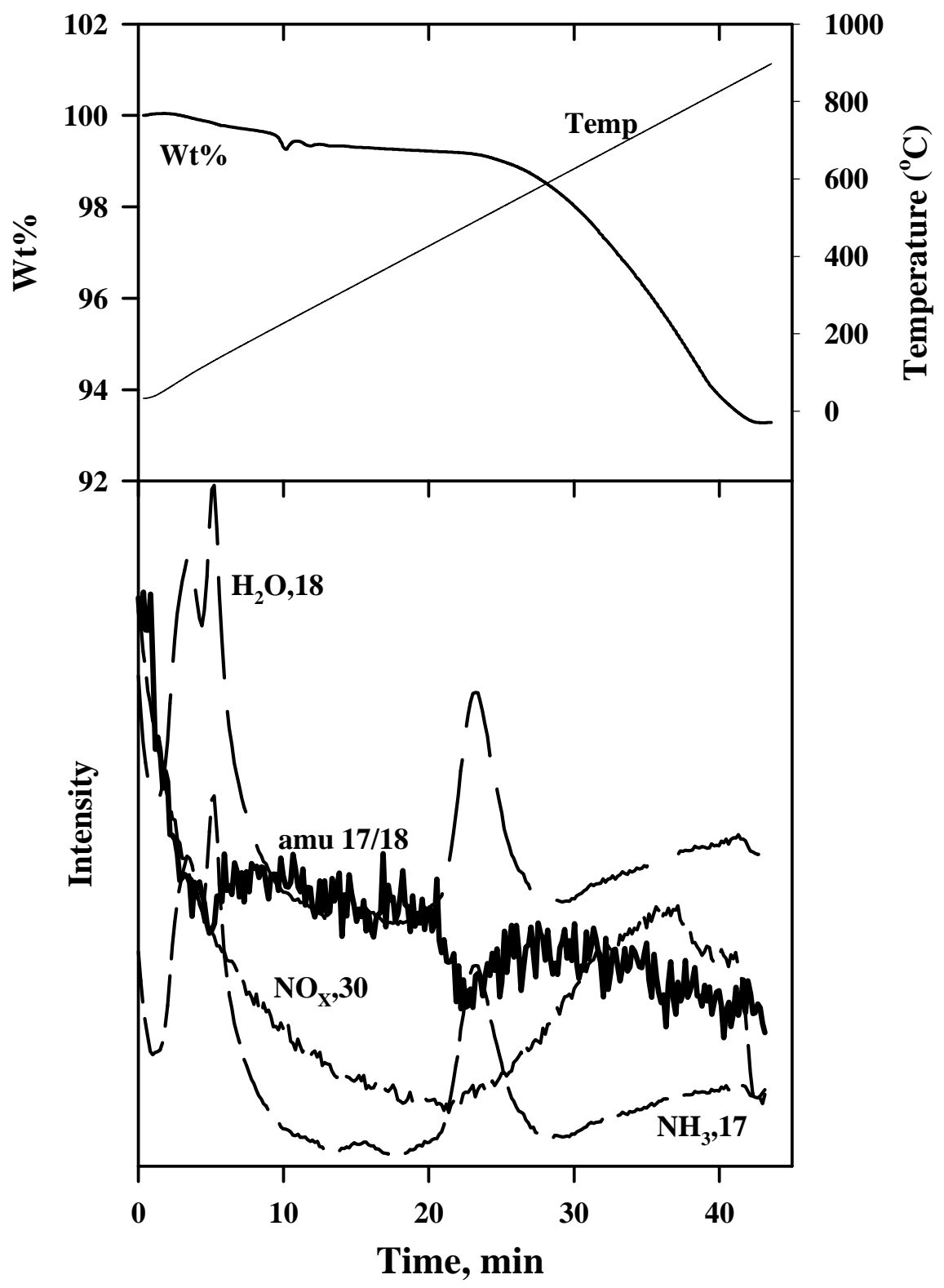

Figure 36. TG-MS spectra for fly ash " $\mathrm{L}$ " heated in $\mathrm{He}-\mathrm{O}_{2}$ atmosphere. 


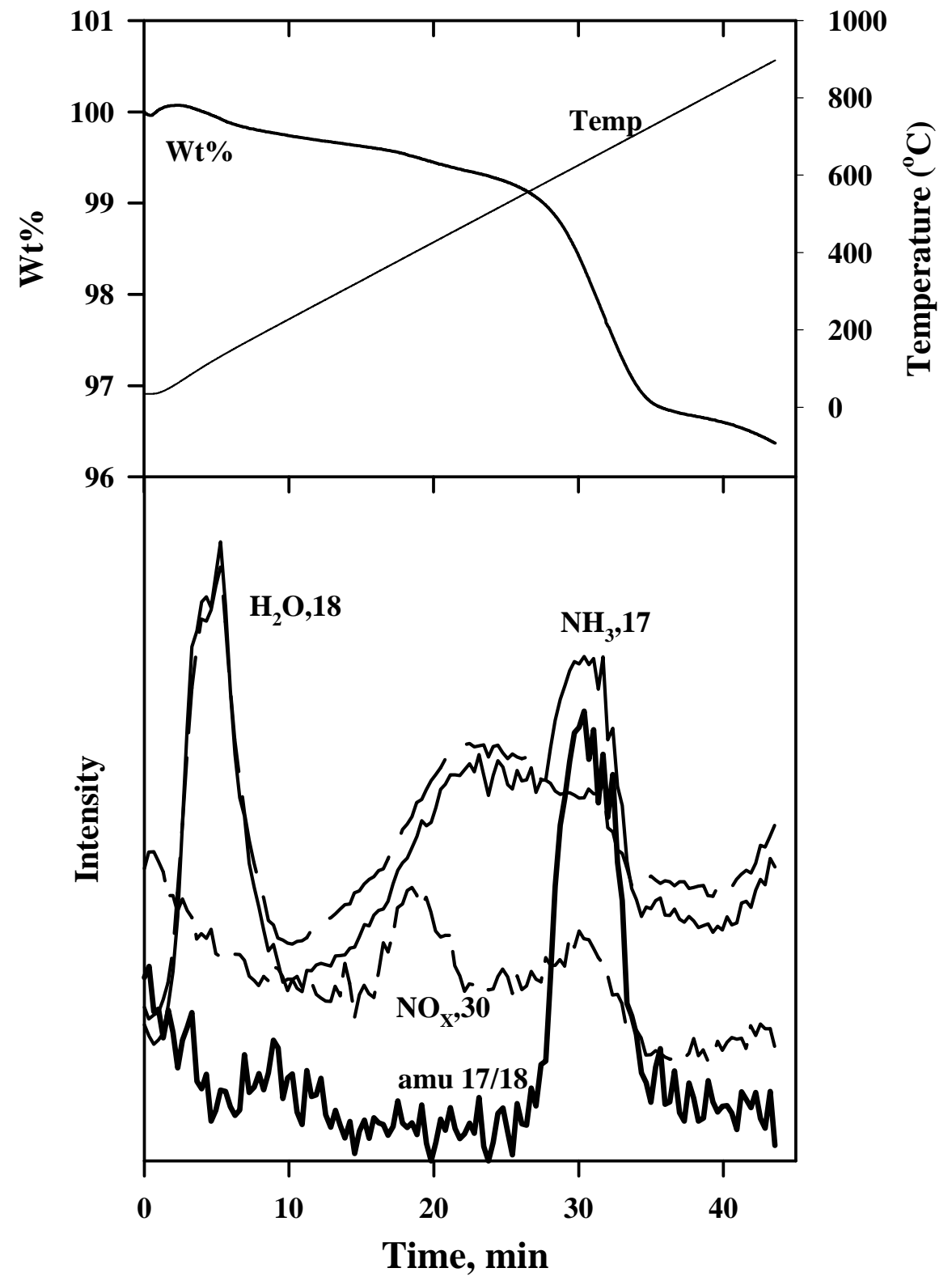

Figure 37. TG-MS spectra for fly ash "P1" heated in $\mathrm{He}-\mathrm{O}_{2}$ atmosphere. 


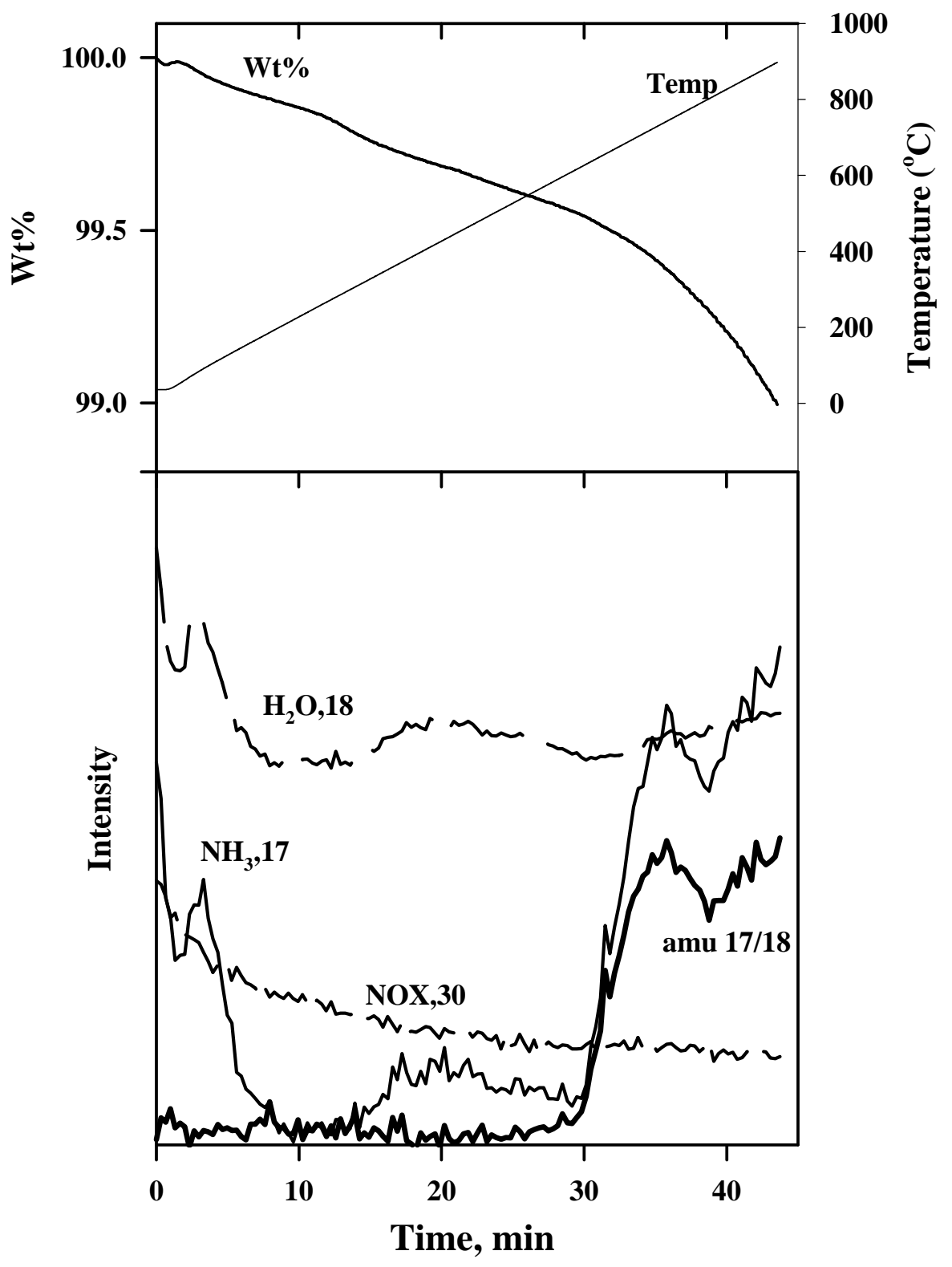

Figure 38. TG-MS spectra for fly ash "S" heated in He atmosphere. 


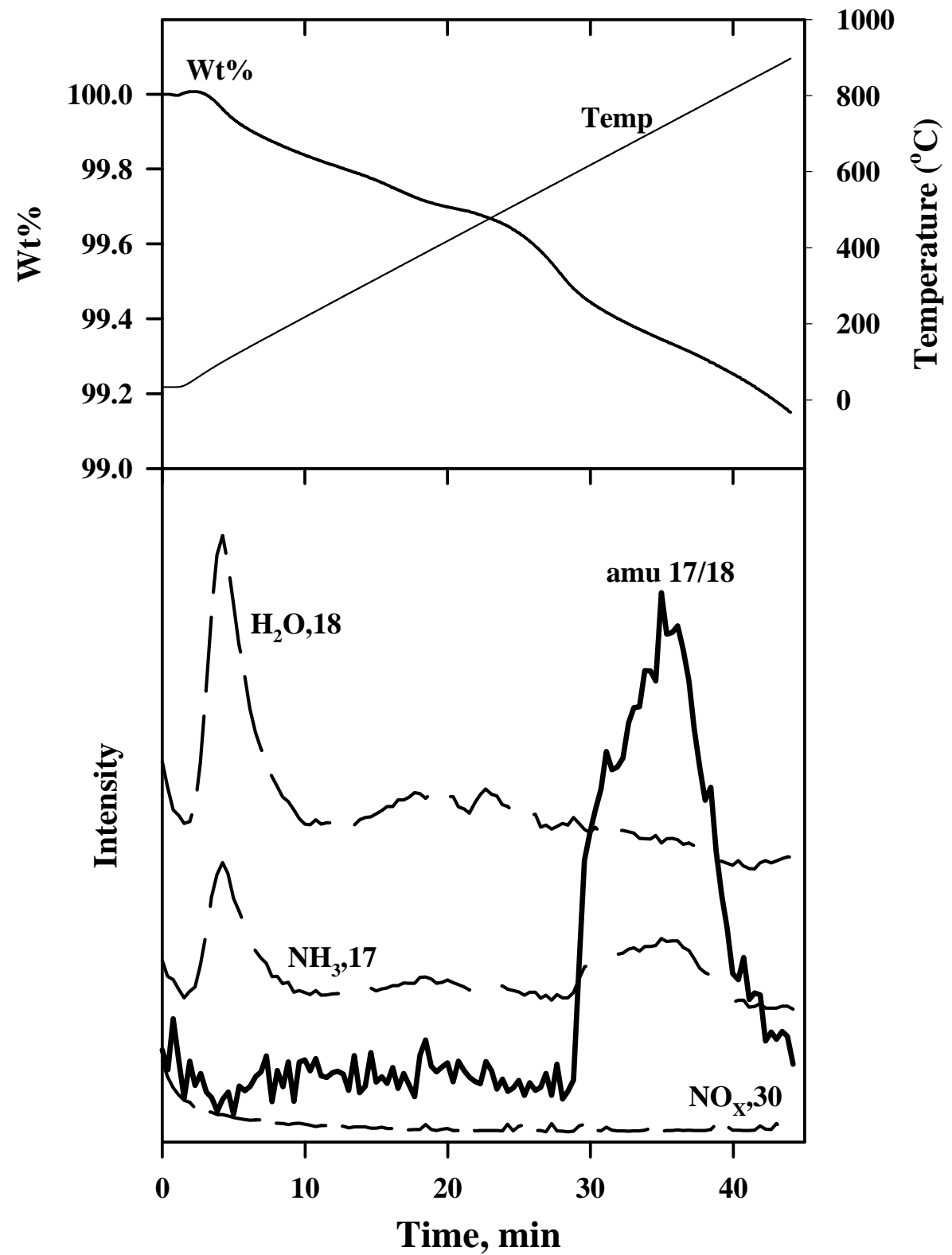

Figure 39. TG-MS spectra for fly ash "B" heated in He atmosphere. 


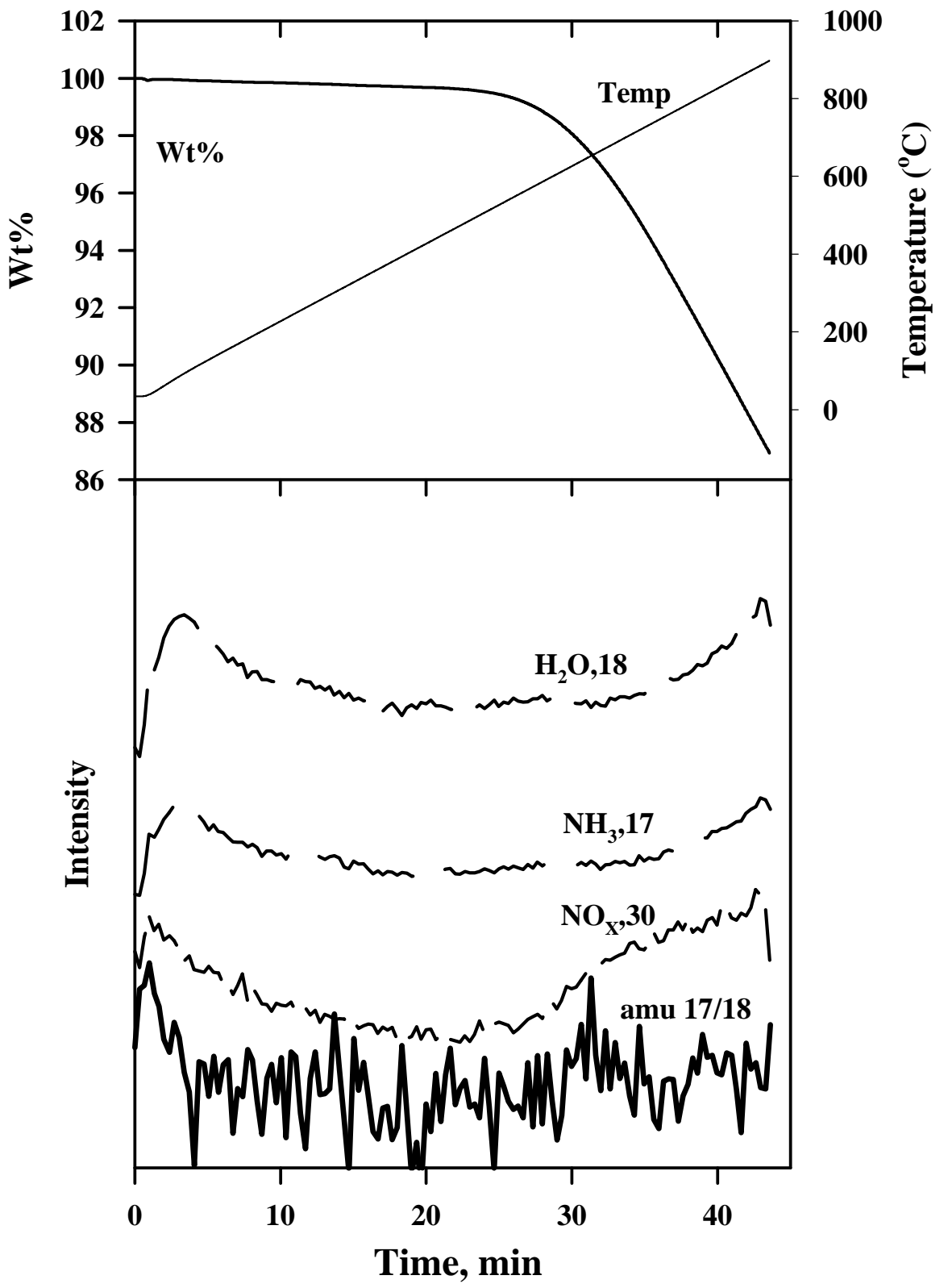

Figure 40. TG-MS spectra for fly ash "S" heated in $\mathrm{He}-\mathrm{O}_{2}$ atmosphere. 


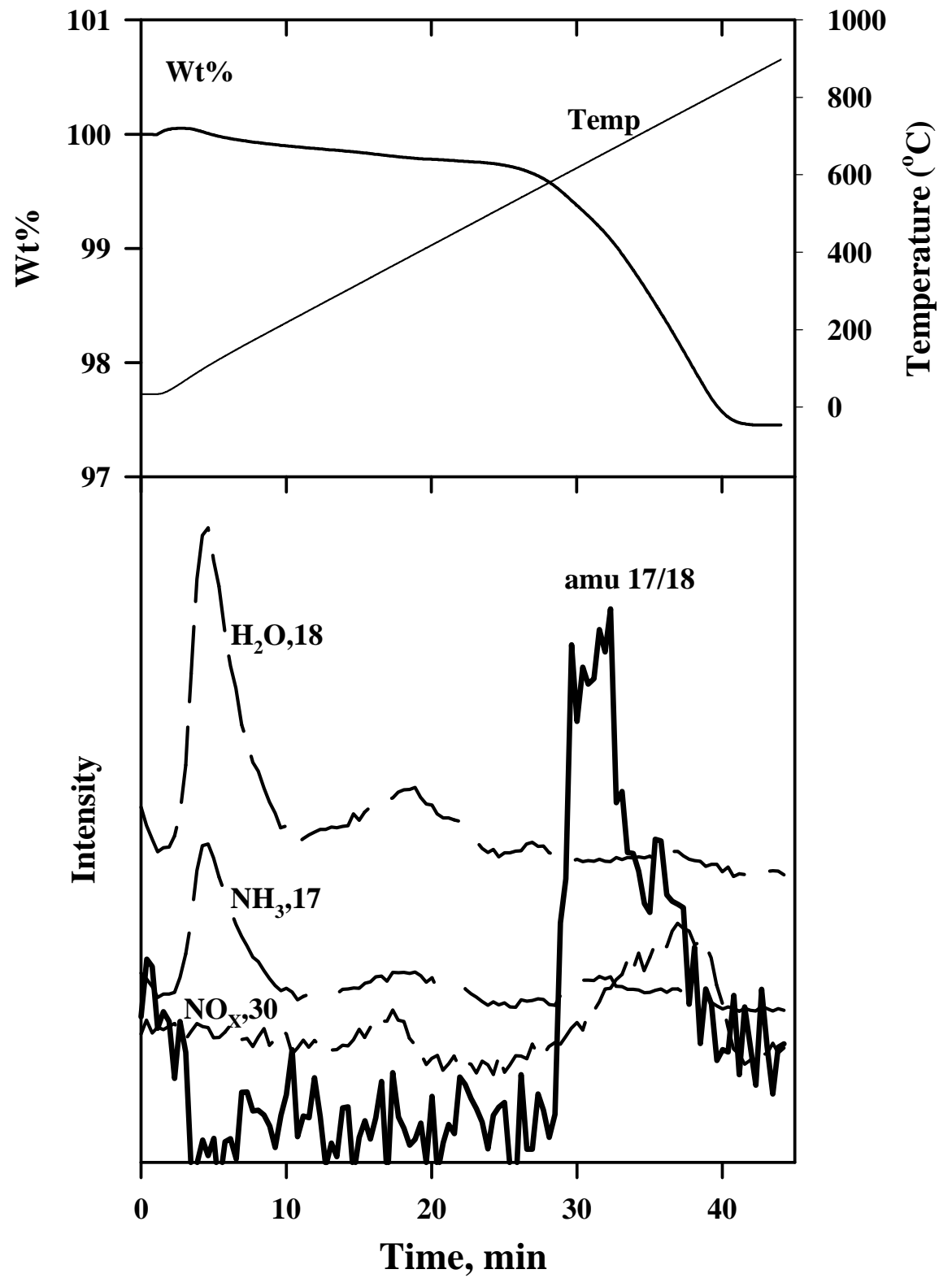

Figure 41. TG-MS spectra for fly ash "B" heated in $\mathrm{He}-\mathrm{O}_{2}$ atmosphere. 